\title{
Nationale Rechte, militärische Führung und Diktaturfrage in Deutschland 1913-1923
}

Die Frage nach dem Charakter des Kaiserreiches von 1871 war immer zugleich auch die Frage nach seiner Anpassungs- und Entwicklungsfähigkeit. Die Diskussion darüber hat sich inzwischen zugespitzt auf die Kontroverse, ob dem Reich ein in seinen konstitutionellen Strukturen angelegter evolutionärer Übergang in den Formen einer »stillen Parlamentisierung ${ }^{1}{ }^{1}$ möglich gewesen wäre, oder ob sich sein "pseudokonstitutioneller Semi-Absolutismus « ${ }^{2}$ erst bis zum revolutionären Umschlag historisch abnutzen mußte. Neben seiner politisch-gesellschaftlichen Innovationsfähigkeit hingen Erfolg oder Scheitern freilich nicht zuletzt von den Ergebnissen jener Strategien einer Stabilisierung von oben $a b$, mit denen nacheinander die drei Machtzentren von ziviler Exekutive, monarchischer Spitze und Militärführung zum Umbau ohne essentielle Machtabgaben zu gelangen suchten. Das begann mit dem ständig präsenten Instrument der Staatsstreichdrohung in Bismarcks Kanzlerzeit ${ }^{3}$, setzte sich fort in den Ansätzen zu einem "persönlichen Regiment " des Kaisers ${ }^{4}$ und mündete schließlich unter dem kumulierenden Problemdruck des Weltkrieges ein in die faktische Dominanz der III. Obersten Heeresleitung ${ }^{5}$. Da sich nach Bismarcks Abgang Kanzler und Kaiser in den Augen der Befürworter eines dynamischen Machtstaates zunehmend unfähig als kraftvolle Vorreiter innerer Stabilisierung und äußerer Machterweiterung erwiesen hatten, schien diese Flucht unter den Schutz der letzten intakten Machtbastion, der Armee im Kriege, im übrigen nur konsequent.

Den Schwebezustand, in den das Reich damit in den letzten beiden Jahren seiner Siegeshoffnungen vor dem Systemzusammenbruch geraten war, hatte Friedrich Meinekke schon 1929 auf den Begriff der "militärischen Diktatur« seit der Juli-Krise von 1917 gebracht ${ }^{6}$. Ob als $"$ Herrschaft des Militarismus ${ }^{7}$, als $»$ silent dictatorship « ${ }^{8}$ oder einfach als die "Militärdiktatur Ludendorffs « ${ }^{9}$ charakterisiert, Übereinstimmung besteht über den generellen Befund vom Vorrang der Militär- vor der Staatsführung in diesen Jahren. Über diesem eher indirekten Zugriff der militärischen Führung auf die Gesamtpolitik des Reiches wurden dagegen die konsequentesten Gedankenspiele in dieser Richtung, die Überlegungen zu einer direkten Militärdiktatur als Personalunion von Kanzleramt und Militärspitze, bisher nur in Einzelbelegen nachgewiesen. Das gilt ebenso für seine zeitlichen Vorläufer in der ersten Kriegshälfte wie für ihr Weiterwirken über den Zusammenbruch von 1918 hinaus. Eine Erklärung für das Fehlen einer zusammenhängenden Darstellung der vielen Einzelüberlegungen oder versuchsweisen Anstöße geht sicher auf die Schwierigkeiten bei der Materialerschließung über verstreute Nachrichtenpartikel aus Memoiren und Nachlässen zurück. Der Hauptgrund für die wissenschaftliche Randlage der Thematik ist dagegen im Nichtrealisierten derartiger Pläne zu suchen, die sie gegenüber dem ungleich relevanteren faktischen Geschehen in den Hintergrund treten ließen.

Die begrenzte Reichweite des historisch nicht unmittelbar wirksam Gewordenen in Rechnung gestellt, bleiben dennoch einige lohnende Aspekte im Blickfeld. Sowohl nach der reinen Anzahl solcher Plan- und Gedankenspiele wie nach der politischen Bandbreite ihrer verschiedenen Befürworter von Class und Ludendorff bis Rathenau und Max Weber versprechen diese Aspekte, im weiteren Rahmen Beiträge zur gesellschaftlichen Befindlichkeit des Wilhelminismus in seiner Spätphase zu liefern. Ihr eigentlicher Aussagewert aber erschließt sich in dem Dreieck von Monarchie, neuer Rechten im Kaiserreich und Militärführung. Im Verhältnis der Krone zu ihren Anhängern in Gesellschaft und Offizierkorps läßt sich der Übergang vom Gedanken der legi- 
timen zur starken Monarchie, also von der angeborenen, nicht mehr hinterfragten Königstreue zum Vorrang der Vaterlandsidee mit monarchischer oder - bei deren Versagen - auch anderer Spitze nachzeichnen. In den Beziehungen zwischen ziviler Rechten und Militär wird daneben jene Rollenverschiebung für das Übergangsjahrzehnt von 1913 bis 1923 sichtbar, die Rechtsparteien und -verbände noch bis in Freikorpszeiten geradezu in eine Klientelposition zur Armee brachte. Erst nach dem Scheitern des letzten paramilitärischen Anlaufs zur Rechtsverlagerung in der Republik im Herbst 1923 sollte ausgerechnet derjenige auf der äußersten Rechten die Dominanz des Politischen wiederherstellen, der seine Laufbahn 1919 als "Trommler “ für den militärischen Arm im Lager der Rechten angetreten hatte: der Parteiführer der jungen NSDAP, Adolf Hitler!

Vor dem Herangehen an die Militärdiktaturpläne selbst ist indes das Faktum erklärungsbedürftig, daß die interessierte Öffentlichkeit zwar erstaunlich früh davon Kenntnis erhielt, sie aber erst relativ spät voll in ihre Betrachtungen einbezog. Schon die ersten Andeutungen in den Memoiren von Ludendorff ${ }^{10}$ und Tirpitz ${ }^{11}$ aus dem Jahre 1919 geben für die in bestimmten Schüben erfolgten Offenlegungen erklärende Anhaltspunkte. Die in der gesamten Zwischenkriegszeit nahezu ausnahmslos über die Erinnerungsliteratur verstreuten Hinweise folgen im wesentlichen zwei Beziehungsmustern: sie sind in das Waffenarsenal von Selbstrechtfertigung und Schuldzuweisung beim Schlagabtausch um die nichtbewältigte Niederlage einzureihen und resultieren daneben aus zeitabhängigen $Z$ weckmäßigkeitserwägungen.

$\mathrm{Da}$ sich die Angriffe aus der Öffentlichkeit in den Revolutionsmonaten besonders heftig gegen den Initiator von U-Bootkriegsbewegung und Vaterlandspartei, Tirpitz, und gegen den eigentlichen Kopf der III. OHL, Ludendorff, gerichtet hatten, saß ihr Rechtfertigungsbedürfnis naturgemäß am tiefsten. Kaum war daher mit dem Abflauen der nachrevolutionären Kämpfe die innere Lage im Sommer 1919 wiederhergestellt, als beide zur publizistischen Gegenoffensive ansetzten. Tirpitz, später in den Reihen der Deutschnationalen, und Ludendorff als Hintergrundfigur der "Nationalen Vereinigung «, dem Sammelbecken der aktionsbereiten Freikorpsteile, suchten freilich mehr als die persönliche Abrechnung mit ihren Gegnern. In ihrem sofort aufgenommenen Kampf gegen die Republik als dem Haupthindernis für die Wiederherstellung des Reiches als Machtstaat knüpften sie an die Sammlungsbestrebungen des radikalen Nationalismus von 1917/18 an. Insbesondere Ludendorff hatte dafür in den Freikorps den "Lichtblick in dieser verhängnisvollen Zeit « ${ }^{12}$ ausgemacht, den es zu organisieren galt. Ihre jungen Frontführer hatten 1918/19 aber nicht nur als Sieg der revolutionären Linken, sondern weit mehr als Zusammenbruch weines Systems, das sich schlotternde Männer und Greise als Stützen gewählt hat ${ }^{13}$, erleben müssen. Warum hatten ihre anerkannten Führer in Heeresleitung und Vaterlandspartei die schleifenden Zügel des schwächlichen Wilhelminismus nicht schon vor der Katastrophe des Reiches in die eigenen Hände genommen? Ihre gegenrevolutionäre Ungeduld, die eben erst im Kampf gegen die Unterzeichnung des Friedensvertrages mit einer "Noske-Diktatur “ ${ }^{14}$ gespielt hatte, war mit Schuldzuweisungen an die politische Führung des Kaiserreiches allein nicht abzuspeisen. Konnte Tirpitz mit seinen Kriegsbriefen von 1914/15 immerhin den Nachweis führen, daß er als Erster seit dem Herbst 1914 auf die Suche nach der diktatorischen Zusammenfassung der Reichsspitze gegangen war ${ }^{15}$, so hatte Ludendorff als der für eine derartige Rolle am häufigsten Genannte jetzt die eigene Verweigerung des angetragenen Doppelamtes zu begründen. Deshalb bekannte er sich dazu, "Deutschland brauchte einen Diktator«, gestand auch ein, daß man dafür an ihn 
"mit dem Vorschlag meiner Kanzlerschaft« herangetreten sei, entschuldigte dann aber seine Abstinenz neben seiner Arbeitsüberlastung durch die Kriegführung mit dem Argument, er »als Vertreter des berüchtigten Militarismus s sei einer breiteren Öffentlichkeit doch wohl kaum zu vermitteln gewesen ${ }^{16}$.

In der öffentlichen Rezeption beider Bücher fand indes keiner dieser Hinweise auch nur andeutungsweise Aufmerksamkeit. Beispielhaft mögen dies die umfangreichen Besprechungen von Hans Delbrück und Johannes Ziekursch belegen ${ }^{17}$, die beide dem späten Wilhelminismus durchaus skeptisch gegenüberstanden. Obwohl in beiden Fällen die militärische und die politische Rolle der Memoirenschreiber kritisch unter die Lupe genommen wurden, blieb die engere Diktaturfrage unberücksichtigt. So kurz nach Niederlage und Revolution erwartete eine aufgewühlte Öffentlichkeit wohl auch erst einmal Antworten auf die drängenden Hauptfragen des zurückliegenden Jahrfünfts. Es galt, zu viel faktisch Geschehenes und Unterlassenes aufzuarbeiten, als daß man auch noch den wenig substantiellen Spuren einer hypothetischen Militärdiktatur nachgehen konnte oder wollte.

$\mathrm{Daß}$ die Hinweise schon jetzt nicht einfach übersehen worden waren, läßt sich aus einem bitteren Brief des Großadmirals Prinz Heinrich von Preußen an Tirpitz ${ }^{18}$ herauslesen. Der Bruder des Kaisers zeigte sich völlig verständnislos gegenüber den angedeuteten Diktaturplänen wie gegenüber ihrer nachträglichen Offenlegung. Für ihn stellte der Vorgang schlechterdings einen offenen Akt der Illoyalität eines ehemaligen kaiserlichen Admirals gegen seinen Obersten Kriegsherrn dar. Hier - wie schon 1915 bei Ludendorffs Unterscheidung des eigenen Vaterlands- von Hindenburgs Legitimitätsgedanken ${ }^{19}$ - baute die Prioritätensetzung zwischen reiner Machtstaatsorientierung und herkömmlicher Königstreue eine nachhaltige Verständnisbarriere zwischen Altkonservativen und neuer Rechten auf. Bei der augenblicklichen Schwäche der gesamten Rechten nimmt es freilich nicht wunder, daß beide Seiten wenig Interesse an einer Vertiefung dieser Diskussion in der Öffentlichkeit haben konnten, die nur die Bündnisfähigkeit des "vaterländischen“ Lagers insgesamt beeinträchtigen mußte. Niemand bekam dieses stillschweigende Einverständnis deutlicher zu spüren als Ludendorffs engster Mitarbeiter seit 1916, Oberst Max Bauer, als er in einem Interview seinen Plan aus dem Januar 1918 publik machte, bei dem er von Ludendorff die Absetzung des »entschlußschwachen« Kaisers zugunsten eines Militärdiktators gefordert hatte. Das Vorhaben sei letztlich an Hindenburg gescheitert. Der Feldmarschall und Ludendorff, die wenige Monate zuvor im Untersuchungsausschuß des Reichstages mit einiger Mühe militärische Übergriffe auf politisches Gebiet durch die III. OHL kategorisch bestritten hatten ${ }^{20}$, dementierten win voller Übereinstimmung « derartige Überlegungen sofort auf das Schärfste ${ }^{21}$. Für Ludendorff stand im übrigen nach seiner führenden Beteiligung am eben unter dilettantischen Begleitumständen zusammengebrochenen Kapp-Putsch zu befürchten, daß eine weitere Debatte um seine Verstrickung in ein ähnlich abenteuerliches Vorhaben während des Krieges sein Renommée als ernstzunehmende politische Größe weiter herabmindern mußte.

Eine Neuauflage fand die Diskussion, als sich Bethmann Hollweg 1921 mit dem zweiten Band seiner "Betrachtungen zum Weltkriege" gegen Ludendorffs Vorwürfe zur Wehr setzte, der Kanzler habe der III. OHL bei der Ausschöpfung der deutschen Kräfte für den Sieg im Wege gestanden. Im Gegenzug warf er dem General vor, dessen Streben nach der "Diktatur « habe aus dem Reichskanzler ein reines »ausführendes Organ seiner eigenen Entschlüsse « zu machen versucht, ohne daß sich dafür zu "militärischer Tatkraft überlegene politische Weisheit gesellt hätte “ ${ }^{22}$. Wieder fing bei den Angegriffenen Oberst Bauer den Ball auf, bestätigte Ludendorffs prinzipielle Bejahung einer diktatorischen Lösung der Bethmann-Krise von 1917 und schob das Zaudern seines Mentors erneut der traditionsverhafteten Haltung Hindenburgs zu. Ohne dessen 
Mitwirkung aber hätte ein Tätigwerden des Generalquartiermeisters "nur des letzteren sofortige Entlassung bedeutet ${ }^{23}$. Ludendorff folgte dieser Argumentation in seiner vehementen Generalabrechnung mit dem "System Bethmann« mit der bezeichnenden Variante, daß ein volles politisches Hervortreten der OHL nur "mit Zustimmung der Krone « hätte gelingen können ${ }^{24}$. Daß seitens der Hohenzollern immerhin der Deutsche Kronprinz mitgezogen habe, ließ dieser in seinen 1922 erschienenen Erinnerungen öffentlich anklingen ${ }^{25}$.

Mit diesen Hinweisen auf einen zwar erwogenen, wegen seiner Realisierungsschwierigkeiten aber nicht beschrittenen Weg sollte es zunächst einmal sein Bewenden haben. Wo die wissenschaftliche und publizistische Debatte den Rahmen der militärischen Weltkriegsforschung verließ, widmete sie sich vorrangig der Widerlegung der sogenannten "Kriegsschuldlüge " ${ }^{26}$ oder verbiß sich in den gehässigen Streit um die »Dolchstoßlegende « ${ }^{27}$. Wenn in Ausnahmefällen, wie bei Friedrich Meinecke oder Arthur Rosenberg, die Diktaturfrage für die Endphase des Kaiserreiches aufgeworfen wurde ${ }^{28}$, dann bezog sich das lediglich auf die faktische Dominanz der III. OHL. Allein aus den 1927 bzw. 1929 herausgegebenen Erinnerungen und Kriegstagebüchern der beiden süddeutschen Thronfolger Max von Baden und Rupprecht von Bayern ${ }^{29}$ konnte der aufmerksame Leser für die Jahre 1916/18 immer wieder kritische Anmerkungen über Diskussionen in Offizier- und Politikerkreisen zur Frage eines Generals als Reichskanzler entnehmen, wobei neben Ludendorff erstmals auch Falkenhayn und Tirpitz als potentielle Kandidaten auftauchten.

Es entsprach dies im übrigen auch der Beschlußlage, wie sie sich dem Untersuchungsausschuß des Reichstages zur Aufhellung des deutschen Zusammenbruchs für sein Schlußvotum von 1926 gestellt hatte: "Die Überlegenheit der O. H. L. gegenüber der Reichsregierung " im Jahre 1918 wurde konstatiert, das KPD-Mitglied Eichhorn sprach in seiner Minderheitsentschließung sogar von der angemaßten munumschränkten diktatorischen Gewalı « der militärischen Führung ${ }^{30}$, aber die weiterreichenden Militärdiktaturpläne fanden keine Erörterung. Der militärische Gutachter, Oberst Schwertfeger gestand zwar ein, daß man sin weitesten Kreisen des deutschen Volkes [. . . ] tatsächlich zeitweise eine Übernahme der gesamten Staatsgewalt durch die Feldherrn ersehnt " habe, erklärte es aber apodiktisch für "zwecklos zu untersuchen, wie weit die einzelnen politischen Parteien des heutigen Deutschlands hierbei beteiligt gewesen sind ${ }^{31}$. Aus der Andeutung über die weite Verbreitung solcher Überlegungen läßt sich ein zusätzlicher Grund für die Zurückhaltung öffentlicher Erörterungen nach 1918 erschließen, denn außerhalb der Linksparteien ließen sie sich in der Tat nicht zur Munition gegen den politischen Gegner verwenden.

Bis zum Ende der Weimarer Zeit hatte sich also bereits eine erkleckliche Anzahl von Mosaiksteinen angesammelt, die aber nicht zu einem kompletten Bild zusammenzufügen waren, da sie allesamt immer noch zu wenig konkret blieben. Außer der Existenz diktatorischer Überlegungen und einigen Begründungen für ihr Nichtzustandekommen blieben greifbare Informationen über Häufigkeit und beteiligten Personenkreis ebenso Mangelware wie Fakten über Anlässe, Zielsetzungen und Wirkungen. Wer von den Betroffenen hätte in einer kritischen republikanischen Öffentlichkeit schon ein gesteigertes Interesse daran haben können, den Mantel über Vorgängen zu lüften, die ihre Verfechter in das ungünstige Licht einer kontinuierlichen Bereitschaft zum Verfassungsbruch tauchen mußte. Gerade das war es doch, was man unter der Formel vom „Hochverrat des 9. November« dem innenpolitischen Gegner vorhielt! Überdies mußte eine solche Diskussion für den neben Ludendorff und Tirpitz am häufigsten im $\mathrm{Zu}$ sammenhang mit Diktaturplänen genannten Hindenburg denkbar ungelegen kommen, der nunmehr nach seinem Amtseid zum höchsten Garanten einer anderen, der Weimarer Reichsverfassung, berufen war. 
Außerhalb solcher Rücksichtnahmen bewegten sich gegen Ende der zwanziger Jahre dagegen bereits einige Kritiker des Kaiserreiches von rechts. Deutlichere Worte enthielten etwa der 1927 veröffentlichte Briefwechsel Ludendorffs mit dem Chefredakteur der Königsberger Allgemeinen Zeitung, Alexander Wyneken ${ }^{32}$, oder die Erinnerungen der Generale Max Hoffmann ${ }^{33}$ und Friedrich v. Bernhardi, wobei Letzterer ganz offen zur eigenen Kandidatur für ein diktatorisch gestrafftes Kanzleramt stand ${ }^{34}$. Zu ihnen gesellten sich 1931 mit dem Vorsitzenden des Alldeutschen Verbandes, Heinrich Class ${ }^{35}$, und dem prominenten Heerführer Max v. Gallwitz ${ }^{36}$ zwei weitere Memoirenschreiber. Sie alle hatten trotz individueller Auffassungsunterschiede im Einzelnen doch etwas gemeinsam: Wie Ludendorff und Tirpitz entstammten sie nach Herkunft und Werdegang der Gedankenwelt des bürgerlichen Nationalismus und hatten von daher schon vor bzw. im Weltkrieg - sei es aus militärfachlicher und/oder politischer Kritik - zunehmend Distanz zum Wilhelminismus gewonnen, der sich trotz seiner martialischen Töne in ihren Augen weder außen- noch innenpolitisch den selbstgestellten Aufgaben gewachsen zeigte. Allesamt auch nach 1918 Anhänger einer Renaissance des Reiches als Großmacht, hielten sie gesellschaftspolitische Auffassungen und bürgerliches Stilempfinden zwar im deutschnationalen Umfeld zurück, abseits eines Radikalismus Ludendorffscher oder frühnationalsozialistischer Prägung. Ihr in Revolution und Republik indes noch verhärteter Antiparlamentarismus, verbunden mit ihrer Skepsis gegenüber einer monarchischen Restauration seit dem schwächlichen Abgang der Herrscherhäuser, führte sie aber zwangsläufig auf die Suche nach autoritären Auswegen jenseits von Monarchie oder parlamentarischer Republik. Blickten sie sich im Europa der zwanziger Jahre mit seinen zusammenbrechenden liberalen Systemen und ihrem Ersatz durch eine Serie »starker Männer wom Zuschnitt der Generale Kemal Atatürk, Pilsudski oder Primo de Rivera um, dann schienen die eigenen Gedankenspiele aus Weltkriegszeiten so perspektivenlos nicht mehr.

Das Gefühl, der Zeit mit den eigenen Überlegungen eigentlich voraus gewesen zu sein, mußte sich naturgemäß mit der Machtergreifung Hitlers noch erheblich verstärken. Angefangen von den Memoiren der konservativen Politiker Graf Westarp und Oldenburg-Januschau fehlten substantielle Hinweise auf Diktaturpläne während des Weltkrieges jetzt auch in keiner Veröffentlichung mehr aus Unterlagen ehemaliger Weltkriegsgenerale ${ }^{37}$. Sie fügten sich nahtlos ein in die allgemeine Kritik des Dritten Reiches an der Selbstaufgabe von 1918 und hoben wenigstens den militärischen Arm des alten Reiches positiv kontrastierend von der durchgängigen "Schwäche“ der wilhelminischen Eliten ab. Selbst wenn dahinter keine einheitliche Strategie nachzuweisen ist, förderte ein so dezidiertes Distanzieren von Mängeln der Vergangenheit unzweifelhaft den Kurs der Wehrmachtführung, mit dem die Armee als intakt gebliebene Säule des alten deutschen Machtstaates ihren Anspruch auf Gleichberechtigung neben den Siegern aus der neuen, nationalsozialistischen Rechten anmeldete. Eine Schonung des Kaisers oder von Relikten eines Gefühlsmonarchismus erübrigte sich um so mehr, als nach 1933 nur zu schnell die wirkliche Gewichtsverteilung zwischen Konservativen und Nationalsozialisten deutlich und damit jede Hoffnung auf eine Art Statthalterschaft des Dritten Reiches für eine monarchistische Restauration in der Zukunft illusorisch geworden war.

Gerade dieses Selbstbildnis von der Armee als jederzeit intaktem Kern des deutschen National- und Machtgedankens mußte die Militärführung dann aber auch in die vorderste Reihe der Verantwortichen für den Zusammenbruch des Reiches in der »deutschen Katastrophe« von 1945 stellen. Die aus der eigenen nationalen Hüterrolle erwachsene und gesuchte Annäherung an einen als lediglich dynamisierte Variante deutscher Machtstaatlichkeit fehlinterpretierten Nationalsozialismus sah sich jetzt gespiegelt in dem Geschwisterpaar von "Militarismus und Hitlerismus « ${ }^{38}$. Rechnete man 
aber die kontinuierliche Dominanz des Militärischen zu den wesentlichen Erklärungen für die historischen Verwerfungen im deutschen Nationalstaat, dann mußte der Blick notwendig auf den Höhepunkt eines derartigen Hervortretens im Ersten Weltkrieg und hier wiederum auf das Wirken der III. OHL fallen. Da im Kriege die "Fiktion" vom persönlichen Oberbefehl Wilhelms II. offensichtlich geworden und die "politische Vernunft« sich mit Bethmann Hollweg in militärischen Dingen einer freiwilligen Selbstbeschränkung unterworfen habe, sei schließlich 1916 das immer fragile Verhältnis von "Staatskunst und Kriegshandwerk" in Preußen-Deutschland zugunsten der stärkeren Willenskraft eines Ludendorff umgekippt, so hatte Gerhard Ritter die Zusammenhänge schon 1953 auf dem deutschen Historikertag in Bremen zu ordnen versucht ${ }^{39}$. Unter dem übergeordneten Gesichtspunkt des Verhältnisses von Politik und Kriegführung spielte die Frage allerdings zunächst eine sekundäre Rolle, ob neben der faktischen Dominanz noch weitergehende Überlegungen zu einer offenen Militärdiktatur im Weltkrieg feststellbar waren. Ähnliches galt auch für den späteren Versuch, die Diskussion um den Charakter des Wilhelminismus im Kriege über die Bonapartismusthese weiterzuführen ${ }^{40}$, wonach der Ausfall von Krone und Reichsregierung den letzten intakten Teil der Exekutive, die Armeeführung, zwangsläufig in die Funktion des Systemstabilisators von oben stellen mußte. Auch für diese Fragestellung blieb das Problem nebensächlich, welche Form eine derartige Rollenübernahme erhielt.

Die Diktaturpläne im engeren Sinne gewannen ihre Relevanz dagegen dort, wo das Objektiv auf den Prozeß der Herausbildung einer neuen radikalen Rechten und ihrer Abnabelung vom herkömmlichen Konservatismus im späten Kaiserreich gerichtet wurde. Schon die erste Gesamtdarstellung über den Hauptvertreter dieses bürgerlich-radikalisierten Nationalismus, das Alldeutschtum ${ }^{41}$, hakte hier ein. Sein Autor wurde in der Folge mehrfach darin bestätigt ${ }^{42}$, daß der Ausgangspunkt aller späteren Diktaturpläne in den Vorstellungen einer "Reichsreform" von rechts aus der unmittelbaren Vorkriegszeit zu suchen war. Editionen aus dem Mitarbeiterfeld von Reichs- und Heeresleitung ${ }^{43}$ haben den quellenmäßigen Nachweis dafür angetreten, daß sich im Kriege die aus Enttäuschung über Schwäche und Inkompetenz der politischen Spitze resultierende militärische Kritik an Kaiser und Kanzler dann ebenfalls zögernd, aber kontinuierlich auf die Suche nach neuer diktatorischer Stabilisierung der Verhältnisse machte. Die neuere Forschung zu Freikorps und Wehrverbänden in der Weimarer Frühzeit ${ }^{44}$ erhärtete schließlich den Befund, daß die Klientelrolle, in der die neue Rechte insbesondere zu Zeiten der Deutschen Vaterlandspartei (1917-1918) zur Armeeführung stand, sich in die unruhigen Gründerjahre der Republik hinein fortsetzte und erst mit dem Scheitern des Putschismus im Herbst 1923 einer selbstbewußteren zivilen Führung im Lager der radikalen Rechten Platz machte. Daran wird in der weiteren Darstellung anzuknüpfen sein, wenn Wege und Wirkungen der Diktaturpläne im Einzelnen durch das Jahrzehnt von 1912/13 bis 1923/24 nachgezeichnet werden.

Wenn die Inkubationszeit für diktatorische Lösungsvorschläge in die unmittelbaren Vorkriegsjahre zurückverlegt wird, dann nicht etwa, um zu suggerieren, als sei die "Autoritätskrise « ${ }^{45}$ des Wilhelminismus erst jetzt sichtbar und mit den alldeutschen Staatsstreichplänen ein gänzlich neues Heilmittel in die Debatte geworfen worden. Die Autoritätseinbußen des Kaisers reichten bis zum Scheitern seines "persönlichen Regiments« an der Jahrhundertwende zurück und waren der Öffentlichkeit spätestens mit der Daily-Telegraph-Affäre plastisch vor Augen geführt worden. Und was den Staatsstreich als ultima ratio der Exekutive gegen einen widerspenstigen Reichstag anbelangte, so hatte zumindest seine Androhung schon für Bismarck zu den unverzichtbaren 
Kanzlerwaffen gezählt ${ }^{46}$ und war auch unter seinen Nachfolgern nie ganz vergessen worden ${ }^{47}$. Gewechselt hatte dagegen die Initiative. Sie ging jetzt nicht mehr von der Regierung aus, sondern vom wichtigsten nationalen Agitationsverband, der sich aus außen- und innenpolitischer Frustration der Kontrolle durch die Exekutive entzogen und im Kern seines Vorstoßes geradezu gegen sie gewandt hatte ${ }^{48}$. Ausgelöst durch die Enttäuschungen über die Marokko-Krise von 1911 und den überwältigenden Wahlsieg der Sozialdemokraten von 1912, machte das alldeutsche Projekt einer "Reichsreform« auch nicht mehr halt beim Kurieren von Symptomen, sondern strebte in doppelter Frontstellung zu Regierung und Reichstag eine umfassende und dauerhafte autoritäre Revision der Reichsverfassung an. Hatte der prinzipiell monarchistisch orientierte Verband zudem bis dahin die Schuld an nationalen Rückschlägen bei den Kanzlern gesucht und den Monarchen damit entlastet ${ }^{49}$, so zielte das Kaiserbuch seines Vorsitzenden Class von 1912 nunmehr auch direkt auf die Krone. In kaum verhüllter Warnung wurde ihr der eigene historische Ursprung im Wahlkönigtum vorgehalten, in dem der »von den gleichberechtigten Volksgenossen auf den Heerschild gehoben wurde, der der Tapferste war«. Aus der Feder eines bürgerlichen Monarchisten geradezu revolutionär mußten Kaiser und Öffentlichkeit die weitere Folgerung in den Ohren klingen, »daß gehäufte Fehler der Krone und dauernde Untüchtigkeit ihrer Träger dahin führen könnten, daß unser Volk sich fragt, weshalb es eine Staatsform weiter hinnehmen soll, die es zwingen will, ein unbrauchbares Oberhaupt zu ertragen«! Natürlich war es zu diesem Zeitpunkt auch für Class noch unzweifelhaft, daß kein Weg zur Durchsetzung der eigenen Pläne »ohne sie [die Krone, d. Vf.] oder gegen sie " gangbar war. Nur hatte die nationale Rechte endlich Abschied zu nehmen von einem »doktrinären Royalismus«, der im reinen Legitimitätsgedanken zur Krone verharrte. Statt dessen wurde der Appell an Wilhelm II. gerichtet, endlich zur »rettenden Tat « zu schreiten, die Reform von oben in Gang zu setzen und dem Volk den erwarteten "Führer" zu berufen ${ }^{50}$. Gedacht war dabei - und dies sollte allerdings bereits auf die künftigen Militärdiktaturpläne vorausweisen - an den Großadmiral Tirpitz ${ }^{51}$, der in diesen Jahren schon erfolgreich Stimmung gegen Bethmann Hollwegs Außenpolitik machte ${ }^{52}$.

Weit davon entfernt, wegen seiner bedenkenlosen Radikalkur, seinem rüden Antisemitismus und seiner herben Kaiserkritik einen Sturm der Entrüstung zu entfachen, hatte Class mit seinem Buch einen wahren politischen Bestseller gelandet ${ }^{53}$. Die Alldeutschen fanden sich damit als Ideenlieferanten einer nationalen Rechten wieder, in deren Einheitsfront von 1913, dem "Kartell der schaffenden Stände “ ${ }^{54}$, sie den Platz als effizientester Organisator einer nationalen Öffentlichkeit einzunehmen verstanden. Das verleitete sie im Herbst desselben Jahres dazu, ihr Vorstandsmitglied v. Gebsattel mit einer Denkschrift hervortreten zu lassen, die über den mit ihnen offen sympathisierenden Kronprinzen an den Kaiser gelangte und in der Forderung nach staatsstreichartiger Ausschaltung des Reichstages gipfelte ${ }^{55}$. In einer Diktion, nach der das deutsche Volk einen »tätig regierenden König, aber keine monarchisch orientierte Gliederpuppe« verlange ${ }^{56}$, forderte wenigstens ihre bürgerlich-nationalistische Avantgarde damit an Stelle der legitimen die starke Monarchie der Zukunft. Das Dilemma, in das sich die Befürworter eines derartigen Kurses indes gestürzt sahen, als sich der Kaiser »Mitteln der Regierungskunst« verweigerte, die »in Deutschland [...] gottlob noch nicht üblich « seien ${ }^{57}$, läßt sich einem Briefwechsel des verbandsnahen Industriellen Kirdorf mit Class wenige Monate später entnehmen. Zwischen einer zu Bruch gehenden monarchischen Gesinnung und dem Bewußtsein, daß die demokratische Alternative »uns erst recht in den Sumpf führen« würde, blieb allein der Ausweg eines Kampfes nach zwei Seiten: gegen die "Demokratie mit ihren Machtgelüsten« und die "Unfähigkeit der Regierenden einschließlich der Herrscher ${ }^{58}$. 
Trotz ihres raschen Scheiterns wiesen die alldeutschen Staatsstreichpläne in mehrfacher Hinsicht auf entsprechende Vorstellungen im Weltkrieg und ihre Realisierbarkeitsgrenzen voraus. Mit ihrer Generalkritik am Wilhelminismus verbanden sich wohl schon konkrete Lösungsansätze, nur blieben sie nach wie vor in einem zentralen Punkt den früheren Stabilisierungsversuchen von oben verhaftet: bei aller Kaiserkritik banden sie sich selbst an ein Mitspielen der Krone; ohne oder gar gegen den Monarchen war die fragile Einheitsfront aus Nationalliberalen, Konservativen und nationalistischen Verbänden um so weniger als Handlungseinheit zusammenzuhalten, als sie schon an ihren ökonomischen Interessendivergenzen jeden Moment wieder zu zerbrechen drohte. Bei der wachsenden Stärke des innenpolitischen Gegners mußte ein eigenes Aktivwerden, bei dem wesentliche Teile der Rechten in ihrer Loyalität zur Krone abgestoßen würden, einem politischen Abenteuer gleichkommen. Mochte daher die neue Rechte auch ein Stück weit aus dem gouvernementalen Schatten ihrer Anfänge herausgetreten sein, zur Aktion bedurfte sie weiterhin der Abstützung auf die Handlungsbereitschaft und die exekutiven Mittel der Reichsspitze. Nachdem unter allen Nachfolgern des Reichsgründers kein »neuer Bismarck« als natürliches Gravitätszentrum auszumachen war, wanderte der Blick der Unzufriedenen von rechts innerhalb der Exekutive lediglich eine Position weiter; das konnte bei den militärischen Vorlieben der Gesellschaft im Kaiserreich nur noch bei den populären Militärführern enden. Insofern beinhaltete der Name Tirpitz bereits ein Quantum Zukunftsprogramm.

In der Euphorie der ersten Kriegswochen schien das alles indes Makulatur geworden zu sein. Für die Ungeduldigen hatten Kaiser und Kanzler unter der Gewalt der Ereignisse endlich einmal die Fesseln ihrer bisherigen Halbheiten abgestreift und an die Stelle verbaler Kraftmeiereien den Aufbruch in die Tat gefunden. Das »Wunder« des August 1914 schien wie ein reinigendes Gewitter auf das Gebäude des Reiches niederzugehen und die einige Nation im Krieg zusammenzuführen. Die intellektuelle Bestandsaufnahme in den "Ideen von 1914« sah in diesem letzten Akt der Reichseinigung gar die historische Bestätigung für den von Deutschland gefundenen Königsweg zwischen westlicher Demokratie und östlicher Autokratie ${ }^{59}$. Der Reichsbau hatte sich schon jetzt bewährt und würde in den kommenden »Stahlbädern« endgültig für die Zukunft gehärtet werden.

Natürlich hatte das allgemeine Stimmungshoch auch bei den Alldeutschen eine tiefe Erleichterung ausgelöst ${ }^{60}$. Nur hatte bei ihnen wie bei Tirpitz schon Bethmanns Erklärung zum Einmarsch in Belgien als einem wiedergutzumachenden Unrecht einen Wermutstropfen in den Wein geschüttet ${ }^{61}$. Deuteten sich hier nicht erneut jene Skrupel an, die eine schwächliche Reichsleitung schon bisher an der vollen Nutzung der Chancen einer aktiven Weltpolitik gehindert hatten? Für Tirpitz im Großen Hauptquartier erwies sich der erste Verdacht nur zu rasch als begründet. Den Beweis lieferten ihm seit Mitte August die Versuche des Kanzlers, den Krieg mit England durch einen möglichst zurückhaltenden deutschen Flotteneinsatz »einzufrieren “ ${ }^{62}$. Damit brach sofort der alte Konflikt aus der Vorkriegszeit über die Englandpolitik wieder auf. Der Marinestaatssekretär, der im britischen Weltreich die eigentliche Blockademacht gegen einen Ausbruch des Reiches aus kontinentaler Enge sah, hatte noch Ende Juli aus Sorge um sein unfertiges Instrument von einer Kriegserklärung abgeraten ${ }^{63}$. Nur wollte er jetzt, da die Würfel einmal gefallen waren, den Krieg wenigstens mit aller Konsequenz geführt wissen. An sich schon wegen seiner persönlich einflußlosen Rolle im Hauptquartier in zunehmend düsterer Stimmung, versetzte ihn die Hintansetzung seiner Marine, die bei einem ohne ihren Einsatz errungenen Sieg der deutschen Waffen für ihr Prestige im Frieden zu fürchten hatte, in eine nervöse Gereiztheit ${ }^{64}$, die sich auch dann nicht legte, als der Kanzler selbst ab Ende August seine englischen Hoffnungen zu begraben begann ${ }^{65}$. Wer immer in den folgenden Wochen und Monaten das Große Hauptquar- 
tier besuchte und den zur Untätigkeit verdammten Großadmiral sprach, sah sich dessen beschwörenden Appellen für eine den deutschen Zukunftsinteressen dienende Kriegszielpolitik gegen England ausgesetzt, die mit dem schwankenden Bethmann nicht zu machen $\operatorname{sei}^{66}$. Da er selbst das Hilfsmittel der Intrige zu handhaben wußte ${ }^{67}$ und deshalb Gleiches bei seinen Gegenspielern voraussetzte, umgab er die Gespräche in seinem Luxemburger Quartier - im übrigen wegen der vermuteten Überwachung durch das Auswärtige Amt - geradezu mit konspirativer Geheimniskrämerei ${ }^{68}$.

Sein Mißtrauen und ein immer wieder durchbrechender, tiefer Pessimismus fanden in der Zusammensetzung der kaiserlichen Umgebung zusätzliche Nahrung. Unter den Beratern Wilhelms II., insbesondere den Chefs von Zivil- und Marinekabinett, v. Valentini und v. Müller, hatte Tirpitz bald eine Riege von Bethmann-Anhängern ausgemacht, die den Kaiser in dessen immer deutlicher werdender Führungsschwäche durch ihre eigene "Flaumacherei« noch bestärkten und ihn außerdem gegen kritischere Ratgeber abschirmten ${ }^{69}$. In dieser Einschätzung fand er frühzeitig Unterstützung bei den Alldeutschen, die ebenfalls bereits Ende August 1914 die Forderung aufstellen, die „Flaumacher«, mit denen der Kanzler unter einer Decke stecke, »wegzufegen « ${ }^{70}$. Gegen Jahresende war der Unmut gegen den Kanzler bereits so verbreitet, daß selbst der sozialdemokratische Reichstagsabgeordnete Eduard David seinem Tagebuch eine Notiz über die "Fronde" anvertraute, die "Dallwitz oder Tirpitz an Bethmanns Stelle bringen« wolle ${ }^{71}$. Der Kanzlervertraute Riezler wollte wenig später gar von einer $\mathrm{Zu}$ sage des Admirals an Maximilian Harden erfahren haben, daß Tirpitz den Publizisten im Falle eigener Kanzlerschaft als Außenminister in Aussicht genommen habe ${ }^{72}$ !

Daß sich Tirpitz für eine derartige Rolle während der gesamten Kriegszeit für geeignet hielt und in allen Kanzlerkrisen dieser Jahre von wesentlichen Teilen der Rechten auch immer mit ins Spiel gebracht wurde, wird noch zu zeigen sein. Ob indes die wenigen Hinweise vom Jahresende $1914 \mathrm{mehr}$ sind als eine der vielen Kandidatenspielereien, an denen das späte Kaiserreich nicht gerade arm war, läßt sich wegen der Dürftigkeit dieser Nachrichten nicht näher ausleuchten. Der Admiral mag mit dem Gedanken gespielt haben $^{73}$, seine konkreten Pläne sollten aber zu Beginn des folgenden Jahres eine andere Richtung einschlagen. Die Basis dafür gaben die Auseinandersetzungen um den politischen und militärischen Kurs des Reiches an der Jahreswende 1914/15 ab. Das deutsche Festlaufen an der westlichen Hauptfront zwang Führung und informierte Teile der Öffentlichkeit seit Anfang November 1914 schrittweise zu der Einsicht in eine längere Kriegsdauer mit ihren Zerreißproben und Risiken für den inneren Zusammenhalt. Sollte unter den sich verschlechternden Bedingungen der Burgfrieden des August 1914 halten, dann mußte er nach Meinung des Kanzlers durch sorgsam dosiertes Entgegenkommen im Innern und konsensfähige Kriegsziele nach außen ständig auf's Neue gesichert werden ${ }^{74}$. Damit setzte er sich freilich nach rechts dem Verdacht aus, einer schleichenden Machtverschiebung zu den parlamentarischen Kräften der Mitte und der Linken Vorschub zu leisten. Hugenberg als Vertreter der rheinischwestfälischen Schwerindustrie im Kriegsausschuß der Deutschen Industrie hielt nämlich "Eroberungen" schon deshalb für unverzichtbar, „damit die Einbildungskraft des Volkes von innen- und sozialpolitischen Reformgedanken abgelenkt werde “ ${ }^{75}$. In gemeinsamen Kriegszielbesprechungen fanden sich deshalb seit November 1914 die Träger der Einheitsfront von 1913 aus Industrie, Landwirtschaft, Konservativen und Alldeutschen erneut vereint. Die Ergebnisse faßte Class in einer Denkschrift zusammen, die vorab an Tirpitz und Ende Dezember 1914 schließlich an 1650 führende Persönlichkeiten im ganzen Reichsgebiet versandt wurde. Der Kanzler, der in dem Vorgang zu Recht einen schweren Verstoß gegen seine Burgfriedenspolitik erblickte, reagierte unverzüglich mit einer Beschlagnahmeaktion der Broschüre ${ }^{76}$. Tirpitz nahm im Gegenzug einen Besuch Krupps im Großen Hauptquartier Mitte Januar 1915 zum Anlaß, 
Industrie und Handwerk nunmehr zu einer Kriegszieleingabe am Kanzler vorbei direkt beim Kaiser zu bewegen. In der Sache einig, gab der Industrielle allerdings zu bedenken, dann müsse man »auch einen Mann haben, der es ausführe, d. h. einen anderen Reichskanzler, und einen solchen wisse er nicht «" ${ }^{7}$.

Damit war zwar der direkte Weg zum Ziel ein weiteres Mal versperrt, doch fand die anti-englische Hauptstoßrichtung in den Plänen des Admirals bis zum Frühjahr 1915 erweiterte Unterstützung. Mit Bassermann und Stresemann für die Nationalliberalen und Erzberger für das Zentrum reichte die Anti-Bethmann-Stimmung jetzt bereits bis weit in die bürgerliche Mitte ${ }^{78}$. Einwirkungsversuche des Kanzlers auf das nationalliberale Lager verstärkten dort die Gegenstimmen nur noch, da Bethmann das umfassende Kriegszielprogramm der Wirtschaftsverbände "selbst für den Fall eines umfassenden deutschen Sieges« ablehnte ${ }^{79}$. Im Mai sah er sich vielmehr einem gemeinsamen Vorstoß von Konservativen, Freikonservativen, Nationalliberalen und Zentrum im Sinne einer verschärften Kriegszielpolitik gegenüber ${ }^{80}$. Ein eigener Versuch, den nationalliberalen Parteiführer Bassermann über eine parteiinterne Fronde zu stürzen und damit wenigstens einen Keil in die Einheitsfront seiner Gegner zu treiben, scheiterte bereits im Sommer $1915^{81}$.

Eine Zuspitzung zur allgemeinen Führungskrise erfuhr die Situation an der Reichsspitze um die Jahreswende 1914/15 zudem über die Frage nach der weiteren Kriegführung. Der "Wettlauf zum Meer hatte die westliche Hauptfront endgültig im Stellungskrieg erstarren lassen, während die Siege des Gespanns Hindenburg-Ludendorff in Ostpreußen und Polen wenigstens im Osten Aussichten auf eine offensive Fortsetzung des Krieges offenzuhalten schienen. Mit dem Verfügbarwerden neuaufgestellter Armeekorps stand somit die Frage an, ob man mit dem neuen Generalstabschef Falkenhayn weiterhin das Hauptgewicht auf den Westen legen oder entsprechend dem Rat aus dem Hauptquartier des „Oberbefehlshabers Ost (OberOst) durch eine feldzugsentscheidende Ostoffensive zumindest Rußland friedensbereit machen sollte. Die strategische Kontroverse, die bei den unvereinbaren Temperamenten der eigentlichen Kontrahenten Falkenhayn und Ludendorff schnell einen Riß quer durch das Große Hauptquartier zog ${ }^{82}$, griff auch auf politisches Terrain über. Falkenhayns wachsende Einsicht in den Charakter dieses Krieges als eines langwierigen und kräftezehrenden Abnutzungskampfes konnte nicht ohne Rückwirkungen auf die Innen- und Außenpolitik des Reiches bleiben. Gerade der lange Krieg mußte nämlich die Chancen jener Ablenkungsstrategien drastisch verringern, die mit dem schnellen und vollständigen Sieg innenpolitische Erwartungen auf außenpolitische Eroberungen abzuleiten gedachten. Vielmehr wurde die unbedingte Aufrechterhaltung des Burgfriedens im Innern und der Fiktion des reinen Verteidigungskrieges nach außen zur conditio sine qua non einer derartigen Durchhaltestrategie. Allein das Erfolgskonzept von OberOst mit seinen harten chirurgischen Schnitten bot demgegenüber auch weiterhin Aussicht auf ein militärisches Resultat des Krieges, das sich mit einer Kriegszielpolitik annexionistischen Zuschnitts zur Deckung bringen ließ.

Diese Konstellation hätte den Kanzler von der Sache her zum natürlichen Verbündeten des Generalstabschefs machen müssen. Doch Bethmann war weder von der fachlichen Richtigkeit der Falkenhaynschen Überlegungen überzeugt, noch konnte er sich von seinem persönlichen Mißtrauen gegen den General als möglichen Konkurrenten um die politische Führung des Reiches ganz freimachen. Im übrigen sah er sich selbst von der Rechten so vehement der "Flaumacherei " bezichtigt, daß er seinen Kritikern nicht auch noch über die Befürwortung einer quasi halbherzigen Kriegführung weitere Nahrung geben wollte. Daraus resultierte im Januar 1915 das unnatürliche Bündnis Kanzler-OberOst, das in einer breit angelegten Intrige beim Kaiser für den Sturz des Generalstabschefs gipfelte ${ }^{83}$. Ihr Scheitern am Widerstand Wilhelms II., der nicht zur 
Berufung Hindenburgs an Stelle seines Favoriten Falkenhayn zu bewegen war, entschied in den politisch-militärischen Führungsauseinandersetzungen im Großen Hauptquartier letztlich nur für den Augenblick. Für den Kanzler sollte sie immerhin insofern für die nächsten Monate von Wert sein, als sein Eintreten für die Ostfeldherrn wenigstens deren Übergang in das Lager der Kanzlergegner verzögerte ${ }^{84}$.

Für Tirpitz hatten sich politische und militärische Führungskrise dagegen im Frühjahr 1915 endgültig zum Chaos totaler Konfusion an der Reichsspitze verdichtet. Ein Kanzler, der schon jetzt die militärischen Erfolge diplomatisch zu verspielen drohte; ein Generalstabschef, über dessen strategische Befähigung nicht einmal unter seinen engeren Mitarbeitern die Zweifel jemals verstummten - und über alledem ein Monarch, der die Fiktion des persönlichen Oberbefehls weniger denn je aufrechterhalten konnte und sich zudem durch seine Umgebung auch noch von den Härten der Gegenwart abschirmen ließ! Kennzeichnend für seine »schwarzseherischen« Zukunftserwartungen in diesen Wochen war ein Gespräch mit dem ehemaligen Kriegsminister und jetzigen Armeeführer v. Einem, in dem er Kaiser und Kanzler vorwarf, wenn es nach ihnen ginge, "sollte alles beim alten bleiben, bei den Opfern " ${ }^{85}$ ! Damit kündigte sich eine weitere Sorge aus der Bilanz der ersten Kriegsmonate mit ihren ungeheueren personellen und materiellen Verlusten an, die die politische und militärische Führung während des gesamten Krieges bedrücken sollte: womit wollte man der Öffentlichkeit gegenübertreten, wenn diese einmal nach dem Sinn dieser Opfer fragen würde? War man dann nicht zur Entlohnung der Massen auf dem Wege innerer Reformen bereit, so blieb eben nur das Setzen auf einen militärischen Sieg um nahezu jeden Preis. Es charakterisiert den neuen Typus auf der Rechten vom Schlage eines Tirpitz oder Ludendorff, daß sie sich frühzeitig dieser Konsequenzen des einmal in Gang gesetzten Krieges bewußt waren und sich - anders als die skrupulösere Mehrheit der wilhelminischen Führungskräfte zum vollen Einsatz aller Ressourcen für ihre Ziele bereitfanden.

$\mathrm{Da}$ Gefahr in militärischer wie politischer Hinsicht im Verzuge war, mußten auch die eingesetzten Mittel den umfassenden Schwierigkeiten adäquat sein. Das hieß zunächst einmal, den vollen und koordinierten Ansatz aller Pläne und Kampfmittel für den militärischen Sieg zu organisieren und dazu die Führungsorganisation mit ihrem Chaos der Ämter und Immediatstellungen zu einem Organ der Gesamtkriegführung zu vereinheitlichen. Es bedeutete darüber hinaus, daß alle Hemmnisse und Gegenwirkungen aus dem politischen Raum auszuschalten waren, die sich schon in der Frage des Flotteneinsatzes störend bemerkbar gemacht hatten und sich jetzt gegen das noch verbleibende Seekriegsmittel des uneingeschränkten U-Bootkrieges sperrten ${ }^{86}$. Es erforderte schließlich die Zusammenführung von Politik und Kriegführung in einem einheitlichen Willen, der die Nation geschlossen hielt, ihre Ressourcen voll zum Tragen brachte und ihre Lebensinteressen nach dem Sieg in einer den Opfern angemessenen Politik der Machterweiterung nach außen wahrnahm.

Für Tirpitz lagen die Notwendigkeiten der Stunde offen zutage, wie er seinem Tagebuch Ende März 1915 anvertraute: »Es gäbe nur ein Mittel, Hindenburg würde Reichskanzler und Chef des Generalstabs und Chef der Admiralität in einer Person. " ${ }^{87}$ Damit zog er die Folgerung aus den Enttäuschungen der Jahreswende. Weder war es gelungen, den Kanzler loszuwerden, noch hatte sich der als inkompetent angesehene Generalstabschef auswechseln lassen. In beiden Fällen hatte sich der Kaiser als das eigentliche Hindernis gegen das dringliche Revirement erwiesen, sich also, wie im Kaiserbuch von Class befürchtet, gegen die Interessen der Nation gestellt. Wollte man unter diesen Umständen die Krone retten, dann mußte man sie vor ihrem derzeitigen Träger schützen. Mit anderen Worten: "Ich sehe nur ein Mittel, der Kaiser muß auf 8 Wochen oder mehr sich krank melden, an Stelle Bethmanns muß Hindenburg kommen und diesem alles unterstellt werden, zugleich Armee und Marine. ${ }^{88}$ Das Problem 
war freilich, wie Wilhelm II. zu dieser Einsicht gebracht werden konnte, denn gegen seinen Willen war jetzt ebensowenig etwas zu bewegen wie 1913. Außerdem mußte das riskante Spiel sich zumindest dem äußeren Anschein nach in konstitutionellen Formen entwickeln, deren innen- und außenpolitische Nebenwirkungen kontrollierbar blieben.

Der ins Vertrauen gezogene Generaladjutant v. Kessel sah im König von Bayern als dem ranghöchsten Bundesfürsten den geeigneten Überbringer der Botschaft. Der Admiral hatte dagegen bereits bei seinem Versuch zum Sturz Bethmanns zu viele Führungsgrößen des Kaiserreichs abwinken sehen, wenn es um einen direkten Vorstoß beim Monarchen gegangen war, als daß er sich aus diesem Kreis noch sonderliche Wirkung versprochen hätte. Er wollte daher ähnlich wie bei der Januar-Intrige gegen Falkenhayn den Weg über die Hintertür der kaiserlichen Familie nehmen ${ }^{89}$. Von seinen alldeutsch gefärbten Parteinahmen her bot sich der Deutsche Kronprinz für eine Vermittlungsaktion dieser Art geradezu an, zumal er auch nach Kriegsbeginn über seinen politischen Berater, den preußischen Landrat v. Maltzan, fest in seiner radikalen Anschauungswelt verhaftet blieb ${ }^{90}$. Die Hinweise, "daß der Kronprinz auch an Hindenburg denkt ", bestärkten Tirpitz jedenfalls in seinem Vorhaben, sich direkt mit ihm ins Benehmen zu setzen ${ }^{91}$. Vorher war allerdings ärztlicher Rat einzuholen, um auch die Kaiserin aus Sorge um die nervliche und körperliche Überbelastung ihres Gatten in das Unternehmen einzubinden. Die Informationen aus dem Munde des kaiserlichen Leibarztes, Professor v. Niedner, »der Kaiser betete förmlich nach einer Erlösung durch Abschiebung der Verantwortlichkeit «"2, klangen so hoffnungsvoll, daß Tirpitz nunmehr an ihn mit seinem eigentlichen Vorschlag herantrat, "den Kaiser zeitweilig für regierungsunfähig zu erklären und eine Regentschaft unter dem Kronprinzen einzusetzen ${ }^{93}$. Der Arzt war aber für einen so weitgehenden Schritt, der sich weder mit dem monarchischen Gedanken generell noch mit seiner persönlichen Königstreue habe vereinbaren lassen, unter gar keinen Umständen zu haben ${ }^{94}$. Zur eigenen Absicherung schaltete er vielmehr von sich aus den Chef des Zivilkabinetts v. Valentini in die Angelegenheit ein. Tirpitz mußte schnell erleben, daß letztlich keiner der ins Vertrauen gezogenen Kaiserberater - weder der Chef des Marinekabinetts v. Müller, noch der Oberhof- und Hausmarschall Frhr. v. Reischach oder gar der Kommandant des Kaiserlichen Hauptquartiers v. Plessen - für einen derart abenteuerlichen Schritt zu haben war ${ }^{95}$. Das Abbrechen aller in diese Richtung laufenden Hinweise in seinem Tagebuch nach einem Gespräch mit Admiral v. Müller am 2. April $1915^{96}$ stützt vielmehr dessen Vermutung, Tirpitz selbst habe "schließlich kalte Füße bekommen «" und den Plan nicht mehr weiterverfolgt.

Die Besonderheit dieses Vorstoßes beruht zunächst einmal auf ihrer radikalen gedanklichen Konsequenz. Weiter als Tirpitz hatte sich bisher und sollte sich auch bis 1918 kein anderer Kritiker von rechts vorwagen. Der preußischen Krone war aus ihrer historischen Stärke die nationale Aufgabe der Reichseinigung und -erweiterung zugewachsen. Fehlten ihr Kraft oder Willen zum Durchhalten dieser Mission, dann mußte ihr Träger zeitweilig suspendiert werden, um die geschichtsmächtige monarchische Idee in Deutschland auch gegen die Intentionen ihres gegenwärtigen Throninhabers stark zu halten. In den Jahren der Einigungskriege hatte Bismarck aus der Position des politischen Führers die Rolle des vorantreibenden Elements gegenüber einem zögernden Monarchen gespielt. Das Tirpitz an "Byzanz« erinnernde späte Kaiserreich verfügte in seinen um einen schwachen Kaiser kreisenden, mediokren Hofgrößen ${ }^{98}$ nicht mehr über eine politische Potenz ähnlichen Kalibers. Also mußte der durch meßbare Leistung ausgewiesene stärkste Armeeführer in die Bresche springen - und das war nach seinem Siegeszug eben Hindenburg, den der Admiral im übrigen bis zu diesem Zeitpunkt noch nicht einmal persönlich kannte ${ }^{99}$. 
Ähnlich wie sich unmittelbar vor dem Krieg somit aus der herkömmlichen Rechten in den nationalen Agitationsverbänden eine neue dynamischere Fraktion herausentwikkelt hatte, so wird hier im Offizierkorps nach den ersten militärischen Rückschlägen in Charakteren wie Tirpitz und Ludendorff ebenfalls ein neuer Typus sichtbar, der in seiner Loyalität stärker an den nationalen Staat als an die legitime Krone und die sie repräsentierende gesellschaftliche Ordnung gebunden ist. Nirgends wird dies deutlicher als im Gegenüber eines Tirpitz und seiner Kontrahenten v. Müller und v. Plessen im Großen Hauptquartier. Seine Konsequenz und seine Maßlosigkeiten lösten bei ihnen Reaktionen der Empörung und des Erschreckens aus. Noch hielten sie mit Bethmann Hollweg an der Reichs- und mit Falkenhayn an der Heeresspitze die zentralen Positionen besetzt. Blieb ihnen indes dauerhaft der Erfolg versagt, dann würden sich immer nachdrücklicher gerade in der Armee diejenigen zu Wort melden, die schon jetzt aus der Position der Stabschefs und Spezialisten heraus die eigentlichen Beweger dieses riesenhaften Militärkörpers darstellten. Sie gingen Probleme und Krisen nicht mehr vorrangig unter dem Gesichtspunkt gesellschaftlicher Rücksichtnahmen, sondern von dem aus ihrer militärischen Professionalität entwickelten Bild des Notwendigen für die Führung dieses Krieges neuen Typs an ${ }^{100}$.

Was die alldeutschen Staatsstreichpläne von 1913 und die Tirpitz-Vorstöße zu einer radikalen Führungsreform von 1914/15 verband, war eine politische Analyse, die sich von einer in den wilhelminischen Führungsschichten weitverbreiteten personellen Einzelkritik zur generellen Skepsis über die Systemschwächen des späten Kaiserreiches vortastete. Das schnelle Verpuffen der euphorischen Stimmung bei Kriegsausbruch und während der ersten Siegesserie wirkte dafür nur als Bestärkung. Solange das wilhelminische System freilich noch nicht faktisch in Frage gestellt war, gab es für alle derartigen Reichsreformpläne von rechts keine andere Realisierungschance als ein Tätigwerden aus der Reichsspitze selbst.

Einig in der Kritik an der Politik des Kanzlers und an den Schwankungen des Kaisers mit diesen konsequentesten politisch-militärischen Verfechtern eines dynamischeren Machtstaates, scheute die überwiegende Mehrheit im Lager der bürgerlichen und altkonservativen Rechten in Gesellschaft und Offizierkorps indes vor deren radikalen Remeduren zurück. An diesem Punkt setzte die bis 1918 fortbestehende relative Stärke der Krone ein, die zwar längst nicht mehr aktiver Impulsgeber sein, die aber wenigstens bis zur Kriegsmitte allein durch ihre passive Resistenz personelle Alternativen blockieren und auch danach noch letzte Systemkonsequenzen nach rechts aus einer sich abzeichnenden Niederlage verhindern konnte. Alle Versuche einer politisch-militärischen Effizienzsteigerung über einen diktatorischen Umbau der Reichsspitze fanden ihre Grenzen in der Person Wilhelms II. Da er weder zum offenen Verfassungsbruch nach alldeutscher Art bereit war, noch über das manipulative Mittel zeitweiliger oder dauerhafter Regierungsunfähigkeit vom Thron zu entfernen war, blieb für die unmittelbare Zukunft nur der Weg offen, einen schwachen Monarchen über starke politische und militärische Ratgeber - am besten in Personalunion - zu stützen.

\section{III}

Das Aufgeben seines Planes einer Totalrevision bedeutete für Tirpitz aber keineswegs ein Abgehen von der ursprünglichen begrenzteren Variante eines Kanzlerersatzes durch einen mit diktatorischen Vollmachten ausgestatteten General. Dazu blieb die allgemeine Bethmann-Kritik vom Zentrum bis zu den Alldeutschen viel zu konstant. Ein immer weitgespannteres Besuchsprogramm von Politikern und Parlamentariern an den Fronten verbreiterte diese Basis seit Frühjahr 1915 sogar noch und trug die Antistimmung jetzt bis in die Korps- und Armeestäbe der Fronttruppen. Der »Schlappmi- 
chel« Bethmann und die »Kamarilla« der Kabinettschefs um den Kaiser wurden zu den bevorzugten Angriffsobjekten für politisch unangenehme Nachrichten aus der Heimat ${ }^{101}$. Dazu gesellte sich die verbreitete Skepsis, ob dieser Kanzler überhaupt das Stehvermögen für einen Friedensschluß haben werde, zu dem sich das Reich "mit dem Millionenopfer an Menschen neues Recht erkauft« habe und der es - dies ein gewichtiger neuer Gedanke aus militärischer Sicht — »stark macht für den nächsten Krieg “ ${ }^{102}$. Schließlich erweiterte sich der Kreis der Kritiker auch noch um die stärker werdende Phalanx derer, die gegen "ein Schlappwerden im Untersee-Boot-Krieg « ${ }^{103}$ Sturm liefen.

Für Tirpitz waren dies Gründe und Anreiz genug, sein ursprüngliches Projekt einer Kanzlerschaft Hindenburgs weiterzuverfolgen, denn "daß wir unser ganzes System änderten [.. .], dazu sehe ich wenig Aussicht « ${ }^{104}$. Die Frage war nur, ob der Feldmarschall überhaupt für einen solchen Schritt zu gewinnen war, nachdem dieser erst im Januar 1915 beim gemeinsamen Vorstoß gegen Falkenhayn die Ungnade seines Monarchen zu spüren bekommen hatte. Im übrigen beschrieb Hindenburg sich selbst als eine "unpolitische Natur», die im Kriege keinerlei Neigungen zur „Gegenwartspolitik“ besessen habe ${ }^{105}$. Als Tirpitz deshalb seine Vorstellungen im April 1915 der Kaiserin anvertraute, schlugen ihm nicht nur Skepsis über die Bereitschaft Hindenburgs, sondern auch Zweifel an dessen Eignung entgegen, denn er »wäre wohl auch zu sehr reiner Militär«. Interessant sind nun die Gegenargumente des Admirals, daß für die vorgesehene Rolle "gesunder Menschenverstand « ausreiche, während Hindenburgs militärische Herkunft schon deshalb das Richtige sei, "damit Einheitlichkeit in das Ganze käme “ ${ }^{106}$. Dazu kam aus der Sicht der Kanzlergegner im Großen Hauptquartier, wo man sich wenig Illusionen über die Aktivität des Feldmarschalls hingab - »mehr Dekoration als handelnde Persönlichkeit« -, daß er immerhin »der Mann des Volkes« sei ${ }^{107}$. Diese Einschätzungen korrespondieren auffällig mit zeitgleichen Überlegungen bei den Alldeutschen. Auch in ihren Vorstellungen eines Militärdiktators sollten militärische Positionsmacht und persönliche Popularität einer Regierung von Fachleuten aus Berufsbeamtentum, Industrie und Landwirtschaft vor allem Durchsetzungskraft und Rückgrat für ihr Handeln geben ${ }^{108}$. Daß Hindenburg tatsächlich dieser Mann des nationalen Lagers war, zeigten die seit seinen ostpreußischen Siegen nicht abreißenden Pilgerfahrten von Fürsten, Politikern und Parlamentariern in sein Lötzener Hauptquartier.

Um sich ein eigenes Bild zu verschaffen und die Realisierbarkeit seiner Kanzlerpläne zu eruieren, entschloß sich Tirpitz daher im August 1915 selbst zum Besuch bei OberOst. Sein Aufenthalt in Lötzen mochte ihm indes eine "Herzenserquickung« sein und "volles Einvernehmen über die Gesamtlage « mit Hindenburg und Ludendorff bringen; sein abschließender Appell, "vom Osten wäre in schwerster Zeit Preußen einst die Sonne aufgegangen, ich hoffte, daß dasselbe in dieser für Deutschland-Preußen ernsten Zeit sich wiederhole“, erreichte sein Ziel dagegen nur bedingt. Der Konsens in allen Sachfragen von Politik und Kriegführung wie die Bereitschaft von OberOst, den Admiral argumentativ zu unterstützen, konnte nicht darüber hinwegtäuschen, daß beide Generale eine Änderung der Gesamtsituation an der Reichsspitze für »aussichtslos« erklärten ${ }^{109}$. Der Grund für diese Zurückhaltung erschließt sich neben Hindenburgs Desinteresse an einer anderen als seiner militärischen Rolle insbesondere aus dem entspannten Verhältnis von OberOst zum Kanzler. Im Frühjahr hatte dies bereits Kapp bei einem ähnlich gelagerten Vorstoß im östlichen Hauptquartier erfahren müssen ${ }^{110}$ und alle weiteren Aussprachen an der Jahreswende 1915/16 sollten zum selben Ergebnis führen: Konservative wie Alldeutsche bekamen in diesen Monaten mehr Vorwürfe als Zuspruch zu hören, wenn sie die Unterstützung von OberOst für ihre Kanzlerfronde zu mobilisieren suchten ${ }^{111}$. Der Kanzler sei nicht so schlecht, wie er ge- 
macht werde, jeder Wechsel vor den Augen des feindlichen Auslandes wäre eher schädlich und der dem Kaiser in einem solchen Falle genehmste Kandidat außerdem Falkenhayn. Der Kampf mit einem gewiß nicht immer glücklichen Bethmann gegen den strategischen Erzrivalen als das kleinere Übel schien besonders Ludendorff da allemal zweckdienlicher. Bethmanns Votum für OberOst gegen den Generalstabschef im Januar trug jetzt seine Früchte. Daß er sich dessen voll bewußt war, zeigte seine Einschätzung, daß Gefahr für seine Kanzlerschaft aus ganz anderer Richtung drohte: von Tirpitz oder Falkenhayn ${ }^{112}$ !

Daß Tirpitz seit dem Herbst 1915 wieder häufiger als Gegenkandidat Bethmanns genannt wurde, lag natürlich zuerst einmal an der Verweigerung Hindenburgs. Damit blieb als national-populäres Aushängeschild nur noch der Flottenschöpfer. In einer militärischen Lage, in der inzwischen alle Landkriegsfronten im Stellungskrieg erstarrt waren, konnte der Admiral aber auch direktes Prestige für sich verbuchen, da er mit der U-Boot-Waffe zeitweilig über das einzige noch verbliebene Siegesinstrument zu verfügen schien ${ }^{113}$. Wesentlicher für alle weiteren Pläne wurde jedoch die seit Anfang 1916 einsetzende Gewichtsverlagerung bei der Begründung einer notwendig werdenden Regierung der starken Hand von den vorrangig kriegszielorientierten zu den jetzt gleichwertig auftauchenden innenpolitischen Argumenten. Ausgelöst wurde diese Wendung durch die Thronrede vom 13. Januar 1916 mit ihrer Anspielung auf eine preußische Wahlrechtsreform nach Kriegsende, die auf der Rechten heftige parlamentarische und publizistische Gegenreaktionen hervorrief ${ }^{114}$. Sie fanden ihren Höhepunkt in einer auf Initiative des Herrenhausmitglieds Fürst Salm-Horstmar formulierten Eingabe an den Kaiser, die vor »besorgniserregenden Zuständen« warnte, falls sich die »sehr auffallende Einwirkung demokratischer Kreise auf die Reichsleitung " fortsetze $^{115}$. Doch die Initiatoren der Eingabe konnten weder für sich selbst noch für die Fraktionsvorsitzenden der Rechtsparteien im preußischen Abgeordnetenhaus eine Audienz beim Kaiser erwirken ${ }^{116}$. Für die Konservativen unternahm daher Oldenburg-Januschau, der mit Hindenburg persönlich bekannt war, nach Rücksprache mit Tirpitz einen erneuten Anlauf bei OberOst, diesmal mit dem Ziel, die Unterstützung für eine Kanzlerschaft des Admirals zu erwirken. Wie zentral hier bereits innenpolitische Überlegungen mitspielten, geht aus der Frage des Feldmarschalls hervor, ob Tirpitz denn mit dem Reichstag fertigwerden würde, was Oldenburg unbedingt bejahte: "Er hat den Reichstag immer geleimt«. Der Emissär mußte das östliche Hauptquartier jedoch ebenso »unverrichteter Dinge wieder verlassen wie seine vielen Vorgänger ${ }^{117}$.

Inzwischen war seit Anfang März 1916 der Reichskanzler selbst entschlossen, dem Treiben ein Ende zu setzen und „Tirpitz, der ihm auf Schritt und Tritt Verlegenheiten bereitet, zu beseitigen « ${ }^{\mathbf{1 1 8}}$. Ein gezielter Affront, bei dem der Marinestaatssekretär zu einem entscheidenden Kronrat über die U-Bootfrage nicht zugezogen wurde, löste am 15. März 1916 dessen Rücktritt aus, nachdem er sich im Großen Hauptquartier gerade in den letzten Monaten völlig isoliert hatte ${ }^{119}$. Geblieben war zunächst nur noch der Rückhalt am Kronprinzen, von dem der Kaiser zu Recht annahm, er werde Tirpitz, "wenn er erst meinen Platz inne hat, sofort zum Reichskanzler machen « ${ }^{120}$. Der Schachzug mochte dem Kanzler auch für den Augenblick Luft verschaffen, da selbst unter den alldeutschen Parteigängern des Admirals zunächst die Enttäuschung über ihren offenbar mutlos gewordenen Heros unüberhörbar war ${ }^{121}$. Schon auf mittlere Sicht sollte sich der Erfolg dagegen als Pyrrhussieg entpuppen, als nämlich der jetzt von allen administrativen Fesseln und politischen Rücksichtnahmen freie Tirpitz genau das tat, wozu ihm bisher in den Augen seiner Anhänger der Mut gefehlt hatte: "mit den unabhängigen nationalen Kreisen des Volkes Verkehr zu suchen « ${ }^{122}$. Ansporn genug konnten ihm dazu die öffentlichen Huldigungen sein, die in ihm das prominenteste Opfer des "Systems Bethmann « feierten ${ }^{123}$. Schon im Sommer 1916 durfte er sich ne- 
ben dem Fürsten Bülow wieder als meistgenannter Kandidat der Rechten von einer bedeutenden Gruppe bayerischer Reichsräte bis zu den Alldeutschen sehen. Über ein Ehrenpräsidium des Admirals im Unabhängigen Ausschuß für einen Deutschen Frieden suchte ihm Kapp dazu das Instrument zu schmieden, über das man ihn öffentlich zum Gegenkandidaten des Kanzlers aufbauen wollte ${ }^{124}$.

Der Weg zur Kanzlerschaft führte jedoch nach wie vor über den Kaiser, bei dem Tirpitz jeden Kredit verspielt hatte. Bethmanns Sorgen und die Hoffnungen seiner Gegner richteten sich denn auch zeitweilig auf einen anderen Kandidaten: den Generalstabschef Falkenhayn. Ihn hatte der Kaiser schon vor dem Kriege für seinen Mann in jedem denkbaren Sattel angesehen ${ }^{125}$. Seine militärische Befähigung war zwar alles andere als unumstritten, dafür genoß er aber in Armeekreisen ${ }^{126}$ wie bei den Nationalliberalen ${ }^{127}$ den Ruf eines ausgesprochen politischen Kopfes. Was ihm weit eher als dem Zauderer Bethmann zugetraut wurde, war ein auf nüchternem Machtkalkül aufgebauter Friedensschluß mit strategischen Zielsetzungen für die Zukunft ${ }^{128}$. Das Denken über den aktuellen Krieg hinaus ist kennzeichnend für die Überlegungen, die sich nach dem Scheitern der schnellen Feldzugsentscheidung ähnlich auch bei anderen hochformatigen Generalstabsoffizieren seit 1915 nachweisen lassen ${ }^{129}$. Selbst ein unter letztem Kraftaufwand doch noch gewonnener Krieg würde das Reich nur kurzfristig entlasten, da die weltweiten Ressourcen dem Ring seiner Gegner relativ rasch zur Erholung verhelfen würden. Ähnlich wie bei den Auseinandersetzungen um Lothringen beim Friedensschluß von 1871 brachten die Militärs deshalb den Gewinn strategischer Positionen in Form von schützenden Vorfeldern oder operativen Ausgangsstellungen für den künftigen Krieg als eigenständige militärische Kriegsziele ein. Sie sind weder mit sozialimperialistischen noch mit ökonomistischen Modellen des Kaiserreiches ganz zu verrechnen, sondern stellen teils zusätzliche, teils sogar konkurrierende Zielprojektionen rein militärischer Provenienz dar. Zugleich rechtfertigten sie für ihre konsequentesten Verfechter wie Tirpitz, Ludendorff oder Bernhardi mit ihren geostrategischen Erfordernissen das Herauswachsen dieses "modernen« militärischen Denkens aus den von Clausewitz gesetzten Begrenzungen. Ging man in dieser Richtung gedanklich noch einen Schritt weiter und fügte der Überbetonung des militärisch Notwendigen die sozialdarwinistische Vorstellung vom Völkerleben als ständigem Kampf um die weltpolitischen Vorzugsplätze hinzu, dann gelangte man schließlich zu Ludendorffs zwangsläufig die Grenzen herkömmlicher Politik sprengendem Militarismus. Die Kriegführung wurde dann von der Dienerin zur Herrin der Politik ${ }^{130}$.

So weit ging zu diesem Zeitpunkt allerdings selbst Ludendorff noch nicht, geschweige denn gemäßigtere Militärs wie Falkenhayn, Groener oder Seeckt. Immerhin spielten sie doch zumindest mit dem Gedanken, den Kanzler durch einen der Ihren zu ersetzen, der zu einem den Opfern angemessenen und die zukünftigen militärischen Notwendigkeiten offensiv vertretenden Frieden fähig schien. Im Unterschied zu den Anhängern einer Militärdiktatur als erstem Schritt zu einer Systemreform von rechts verblieben Falkenhayn und seine Parteigänger aber innerhalb der von Verfassung und Loyalität gesteckten Grenzen ${ }^{131}$. Hinzu kam, daß der Generalstabschef erst dann zu einer aktiveren politischen Rolle bereit war, wenn er dafür durch militärische Erfolge die Voraussetzungen vor Kaiser und Öffentlichkeit geschaffen hatte ${ }^{132}$.

Der Reichskanzler war jedenfalls schon in den ersten Monaten des Jahres 1915 aufs höchste alarmiert, als er zunächst über Staatssekretär Helfferich ${ }^{133}$ und seit Frühjahr 1915 auch aus nationalliberalen Quellen ${ }^{134}$ zunehmend Stimmen für eine Kanzlerschaft Falkenhayns vernahm. Die Gefahr aus dieser Richtung mußte er für ungleich gravierender als im Falle von Tirpitz halten, da er eben erst am eigenen Leibe bei seinem Zusammenspiel mit OberOst gegen den Generalstabschef dessen persönlich stabile Position beim Kaiser vorgeführt bekommen hatte. Die Nervosität steigerte sich da- 
her, als sich mit den Abwehrerfolgen im Westen und dem Durchbruchssieg von Gorlice-Tarnow in der Jahresmitte 1915 auch die militärischen Hoffnungen an Falkenhayn zu heften begannen. Selbst ein so treuer Weggenosse des Kanzlers wie v. Valentini mochte jetzt nicht mehr ausschließen, daß Bethmann seinen Platz an Falkenhayn abtreten und diesem als neuer Generalstabschef der Heros der Öffentlichkeit, Hindenburg, an die Seite gestellt werden mußte ${ }^{135}$. Die Lösung schien schon deshalb etwas Bestechendes zu haben, weil damit möglicherweise auch der Dauerkonflikt zwischen der II. OHL und OberOst neutralisiert werden konnte.

Die Besorgnis Bethmanns stieg, als Falkenhayn aus seiner zunächst geübten Zurückhaltung in der U-Bootfrage heraustrat. Das Zusammenwirken von Heeres- und Marineleitung wie ihr breiter Rückhalt in einer von Publizisten und Professoren für die Verschärfung des Seekrieges gewonnenen Öffentlichkeit ${ }^{136}$ konnten dem Kanzler um so gefährlicher werden, als er schon mit seinen innenpolitischen Ansätzen zu moderater Kursänderung erheblich an Vertrauen bei den Mitte- und Rechtsparteien eingebüßt hatte. Daß in dieser gespannten Situation zwischen politischer und militärischer Führung auch wenig Hoffnung auf die von der Verfassung geforderte Ausgleichsrolle des Kaisers zu setzen war, Wilhelm II. vielmehr selbst mit seinen militärischen Vorlieben immer stärker in den Bann einer rein militärisch ausgerichteten Kriegführung geriet, ließ im übrigen eine seiner gefürchteten Randbemerkungen am Jahresende 1915 erkennen. Einen für den Vorrang der Politik plädierenden Artikel der Frankfurter Zeitung vom Dezember 1915 glossierte er mit dem Verdikt: "Politik hält im Kriege den Mund, bis Strategie ihr das Reden wieder gestattet. “ ${ }^{137}$

Wie schon in der Kriegszielfrage sah sich Bethmann denn auch beim U-Bootkrieg bald wider besseres Wissen zu wenigstens teilweisem Entgegenkommen genötigt, wollte er seine angeschlagene Position im Machtspiel um das Kanzleramt nicht über Gebühr belasten ${ }^{138}$. Man muß diese Fragilität einer zwischen Reformbedürfnissen und Beharrungsinteressen eingezwängten Reichsleitung, deren hauptsächlicher Rückhalt auf dem Stehvermögen eines Monarchen vom Zuschnitt Wilhelms II. beruhte, und die sich auch im politischen Kräfteparallelogramm des späten Kaiserreiches zu keiner Zeit ihrer Stellung aus eigener Kraft versichern konnte, bei der Bewertung des Kanzlerspielraums berücksichtigen, wenn man sein Lavieren nicht nur als Opportunismus reiner Machtbehauptung mißverstehen will. Damit werden freilich zugleich die Begrenztheiten des bismarckschen Verfassungskompromisses unübersehbar. Indem er das freie öffentliche Austragen der sich gegenseitig blockierenden Kräfte zurückschnitt, verbannte er es schließlich in seiner spätwilhelminischen Spielform in das intrigenreiche Halbdunkel des innerexekutiven Positionenkampfes.

Ähnlich wie beim Ausspielen seines Gegners Tirpitz sollte in diesem personellen Interessenkampf auch der Etappensieg des Kanzlers über Falkenhayn Mitte 1916 die Voraussetzungen für den vollständigen Mißerfolg der politischen Reichsspitze in ihrem Ringen mit der militärischen Führung schaffen. Mit dem Auslösen des strategischen Großunternehmens von Verdun hatte sich der Generalstabschef nämlich seit Februar 1916 selbst militärisch unabkömmlich gestellt ${ }^{139}$ und durch den folgenden Fehlschlag dann gerade die Kräfte gegen sich versammelt, die im Vorjahr noch bereit gewesen waren, ihn gegen Bethmann auf den Schild zu heben. Angesichts der drohenden Niederlage gelang dem Kanzler jetzt, was ihm im Januar 1915 versagt geblieben war: das Bündnis mit der Öffentlichkeit und ihren Hoffnungsträgern bei OberOst gegen den Konkurrenten Falkenhayn ${ }^{140}$. In diesem Falle intuitiver als sein Kanzler erahnte allerdings der Kaiser, was das Hereinlassen der Publikumsheroen Hindenburg und Ludendorff für seine Stellung bedeutete: Noch Anfang Juli 1916 hatte er auf das Drängen seiner Ratgeber nach einer Aufgabenerweiterung für OberOst wütend vermerkt, "er wolle nicht zugunsten des Volkstribuns Hindenburg abdanken « ${ }^{141}$. 
Daß der Reichskanzler in der militärischen und psychologischen Krisenstimmung des August 1916 den Wünschen von Öffentlichkeit, Armeeführern und Bundesfürsten folgte und den kaiserlichen Widerwillen gegen das Gespann von OberOst überwinden half, war bei seiner permanent prekären Stellung zu diesem Zeitpunkt wohl unvermeidlich. Seine bisherigen Erfahrungen mit OberOst gegen Falkenhayn mochten ihn hoffen lassen, deren überragendes Prestige für die Stabilisierung der eigenen Position und vielleicht sogar für die öffentliche Akzeptanz eines allenfalls notwendig werdenden Verständigungsfriedens ohne Zugewinne einsetzen zu können ${ }^{142}$. Ludendorffs offen gezeigte Bereitschaft gegenüber seinen engsten Mitarbeitern unmittelbar nach Übernahme der Geschäfte eines Ersten Generalquartiermeisters, er werde sich anders als Falkenhayn »um Politik nicht kümmern, sondern den Krieg führen « ${ }^{143}$, schien solcher Zuversicht des Kanzlers zu entsprechen. Daß es dem General damit subjektiv durchaus ernst war, wenn sein Vertrauter Wetzell auch in dieser Beziehung von Anfang an seine Zweifel hegte ${ }^{144}$, zeigte der General gegenüber den sofort einsetzenden alldeutschen Vorstößen für ihren Kanzlerkandidaten Tirpitz. Ludendorff bekannte zwar gegenüber Kapp: »Mit Tirpitz würde ich unbedingt gehen«, hielt im übrigen aber daran fest, daß er gegen Bethmann "z. Zt. [...] keine Veranlassung zu irgendeiner Klage habe « ${ }^{145}$. Das mußte die Kanzlerfronde umso härter treffen, als auch der Kaiser weiterhin unmißverständlich an seiner Weigerung festhielt, »jemals an Tirpitz als Kanzlernachfolger zu denken “ ${ }^{146}$.

Damit mochte für Bethmann im Augenblick Luft geschaffen sein; nur war nichts darüber ausgesagt, was geschehen würde, wenn Ludendorffs militärische Unbedingtheit einmal Widerstand am Kanzler finden sollte. Eine Aufsplitterung seiner militärischen Gegenspieler wie noch zu Falkenhayns Zeiten war dann nämlich ebensowenig möglich wie ein Ersatz der III. OHL, die durch ihre quasi-plebiszitäre Abstützung in der Öffentlichkeit schon jetzt faktisch unabsetzbar war. Genau für diesen Fall aber begann Ludendorffs politischer Berater für die folgenden Jahre, Oberst Max Bauer, schon im Frühherbst 1916 die Minen zu legen. Von dem für Waffen- und Munitionsbeschaffung verantwortlichen Artilleriefachmann in der OHL hat ein Generalstabsoffizier aus der benachbarten Eisenbahnabteilung eine eindringliche Charakteristik überliefert ${ }^{147}$ : Nach seiner Arbeitswut, seinem Organisationstalent und seiner militärfachlichen Einseitigkeit nahezu kongenial zu Ludendorff, sollte Bauer auf den Generalquartiermeister ab 1916 gerade auf den Gebieten besonders bestechend wirken, auf denen sich dieser nach eigener Einschätzung am wenigsten zuhause fühlte: Politik und Wirtschaft. Bauers Verbindung zu Technikern und Industriellen hatte ihn noch unter Falkenhayn davon überzeugt, daß die Entente nur zu bezwingen war, wenn die erkennbaren Defizite bei der materiellen Kriegführung durch fachliche Konzentration unter rücksichtsloser Führung beseitigt würden ${ }^{148}$. Für diese Aufgabenstellung war im deutschen Generalstab niemand besser geeignet als Ludendorff, der bereits 1912/13 im Kampf um die Heeresvermehrung jene Energie - frei von gesellschaftlichen Rücksichtnahmen - bewiesen hatte, auf die es jetzt ankam. Deshalb gehörte Bauer seit Frühjahr 1916 zu den Parteigängern von OberOst im Großen Hauptquartier, die hinter Falkenhayns Rücken auf seinen Sturz hinarbeiteten ${ }^{149}$. Kaum war daher das erhoffte Revirement in der OHL erfolgt, als er seine Gedanken für eine Intensivierung der Kriegswirtschaft im Entwurf für eine Eingabe Hindenburgs an den Kaiser Anfang September 1916 fixierte. In kaum einem anderen Schriftstück finden sich Begründung und Programm einer auf das Militär gestützten Diktatur als zwingendes Erfordernis in der Kriegsmitte so komprimiert und ungetarnt vorgetragen wie hier ${ }^{150}$.

Bezeichnend für Autor und Zeitpunkt ist bereits die Zusammenstellung der Krisensymptome, die sich allein über einen »einheitlichen Willen und eine starke Macht dahinter“ noch kurieren ließen. Sie nehmen ausnahmslos ihren Ausgang von den wirt- 
schaftlichen Schwierigkeiten des Reiches und ihrer Doppelwirkung auf Innenpolitik und Kriegführung. Rüstungswirtschaftliche Eigenerfahrung und die Klagen seiner industriellen Gesprächspartner haben dabei unzweifelhaft die Feder mitgeführt, aber eben nicht nur in einer einseitigen Lobbyistenrolle, die dem Oberst als Mann der Schwerindustrie in der OHL gerne zugeschrieben wird ${ }^{151}$. Schwachpunkte wie Lebensmittelknappheit, Rohstoffengpässe und Arbeitskräftemangel werden vielmehr vorrangig in ihrer funktionalen Bedeutung für die Kriegführung analysiert. In diesem Spätsommer 1916 mußte sich selbst die militärische Führung eingestehen: "Wie der Krieg abläuft, ist heute schwer zu sagen«. Das Neue war nun, daß man in dieser Situation nicht mehr zuerst nach einem neuen Feldzugsplan suchte, sondern endlich den Finger auf den viel entscheidenderen Schwachpunkt bisheriger Kriegführung legte: das nicht mehr zu übersehende Versagen der deutschen Kriegswirtschaft. Hier Abhilfe zu schaffen, bedeutete zweifellos auch, einer Umverteilungspolitik bei Arbeitskräften und Rohstoffen gegen Kleingewerbe und mittelständische Industrie zugunsten eines schwerindustriellen Konzentrationsprozesses das Wort zu reden. Dafür und für das Vorgehen gegen die „üblen Elemente«, die sich die wirtschaftliche Lage agitatorisch zunutze machen wollten, die Durchsetzungskraft des Militärapparates rücksichtlos und das hieß, vor allem unter Ausschaltung jedes mäßigenden Einflusses seitens der gesetzgebenden Körperschaften - zur Geltung zu bringen, korrespondierte ebenso fraglos mit den Ordnungsvorstellungen wesentlicher Teile der deutschen Industrie. Schon Kampfrufe des Obersten gegen »wilde Spekulation«, »unerhörte Kriegsgewinne« oder »Luxus und Wohlleben«, vor allem aber die Forderung nach »schonungsloser Ausnutzung der Industrie « für reine Kriegführungszwecke markierten aber auch die gedankliche Grenzlinie der hier angestrebten Zusammenarbeit von OHL und Schwerindustrie. Diese Denkansätze im Kriege und ihre nationalbolschewistische Variante nach der Niederlage ${ }^{152}$ finden bei Oberst Bauer ihr vorrangiges Ziel eben nicht in einer Befreiung des Kapitalismus von den konstitutionellen und sozialpolitischen Fesseln des modernen Industriestaates, sondern in einer letzten Verfügbarmachung der wirtschaftlichen Ressourcen für die totale Kriegführung durch effizienzsteigernde Konzentration und volksgemeinschaftliche Harmonisierung.

Beim Vergleich mit den Gedankenspielen eines Tirpitz fällt die geringere Reichweite der Bauerschen Überlegungen auf. Einen wesentlichen Grund dafür liefern zweifellos die unterschiedlichen Ausgangserfahrungen der beiden Offiziere. Der ehemalige Marinestaatssekretär sah von seiner umfassenderen politischen Warte aus die Kriegführungsprobleme hauptsächlich als Ausfluß der innen- und außenpolitischen Schwächen des »Systems Bethmann «; eine effizientere Kriegführung setzte für ihn daher die radikale "Umkehrung unserer gesamten Politik« voraus ${ }^{153}$. Vor seinem engeren militärisch-kriegswirtschaftlichen Hintergrund ging Bauer dagegen den umgekehrten Weg: eine inhaltlich als total verstandene Kriegführung forderte um ihres Erfolges willen die Entgrenzung des militärischen in den politischen Raum hinein. Die Zukunft von Krone und Reich beruhte auf ihren militärischen Möglichkeiten im Kriege, deren volle Entwicklung diktatorische Übergangsmaßnahmen erzwangen: "Erst wenn ruhigere Zeiten wiedergekehrt sind, kann man wieder zu einer Regierung wie im Frieden zurückkehren.«154 Voneinander abweichende Wege fanden sich aber im gemeinsamen Zielpunkt, weshalb Bauer seit Frühjahr 1916 in engem Kontakt zum Großadmiral und zum Deutschen Kronprinzen stand und bei einem notwendig werdenden Kanzlerwechsel ebenfalls bereits an Tirpitz als Nachfolger dachte ${ }^{155}$.

Seine vorerst begrenzteren Zielsetzungen wird man indes auch sehr stark vor dem zeitlichen Hintergrund des gerade erst erfolgten militärischen Führungswechsels zu sehen haben. Das neue Führungsgespann war nämlich weder von seiner ursprünglichen Politikferne noch von seinen intakten Beziehungen zu Bethmann her so kurz nach dem ge- 
meinsamen Erfolg gegen Falkenhayn schon für Radikalkuren à la Tirpitz zu haben. Faßte man sie dagegen bei ihrem militärischen Sachverstand mit einem Programm zur effizienteren Kriegführung an, dann würde die Radikalität der vorgeschlagenen kriegswirtschaftlichen Heilmittel bei ihnen ganz von selbst den Erkenntnisprozeß über die Unbrauchbarkeit der zivilen Reichsleitung reifen lassen. Wenn Bauer daher in seinem Denkschriftentwurf die neue OHL an Wilhelm II. appellieren ließ, ihnen an einer zeitweilig suspendierten Reichsverfassung vorbei Sondervollmachten per kaiserlichem Dekret zu übertragen, so konnte die klärende Wirkung für die Zukunft nicht ausbleiben. Sprang der Kaiser doch noch über seinen Schatten, dann brachten die beantragten Maßnahmen mit ihrer Neuverteilung der Gewichte zugunsten der Kriegführung die Politik ganz von selbst in die Rolle einer reinen Zuarbeiterin für die Heeresleitung; verweigerte sich der Monarch dagegen, was nach allen bisherigen Erfahrungen wahrscheinlicher war, so wurde wenigstens die Desillusionierung der neuen militärischen Führung vorangetrieben. Jedenfalls beobachtete Bethmanns zuverlässigster Parteigänger im Großen Hauptquartier, v. Valentini, die Aktivitäten der jüngeren Offiziere um Bauer, »die den Kampf gegen die Zivilregierung in der Ära Falkenhayn als Hauptaufgabe eingesogen hatten « ${ }^{156}$, von Anfang an mit unverhohlenem Mißtrauen. Mit ähnlicher Aufmerksamkeit, wenn auch naturgemäß mit völlig entgegengesetzten Hoffnungen, verfolgte gleichzeitig von außen her Tirpitz den sich anbahnenden Klärungsprozeß, der früher oder später »die Firma $H$. und L. die Notwendigkeit dieses Wechsels [weg von Bethmann; d. Vf.] voll übersehen « lassen mußte ${ }^{157}$. Die Befürchtungen des einen wie die Hoffnungen des anderen sollten sich schneller als erwartet erfüllen. Kaum zwei Monate nach Amtsantritt der III. OHL sollte Ende Oktober 1916 der ebenfalls neuberufene preußische Kriegsminister Stein bereits aus Ludendorffs eigenem Munde das Verdikt gegen den Kanzler vernehmen: »Er muß fort! « 158

Wenn Bethmann in der militärischen Allfrontenkrise des Sommers 1916 nämlich gehofft haben mag, das populäre Feldherrnpaar von der Ostfront für eine Stabilisierung der militärischen Lage und von da aus für eine schrittweise Aufklärung der Öffentlichkeit über die Notwendigkeit eines Verständigungsfriedens gewinnen zu können, so sollte die tatsächlich eintretende Besserung der Situation geradezu kontraproduktiv wirken. Mit den ersten militärischen Erfolgen verstärkte sich besonders bei Ludendorff die schon vorher gehegte Vermutung, daß nicht objektive Schwächen der Mittelmächte, sondern subjektive Führungsfehler zu den Einbrüchen des Sommers 1916 geführt hatten. Das mit der Stabilisierung der Landfronten erreichte militärische Patt wurde damit nicht zur Grundlage einer Friedenssuche aus gefestigter Position, sondern zur Atempause für die bisher vernachlässigte volle Mobilisierung der eigenen Ressourcen und die Suche nach dem alles entscheidenden strategischen Ausbruchmittel aus der erzwungenen Ruhestellung der Fronten. Da sich Ludendorff mit seinen Ostkriegserfahrungen geistig nie freigemacht hatte von den Illusionen eines schnellen Sieges durch Überraschung und konzentrierten Kräfteansatz an feldzugsentscheidender Stelle, kreiste sein Denken denn auch ab Herbst 1916 um die beiden Erfolgshoffnungen: personelle wie materielle Reorganisation der eigenen angeschlagenen Kräfte und nach ihrer Wiederherstellung geballter und überraschender Ansatz am richtigen Punkt. Die Schnelligkeit, mit der das Erstere gelang, mußte ausschlaggebend für den Erfolg des Letzteren werden.

Stimmte diese militärische Rechnung, dann mußten Hemmnisse und Verzögerungen, woher auch immer sie kamen, mit aller verfügbaren Energie überwunden werden, sollte das untrügliche Siegesmittel nicht erneut wie 1914 an seiner unentschlossenen Durchführung scheitern. Bis zum August 1916 hatten aus der Optik von OberOst noch militärische Führungsdefizite in den beiden ersten Heeresleitungen dagegen gestanden; da diese mit dem Amtsantritt der III. OHL ausgeräumt waren, konnten Behinde- 
rungen jetzt nur noch aus einer Richtung auftreten: aus dem politischen Raum. Ludendorff mochte daher seine Bereitschaft zu politischer Abstinenz subjektiv zu Beginn seiner neuen Tätigkeit durchaus ernst gemeint haben; die Absolutheit, mit der er seine militärischen Ziele setzte, und die Rigorosität, mit der er die dazu nötigen Mittel verfügbar machen wollte, mußten ihn dagegen mit innerer Notwendigkeit an die Grenzen der Politik heran- und bei deren Widerstand über sie hinausführen.

Dabei stand Bethmann eigentlich auf keinem der Konfliktfelder des Herbst 1916 Hindenburg-Programm, Polen-Proklamation und U-Boot-Krieg - in erklärtem Gegensatz zur neuen OHL. Da sich die militärische Führung aber in jedem dieser Fälle zur Fürsprecherin von innen- wie außenpolitisch umstrittenen Lösungen machte, mußte der um Ausgleich der Interessen zwischen den innenpolitischen Lagern und den Bündnispartnern bemühte Reichskanzler zwangsläufig in die Rolle des Verzögernden geraten. Bei Ludendorffs Naturell und dem Zeitdruck, der auf seinen Plänen lastete, war das Ende einer auf gegenseitiger Fehleinschätzung über die Benutzbarkeit des anderen aufgebauten Zusammenarbeit damit vorprogrammiert. Anfängliche Reibungen verhärteten sich schnell zur Unversöhnlichkeit, da Ludendorff - dem selbst ursprünglich Wohlmeinende unter politischer denkenden Offizieren bescheinigen mußten, wie "unerhört kurzsichtig und verständnislos in der Politik« er war ${ }^{159}$ - in den sachlich bedingten Verzögerungen nur Unfähigkeit und schließlich bösen Willen des Kanzlers zu erkennen vermochte. Dabei half es Bethmann auch nicht mehr, daß er in letzter Konsequenz seine politischen Bedenken in den kontroversen Fragen um die Jahreswende 1916/17 doch immer hinter die Wünsche der OHL zurücktreten ließ. Exemplarisch wurde dies im Falle der Wiederaufnahme des uneingeschränkten UBoot-Krieges, als der Kanzler sich zunächst durch sein Zögern den Unwillen des Generals zuzog, um schließlich mit seinem Nachgeben Anfang Januar 1917 auch noch den letzten Rest an Respekt bei seinem Widerpart einzubüßen ${ }^{160}$. Bethmann Hollweg mochte sich in den letzten Monaten seiner Amtszeit vormachen, daß es durch sein Bleiben Schlimmeres zu verhindern galt; seine Gegner suchten dagegen seit Ende 1916 längst nur noch nach dem Anlaß zu seinem Sturz und - was sich wesentlich schwieriger gestalten sollte - nach einem Nachfolger für das Kanzleramt.

Die Diskussion innerhalb der OHL und die von außen an sie herangetragenen Aufforderungen zum Handeln aus Armeekreisen erwiesen dabei schon im Dezember 1916, daß es zum Bruch der militärischen mit der politischen Reichsleitung Anfang 1917 auch keiner »allmählichen " Überzeugungsarbeit mehr durch interessierte Kreise aus Rechtsparteien und Schwerindustrie bedurfte ${ }^{161}$. Schon Anfang November 1916 hatte vielmehr Ludendorffs Vertrauter aus OberOst-Zeiten, Max Hoffmạnn, den Ersten Generalquartiermeister in Pleß davon zu überzeugen versucht, daß er zur Überwindung der aufgetretenen Hindernisse das Kanzleramt selbst übernehmen müsse ${ }^{162}$. Anfang Dezember stieß Bauer im Gespräch mit dem Abteilungschef in der OHL, Mertz v. Quirnheim, in dasselbe Horn, wenn er ganz offen die Militärdiktatur für Ludendorff ins Spiel brachte. Für ihn hatten die schon jetzt erkennbaren Schwierigkeiten bei der Durchführung des Hilfsdienstgesetzes den Beweis geliefert, "daß wir nur mit Hilfe einer absoluten Militärdiktatur, die allein eine restlose Zusammenfassung aller nationalen Kräfte ermögliche, zu einem erfolgreichen Ende kommen könnten«. Wie weit sich der Oberstleutnant dazu den früheren Plänen von Tirpitz geöffnet hatte, ließ der zur Diktaturlösung vorgeschlagene Weg erkennen. Wie bei den Vorstellungen des Admirals sollten nicht nur die Hemmnisse aus dem parlamentarischen Bereich, sondern auch der entschlußschwache Kaiser "praktisch völlig ausgeschaltet werden«. Erneut sollte dabei der König von Bayern als ranghöchster Bundesfürst den konstitutionellen Anstoß geben oder die Lösung zumindest durch sein Stillhalten nicht behindern ${ }^{163}$. 
Die Bauersche Radikalkur mochte die Mehrheit im Offizierkorps in seiner traditionellen Loyalitätsauffassung jetzt ebenso überfordern, wie dies die Tirpitzpläne im Vorjahr getan hatten. Nicht mehr zu verkennen war dagegen, wie verbreitet die Kaiserkritik inzwischen in Armeekreisen geworden war. Selbst bei den älteren Kommandeuren mit tiefverwurzelter Königstreue stellte sich in der Kriegsmitte zunehmend Fassungslosigkeit über die dem Ernst der Lage so wenig angemessenen Auftritte ihres Monarchen an der Front ein ${ }^{164}$; für ihre jüngeren Stabschefs und Frontoffiziere entpuppte sich die "offenkundige Unfähigkeit« ihres Obersten Kriegsherrn sogar schon ganz ungeschminkt ${ }^{165}$; für Ludendorff und seine Mitarbeiter in der OHL bildeten kaiserliche Einlassungen zur Kriegführung binnen kurzem »überhaupt keinen Gegenstand von Kopfzerbrechen« mehr ${ }^{166}$. Bei aller internen Kaiserkritik führte jedoch auch jetzt noch kein Weg am Monarchen vorbei, wenn es um eine autoritäre Straffung an der Reichsspitze ging. Die Befürworter derartiger Pläne standen daher auch weiterhin vor der doppelten Problemstellung: man mußte einen »starken« Mann finden, der gleichzeitig für Wilhelm II. akzeptabel war.

Den einfachsten Weg dazu schlug Ende 1916 der persönlich mit Hindenburg befreundete Militärschriftsteller und Korpsführer an der Ostfront, General v. Bernhardi, vor. In einem Appell an das vaterländische Pflichtgefühl des Feldmarschalls forderte er diesen zum offenen Handeln auf, da seine Popularität ihn faktisch unentbehrlich und damit unabsetzbar mache. Wenn er, dem "nicht nur militärisch, sondern auch politisch [...] das Schicksal Deutschlands in die Hand gegeben « sei, den Kaiser unausweichlich vor die Wahl Kanzler oder Generalstabschef stelle, müsse der Monarch endlich handeln. Hindenburg stimmte wohl mit seinem Briefpartner in der Unmöglichkeit einer weiteren Zusammenarbeit mit Bethmann überein, sagte ihm auch zu, daß er sich »von ihm trennen« werde, nur verwies er sofort auf das Kernproblem: einen "zuverlässigen Ersatzmann « zu finden ${ }^{167}$ !

Immerhin schien Anfang Januar 1917 der Sturz des Kanzlers unausweichlich, da sich Heeres- und Marineleitung auf unbedingten Konfliktkurs zur Durchsetzung des uneingeschränkten U-Boot-Krieges verständigt hatten. Sollte Bethmann weiteren Widerstand leisten, dann mußte die Kabinettsfrage gestellt werden. Als einfachste Lösung schwebte dabei Admiral v. Holtzendorff die Übernahme des Kanzleramts durch Hindenburg selbst vor, dem die Öffentlichkeit daś größte Vertrauen entgegenbringe ${ }^{168}$. Der Feldmarschall lehnte für seine Person zwar ab, forderte aber zwei Tage später trotz Bethmanns Nachgeben in der U-Boot-Frage beim Kaiser die Entlassung des Kanzlers aus "Mangel an Entschlußfähigkeit " ${ }^{169}$. Die Frage war freilich, wer an seine Stelle treten solle, da Hindenburg selbst nicht wollte und Ludendorff sich mit Blick auf die vorrangigeren militärischen Führungsprobleme ebenfalls unabkömmlich gestellt hatte. Einmal mehr schien damit die Stunde für Tirpitz zu schlagen, von dem Ludendorff ja bereits im September 1916 gesagt hatte, daß er ihn sich durchaus als Kanzler vorstellen könne.

Die Parteigänger des Admirals streckten denn auch schon Mitte Januar 1917 über den Stab von OberOst und über persönliche Bekannte im Großen Hauptquartier entsprechende Fühler aus ${ }^{170}$. Ihr Hauptargument galt dem außenpolitischen Terrain. Da man sich endlich zu entscheidungssuchender Kriegführung gegen England durchgerungen habe, solle man jetzt doch nicht auf halbem Wege stehenbleiben, sondern die Geschäfte dem in die Hände legen, der seit Kriegsbeginn Bethmanns »unseligen« Verständigungshoffnungen entgegengearbeitet habe. Der Vorstoß zeitigte Erfolg, denn schon Ende Januar trat Hindenburg bei dem Chef des Militärkabinetts für eine Kanzlerschaft von Tirpitz ein. Diesmal reagierte der Kaiser sofort. Schon beim nächsten Lagevortrag am 1. Februar stellte er die beiden Führer der OHL, machte ihnen wegen ihres Übergriffs auf die politische Ebene »eine heftige Szene und qualifizierte Tirpitz »in den 
wegwerfendsten Ausdrücken « als Kanzlerkandidaten $a b^{171}$. Nach dieser Abfuhr hielten sich die beiden Generale zwar selbst in den nächsten Wochen zurũck, ließen es aber weiterhin zu, daß in ihrer Umgebung in einer Weise gegen den Kanzler polemisiert wurde, "die jedes Maß politischen und persönlichen Anstandes außer Acht ließ « ${ }^{172}$. Das gab wiederum der Kanzlerfronde außerhalb des Hauptquartiers genügend Rükkenwind, um ihre Kampagne in der Öffentlichkeit zu verschärfen.

Den Auftakt bildete ein Besuch des Industriellen Carl Duisberg in Pleß am 24. Januar $1917^{173}$, bei dem dieser die volle Schärfe der Anti-Bethmann-Stimmung erkannt haben dürfte. In einer Rede im Münchner Deutschen Museum trat Duisberg nämlich schon am 6. Februar mit der Forderung an die Öffentlichkeit, den Kanzler durch Hindenburg zu ersetzen, »dem dann als Vertreter der Großadmiral von Tirpitz beizugeben sei « ${ }^{174}$. Was hinter dieser eigentümlich anmutenden Formel steckte, wird bei einem Rückblick auf die bereits angeführten Kontakte der Tirpitz-Vertrauten Gildemeister und Kapp ins Große Hauptquartier bzw. zu OberOst Mitte Januar 1917 deutlicher. Hindenburg war ganz offensichtlich nicht für eine politische Rolle zu gewinnen gewesen, der eigentliche Motor der OHL und geheime Wunschkandidat der jüngeren Offiziere, Ludendorff, hatte sich militärisch unabkömmlich erklärt und Tirpitz war nach seinem Zerwürfnis mit dem Kaiser bei diesem persona non grata. Dazu kam die Einsicht selbst bei den wärmsten Befürwortern einer Zusammenlegung von Staats- und Armeespitze, daß sie sich über den politischen Sachverstand Hindenburgs und Ludendorffs wenig Illusionen machen konnten ${ }^{175}$. Außerdem scheint man sich über die Prioritäten in der Kriegszielfrage nicht völlig einig gewesen zu sein. Tirpitz und seine Anhänger in Marine- und Industriekreisen sahen den Hauptgegner in Englands See- und Handelsmacht, die es mit der U-Boot-Waffe zu brechen und mit dem Besitz der Kanalküste dauerhaft auf Distanz zu halten galt. Um darauf alle Kräfte konzentrieren zu können, war der Admiral daher seit Kriegsbeginn immer wieder für einen Kompromiß mit Rußland eingetreten ${ }^{176}$. Dagegen hatten sich Hindenburg und Ludendorff schon in OberOst-Zeiten stärker den kontinentalen Expansionsplänen ostdeutscher politischer Kreise geöffnet ${ }^{177}$, weshalb Gildemeister jetzt aus seinen Kontakten ins Große Hauptquartier entnehmen mußte, »dass Lu[dendorff; d. Vf.] nur gegen Rußland orientiert und wenig für das Festhalten Belgiens zu haben sei. Insofern könnte ihm Tirpitz vielleicht nicht passen. « ${ }^{178}$ Aus dieser konfliktträchtigen personellen und politischen Konstellation suchte man daher anscheinend erst einmal durch ein Konstrukt herauszukommen, in dem Hindenburg nominell Reichs- und Heeresleitung auf sich vereinigen und Tirpitz unter ihm faktisch die Geschäfte führen sollte. Dem Kaiser wurde damit die direkte Berufung des ungeliebten Admirals erspart und dieser würde, wie Hoffmann unverhohlen seinem Tagebuch anvertraute, "uns als Platzhalter fungieren«, bis Ludendorff selbst bei Friedensschluß für die Armee hervortreten könne ${ }^{179}$.

Schon am 25. Februar brachte Duisberg jedenfalls im Berliner Hotel Adlon eine Konferenz von Wirtschaftsführern und Vertretern der Rechtsparteien zusammen, um eine Eingabe an den Reichstag und den Kaiser zu formulieren, die in der Forderung nach Hindenburgs Berufung zum Reichskanzler gipfelte: "Wollen wir siegen und bald siegen, so haben unsere ganze Politik und Diplomatie aufzugehen in die Kriegführung; was übrig bleibt an Erledigung politischer und diplomatischer Formalien, können die Staats- und Unterstaatssekretäre und Ministerialdirektoren der Wilhelmstraße besorgen. ${ }^{180}$ Daß sich Duisberg als Initiator der Veranstaltung zu Recht auf sein Einverständnis mit der OHL berief, zeigt eine Denkschrift Bauers vom 6. März, die mit der kategorischen Feststellung begann: "Unsere Reichsregierung hat während des Krieges versagt. « ${ }^{181}$ Bezeichnend für die Argumentationsweise von Ludendorffs Berater ist dabei erneut die Voranstellung des kriegswirtschaftlichen vor dem innen- und außenpolitischen Versagen des Kanzlers. Mit der Begründung, Bethmann habe durch seine man- 
gelhafte Unterstützung die volle Durchsetzung des Hilfsdienstgesetzes verhindert und damit die erfolgreiche Fortsetzung des Krieges gefährdet, verstärkte Bauer daher das Verlangen der Adlon-Konferenz, "einen ganzen Mann an die Spitze zu setzen«. Wie allgemein in diesem Frühjahr gerade bei Fachleuten im Bereich der Kriegswirtschaft die Skepsis über die zivile Reichsleitung war, mag ein zeitgleiches Beispiel belegen. Selbst der spätere Berater der Revolutionsregierung für Wirtschaftsfragen, Wichard v. Moellendorff, sah im April 1917 keinen anderen Ausweg aus der verfahrenen kriegswirtschaftlichen Situation mehr, »als den Feldmarschall Hindenburg zur Übernahme einer diktatorischen Gewalt und Verantwortung zu bewegen “ ${ }^{182}$.

In einer konzertierten Aktion bearbeiteten daher die Kanzlergegner aus dem Adlon in Briefen Kaiser und OHL von außen ${ }^{183}$ und Oberst Bauer mit seiner bereits erwähnten Denkschrift von innen das Große Hauptquartier zum Zwecke des Kanzlersturzes. Nur war Bethmann selbst inzwischen nicht untätig geblieben. Über seinen Vertrauten Riezler hatte er sofort nach seiner Benachrichtigung über die Adlon-Konferenz den liberalen Abgeordneten Haußmann mit entsprechenden Informationen versorgen lassen, die dieser schon am 27. Februar im Reichstag dazu benutzte, die ganze Angelegenheit öffentlichem Spott preiszugeben ${ }^{184}$. Außerdem klärte Bethmann den Kaiser über das Gegenwirken der Kanzlerfronde innerhalb der OHL auf, nachdem er über Valentini Kenntnis von der Bauer-Denkschrift erhalten hatte ${ }^{185}$. Als Hindenburg deshalb am 14. März im Sinne der Adlon-Eingaben und der Bauer-Denkschrift beim Kaiser vorstellig wurde, holte er sich wie schon Ende Januar eine erneute Abfuhr ${ }^{186}$. Noch einen Monat später war in Ludendorffs Korrespondenz das Nachbeben unterdrückter Wut über diesen Fehlschlag zu spüren: "Man predigt tauben Ohren und ist als wilder General in Berlin verschrien, nur weil man ein Handeln sehen möchte.« ${ }^{187}$

$\mathrm{Daß}$ der General seiner »Galle die Zügel schießen« ließ, hatte freilich inzwischen einen weiteren schwerwiegenden Grund erhalten: die durch Bethmann veranlaßte Osterbotschaft des Kaisers zur Wahlrechtsfrage. Dabei gab Ludendorff selbst zu, daß man »ein unhaltbares Wahlrecht rechtzeitig « hätte ändern müssen; daß man indes jetzt in innenwie außenpolitisch gefährlicher Zeit eine derartige Ankündigung vornahm, mutete ihm schlicht wie ein "Kotau vor der russischen Revolution« an. Damit kam ein Argument ins Spiel, das alle weiteren Diktaturpläne bis Kriegsende begleiten und mit der bolschewistischen Oktoberrevolution noch an Gewicht gewinnen sollte: die Revolutionsfurcht. Sie würde immer dann besonders brisant werden, wenn eine sich verschlechternde Frontlage die Frage aufwerfen mußte, wie das Kaiserreich analog zum Zarenreich eine Niederlage überstehen sollte, die nationale Enttäuschung und soziale Unzufriedenheit bündeln würde. Für Ludendorff rief die von Bethmann begonnene Auslieferung des Systems an die parlamentarischen Kräfte dabei eben die Gefahr erst wirklich hervor, die sie abzuwenden vorgab, denn: »Mit dem Gefühl der Angst regiert man keinen Staat.« Erste Streikbewegungen bestätigten ihn noch im selben Monat darin, daß damit die "unverschämte Antwort der Arbeiterschaft auf eine von Angst diktierte Politik “ gegeben worden se ${ }^{188}$. In diesem Zusammenhang tauchte ein weiterer Kritikpunkt auf, der ein bezeichnendes Licht auf das veränderte Selbstwertgefühl in Armeekreisen gegenüber der zivilen Reichsleitung wirft. Wie konnte sich der Kanzler in der Wahlrechtsfrage auf den Volkswillen berufen, »ohne das Volk in Waffen mitsprechen $\mathrm{zu}$ lassen ${ }^{189}$, dessen durch seine Blutopfer legitimiertester Sprecher aus der Sicht von OHL und Armeeführern das Offizierkorps war? Ludendorff setzte dem Kanzler dieses Überspielen der OHL jedenfalls zusätzlich auf das Schuldkonto ${ }^{190}$.

Die Kritik an der Wahlrechtspolitik des Kanzlers, die ihm als Öffnung zur Linken hin ausgelegt wurde, hinderte seine Gegner freilich nicht, selbst die Fühler bis zu den Sozialdemokraten auszustrecken. Einem Bericht Wolfgang Heines zufolge scheuten "gewisse Kreise« offenbar nicht davor zurück, den Köder der Parlamentarisierung auszu- 
werfen, falls die SPD sich für eine Kanzlerschaft Ludendorffs bereitfinden würde. Als Grund für den notwendigen Wechsel habe man ihm gegenüber die Unmöglichkeit angegeben, mit Bethmann zu einem Frieden zu kommen. Dem halte er entgegen, „daß ein General noch weniger dazu geeignet ist “ ${ }^{191}$. Hintergrund und Stellenwert des Vorstoßes lassen sich bisher nicht näher bestimmen. Da die OHL indes zu dieser Zeit auch bereits über gute Kontakte zu anderen Parlamentsfraktionen verfügte - so konnten sich Erzberger für das Zentrum und Stresemann für die Nationalliberalen ihrer persönlichen Beziehungen zu Ludendorff rühmen - ${ }^{192}$, wird man in solchen Versuchsballons immerhin eine Art Vorrunde für das so erfolgreiche Zusammenspiel von OHL und Reichstag in der Juli-Krise von 1917 sehen dürfen.

Fest stand jedenfalls in diesem Frühsommer 1917, daß die Dauerkrise zwischen Kanzler und OHL so oder so zum Austrag kommen mußte. Eine Lösung war um so dringlicher, als sich unter dem Mantel einer stark personal eingefärbten Führungskrise das weitaus tiefgreifendere Problem einer Aufweichung der inneren Front verbarg. Das mit so vielen Voraushoffnungen befrachtete Siegesmittel der U-Boot-Waffe hatte schon jetzt erkennbar die überzogenen militärischen Hoffnungen nicht erfüllt; im Gegenteil, es hatte mit dem Kriegseintritt der USA den Ring der Gegner nur noch um ein entscheidendes Glied verstärkt. Das war umso mißlicher, da ein relativ stabiles Patt an den Landfronten zunächst ebenfalls keinen die Stimmung befeuernden Ausbruch aus der militärischen Stagnation zuließ. Psychologische Enttäuschung über ein weiterhin nicht absehbares Kriegsende verband sich deshalb mit den materiellen Erschöpfungssymptomen des zurückliegenden Hungerwinters zu einer um sich greifenden Kriegsmüdigkeit. Deutlichstes Barometer für dieses Stimmungstief war die hörbare Rückmeldung des Reichstages im politischen Kräftespiel, nachdem er sich im Zeichen des Burgfriedens in den ersten beiden Kriegsjahren doch weitgehend zurückgehalten hatte. In ihm formierte sich eine interfraktionelle Mehrheit, deren Stärke aus ihrer Sprachrohrfunktion für die wachsende Unzufriedenheit im Lande herrührte. Und obwohl das Zusammenrücken von bürgerlicher Mitte und gemäßigter Linken vorerst noch mehr Friedenssehnsucht als Systemveränderungswillen repräsentierte, löste es auf der Rechten in und außerhalb des Parlaments entsprechend spiegelverkehrte Alarmreaktionen aus. Wesentlich verschärft durch die Kriegsumstände stand das Kaiserreich damit jetzt vor einer ähnlichen Situation wie 1912/13, als ebenfalls außenpolitische Rückschläge und innenpolitische Kräfteverschiebungen das System zu den Flügeln hin auseinanderzureißen drohten.

Wenn Bethmann Hollweg die sich aufschaukelnde Polarisierung mit seiner "Politik der Diagonale» noch einmal durch dosiertes Entgegenkommen an die Parlamentsmehrheit - und nichts anderes besagte doch die Osterbotschaft - aufzufangen suchte, dann laborierte ein derartiger Kurs allein schon an dem Machtverfall, dem seine Position in den letzten Monaten ausgesetzt war und den eine Abstützung auf den mehr und mehr zum "Schattenmonarchen ${ }^{193}$ absinkenden Kaiser nicht mehr auszubalancieren vermochte. Zu wenig, um eine Mitte-Links-Mehrheit hinter dem Kanzleramt zu versammeln, war der Schritt seinen um die OHL gruppierten Gegnern doch bei weitem zu groß, als daß sie ihn noch als konsensfähig hätten hinnehmen wollen. Was den Kompromiß des Burgfriedens in verschärfter Lage retten sollte, erwies sich mithin gerade als der Sprengsatz, der das wilhelminische System wieder in seine unversöhnlichen Lager teilte. Daß der Kanzler dann Anfang Juli 1917 mit der Friedensresolution des Reichstages das nach außen sichtbare Eingeständnis für die Stimmungslage im Innern hingehen lassen mußte, machte seine Stellung vollends unhaltbar.

Damit war für etwa ein Jahr, also so lange, wie die III. OHL in der Öffentlichkeit die Garantenrolle für einen positiven Kriegsausgang aufrechtzuerhalten vermochte, eine Machtverteilung vorgegeben, die bei weitgehendem Zurücktreten von Kaiser und 
Kanzlern und einem mehrheitlich noch stillhaltenden Reichstag durch das eindeutige Übergewicht der Heeresleitung geprägt war. Wenn jemals mit Aussicht auf Erfolg, dann wäre dies die Stunde für einen möglichen Übergang zur offenen Militärdiktatur gewesen, wie ihn die von Tirpitz zunächst in der U-Boot-Bewegung, ab Spätsommer 1917 in der Deutschen Vaterlandspartei zusammengeführten Kräfte von der OHL erwarteten. Dazu hätten sich freilich Hindenburg oder Ludendorff offen auf den Schild heben lassen oder zumindest Tirpitz beim Kaiser durchsetzen müssen. Die gemäßigteren Befürworter einer solchen Entwicklung sahen darin die logische Konsequenz aus den tatsächlichen Machtverhältnissen, die es um einer einheitlichen Führung willen auch nach außen personell darzustellen galt, wollte man den unhaltbaren Gegensatz von Kriegführung und Politik zum stärkeren Pol hin auflösen ${ }^{194}$. Hinter einer derart plebiszitär abgestützten, zeitweiligen Militärherrschaft konnten sich monarchische Spitze und konstitutionelles System für die Dauer des Krieges erholen, um die Führung im ruhigeren Fahrwasser nach einem erfolgreichen Kriegsausgang wieder zu übernehmen.

Beim radikaleren Kern in Armeekreisen, bei Alldeutschen und Konservativen sowie in Teilen der Schwerindustrie erwartete man dagegen ein wesentlich offensiveres Programm. Für sie hatte gerade die beunruhigende Erholung der parlamentarischen Kräfte in der Kriegsmitte zur Folge, daß man schon jetzt in noch relativ starker Position die Weichen für die Nachkriegszeit stellen mußte. Mochte das nicht überall so drastisch ausgedrückt werden wie von Admiral v. Hipper, der die Zeit gekommen sah, »den Reichstag heim[zu]schicken «, um den "Riß» im Innern zu kitten ${ }^{195}$; in der Substanz war das Mindestziel einer militärisch gestärkten Exekutive doch allgemein eine Bändigung des Parlaments, deren Erfolg dann auch für die Zeit nach dem Kriege nicht ohne Wirkung bleiben konnte. Es kam, wie General v. Bernhardi als einer der genannten Kanzlerkandidaten dieser Tage vermerkte, nicht mehr darauf an, "sich mit dem Reichstag zu vertragen, [...] sondern darauf, trotz des Reichstages eine zielbewußte und energische Politik durchzusetzen ${ }^{196}$. Den Weg dahin beschrieb ein weiterer Kandidat, der von den Konservativen im Preußischen Herrenhaus und zeitweilig auch von Ludendorff favorisierte Armeeführer v. Gallwitz ${ }^{197}$, in einer Art Aktionsprogramm für den Fall seiner Kanzlerschaft. Bei Amtsantritt wollte er dem Reichstag ein letztes Angebot zur Güte machen, das in der ultimativen Aufforderung zur Beilegung des Parteienstreits in schwerer Stunde gipfeln sollte. Würde dies nichts fruchten, gedachte er das Parlament aufzulösen und die Geschäfte mittels einer reinen Kabinettsregierung fortzuführen. Dies sollte »ohne Brüskierung der Mittelparteien, aber mit schärfstem Beobachten und Anfassen des sozialistischen Führertums« geschehen, wobei er »Revolutionsversuche sofort militärisch niederschlagen« wollte ${ }^{198}$. Noch einen Schritt weiter ging schließlich Oberst Bauer, wenn er eine Bändigung des Reichstages über das Kriegsende hinaus anvisierte. Gefragt, ob er denn dem deutschen Volk nach den Massenopfern des Weltkrieges allen Ernstes das Wahlrecht vorenthalten wolle, antwortete er mit nicht zu überbietender Deutlichkeit: "Wir behalten ja die Maschinengewehre! ${ }^{199}$

Eine weitere interessante Version für die Notwendigkeit zur politischen Machtübernahme durch Ludendorff persönlich warf schließlich dessen Mitarbeiter Mertz v. Quirnheim in die Debatte. Gegen Bauers riskante Spielereien, mitten im Kriege mit einem Teil der Nation Front zu machen gegen den anderen, sah er gerade im bürgerlichen General als Diktator die Chance zu einer Art »Volkstribun [. . .] gestützt auf links d. h. auf die breite Volksmasse « ${ }^{200}$. Diese Variante einer Verbindung von populärer Armeeführung und Massen vorbei an den herkömmlichen Eliten und Funktionären sollte sich in den noch zu würdigenden Plänen Walther Rathenaus für eine »levée 
en masse« unmittelbar vor und in den frontsozialistischen Überlegungen für eine »Noske-Diktatur« nach der Niederlage wiederfinden.

Alles hing mithin in der Juli-Krise 1917 davon ab, ob die OHL - und das hieß zu diesem Zeitpunkt ohne Frage: Ludendorff - zum offenen Hervortreten bereit war. Doch der Erste Generalquartiermeister blieb jetzt und bis zum Kriegsende seiner Auffassung treu, daß er für die Kriegführung unentbehrlich und deshalb mit einer Ämterunion von politischer und militärischer Führung überlastet sei ${ }^{201}$. Bei näherem Hinsehen läßt sich diese scheinbar so eindeutige Haltung allerdings differenzierter ausleuchten. Der absolute Bedeutungsvorrang seiner militärischen vor einer eventuellen politischen Rolle läßt schon im Krieg seine später nur noch theoretisch untermauerte ${ }^{202}$ Grundannahme vom Verhältnis der Kriegführung zur Politik durchscheinen. Die Lebensrechte auf der internationalen Wildbahn erkämpfte und sicherte einem Volk seine militärische Kraft und ihr sachgerechter Einsatz durch den Feldherrn, dem der Staatsmann das militärisch und wirtschaftlich voll mobilisierte und innerlich geschlossene Wehrpotential der Nation ständig aufs Neue zuzuführen hatte. Wo die Haupt- und wo die Nebenrolle in einem so geformten Weltbild lagen, konnte da nicht in Zweifel stehen. Offenbar hatte sich Ludendorff im Kriege aber auch noch eine realistischere Selbsteinschätzung bewahrt, die ihn vor der Übernahme einer Verantwortung zurückschrecken ließ, der er sich als rein militärischer Fachmann nicht gewachsen fühlte ${ }^{203}$. Nach seinen Erfahrungen mit wechselnden Kriegskanzlern und mit den Verhältnissen nach Niederlage und Revolution sollte er später solche Selbstbeschränkungen freilich über Bord werfen und analog zu den Vorbildern eines Friedrich und Napoleon der Personalunion von Feldherrn und Staatsmann das Wort reden.

Im übrigen sprach 1917/18 noch ein anderer Gesichtspunkt gegen die offene Machtübernahme der OHL, den Ludendorff in seinen "Kriegserinnerungen« nur verklausuliert eingestand. Unter den erschwerten inneren Bedingungen hatte jeder Kanzler so vielen "Widerständen und Reibungen« zu begegnen, daß er selbst "als Vertreter des berüchtigten Militarismus« wohl mehr zur weiteren Polarisierung als zur notwendigen Geschlossenheit beigetragen hätte ${ }^{204}$. Mit andern Worten: das Risiko bei einem vollen Hineinspringen in die öffentliche Arena in einer Lage, da rasch wirkende Heilmittel für die Stimmungseinbrüche nicht zu Gebote standen, war doch zu unkalkulierbar. Nur zu schnell konnte sich die Militärführung dann nämlich demselben innenpolitischen Verschleißprozeß ausgesetzt sehen, den sie bisher mit so viel Erfolg auf das Konto eines von allen Seiten kritisierten Kanzlers geschrieben hatte ${ }^{205}$. Die hinter dem Experiment eines Generals als Kanzler stehende Gefahr hatte denn auch Rathenau schon im Frühjahr 1917 in das Bild gekleidet, „daß jeder Nachfolger, wenn er nicht ein Wahnsinniger ist, am Morgen nach seiner Berufung als Bethmann aus dem Bette aufsteht ${ }^{206}$.

Damit aber blieb nur der Weg über einen Ersatzkandidaten, einen Vertrauenskanzler der OHL, der für sie die bisherige Abdeckung der innenpolitischen Flanke übernahm und sich für seine härtere Gangart doch gleichzeitig auf sie abstützen konnte. Dieser Weg brachte freilich sofort das Dauerproblem der Kandidatensuche auf die Tagesordnung, die inzwischen noch komplizierter geworden war. Seit nämlich die Innenpolitik auch wieder eine deutlichere parlamentarische Handschrift trug, mußte jeder neue Kanzler nach drei Seiten hin vermittelbar sein: für den Kaiser, die OHL und den Reichstag. Der ewige Kandidat Tirpitz, der nach den zurückliegenden Abfuhren durch den Kaiser nach dem Willen der OHL diesmal vom Kronprinzen vorgeschlagen werden sollte, fand jetzt so wenig Gnade wie vorher. Die Ablehnung fiel eher noch deutlicher aus, da auch Botschafter Hohenlohe vor dem Großadmiral warnte, der »für 
Bezeichnend für die selbstgewählte Abhängigkeit der zivilen Rechten von ihrem militärischen Arm war es nun, daß man hier letztlich über keine im eigentlichen Sinne politische Alternative mehr verfügte. Nirgends kam dies klarer zum Vorschein als beim jetzt immer hektischer in Gang kommenden Kandidatenkarussell, so vor allem von seiten des Preußischen Herrenhauses. Genannt wurden ausschließlich Militärs, die während ihrer Laufbahn den Ruf eines politischen Generals erworben oder in dienstlicher Funktion mit dem Reichstag zu tun gehabt hatten, so Kriegsminister Stein, der Armeeführer Gallwitz, der Militärschriftsteller und derzeitige Korpskommandeur Bernhardi oder der ehemalige Kavallerie-Inspekteur Kleist-Wusseken aus dem Herrenhaus selbst ${ }^{208}$. Keiner von ihnen hatte indes ernsthafte Aussichten, da der Kaiser nach seinen Erfahrungen mit Caprivi offenbar keinen General mehr als Kanzler akzeptieren wollte ${ }^{209}$ und darin auch von seiten der Bundesstaaten, hier insbesondere vom bayerischen Ministerpräsidenten Graf Hertling bestärkt wurde ${ }^{210}$.

Damit stand die OHL, nachdem sie mit ihrer Rücktrittsdrohung und im Verbund mit führenden Parlamentariern den Kanzlersturz erzwungen hatte, vor der fatalen Situation, keinen ihr und dem Kaiser genehmen Nachfolger präsentieren zu können. Zwar hatte Unterstaatssekretär Zimmermann schon im Frühjahr 1917 über Bauer für den ehemaligen Kanzler v. Bülow vorgefühlt, der seither auch von Ludendorff neben Tirpitz favorisiert wurde, da ihm besonderes Geschick beim Umgang mit dem Reichstag nachgerühmt wurde. Nur war allein schon seine Nennung nach der Daily-TelegraphAffäre eine derartige Zumutung für Wilhelm II., daß der Fürst schnell wieder fallengelassen werden mußte ${ }^{211}$. Als sich nach kurzer Bedenkzeit mit dem bayerischen Ministerpräsidenten Hertling auch noch der letzte Kandidat von einigem politischem Gewicht versagte ${ }^{212}$, glitt die weitere Suche endgültig zur politischen Farce ab. Die „Kanzlerstürzer" in OHL und Parteien erklärten sich schlicht für unzuständig und forderten den Chef des Zivilkabinetts zur Präsentation eines neuen Kandidaten auf. Valentini und Lyncker brüteten daraufhin in verständlicher Verzweiflung über dem „Gotha und Staatshandbuch«, bis sie schließlich »in der Not des Augenblicks« dankbar zugriffen, als Plessen den preußischen Bevollmächtigten für die Getreidewirtschaft und Unterstaatssekretär im Finanzministerium Georg Michaelis anbot. Bedenken über seine "völlige Unorientiertheit in allen Dingen der auswärtigen Politik“ wurden beiseitegeschoben; der Mann hatte bei seinen wenigen Auftritten im Großen Hauptquartier den Eindruck hinterlassen, daß er »energisch sei« - und das zählte! Hindenburg und Ludendorff stimmten daher sofort zu, und die Verlegenheitskanzlerschaft Michaelis' konnte ihren Lauf nehmen ${ }^{213}$.

Mit der Ersetzung Bethmann Hollwegs durch Michaelis war eine Phase zum Abschluß gekommen, die sich trotz aller intrigenreichen Begleitumstände letztlich immer noch im Rahmen des bismarckschen Verfassungssystems abgespielt hatte. Von den tirpitzbauerschen Planspielen einmal abgesehen, hatte eine Kanzleropposition nach Mitteln und Wegen gesucht, einen innenpolitisch als zu konzessionsbereit und außenpolitisch als zu risiskoscheu angesehenen Regierungschef abzulösen. Neu war allerdings schon unter Falkenhayn und verstärkt mit dem Amtsantritt der III. OHL die wachsende Gewichtsverlagerung vom zivilen zum militärischen Ast der Exekutive. Noch hatte jedoch ein gewiß schwächer werdender Widerstand der Krone die völlige Überwältigung der einen durch die andere Seite verhindern geholfen. Da auch Hindenburg und Ludendorff trotz ihrer faktischen Machtfülle dem Drängen ihrer Anhänger nach einer offenen Militärdiktatur nicht folgten, blieben Aufgabenverteilung und Vorrangstellung im Dreieck Kaiser-Kanzler-Heeresleitung wohl selbst nach dem Sommer 1917 optisch noch intakt. Die Verfassungswirklichkeit sollte sich dagegen unter Michaelis und Hertling von der zivilen Reichsspitze weg zu den beiden Antipoden von OHL und Reichstagsmehrheit hin verlagern. In diesem Machtspiel fiel den Kanzlern praktisch 
die Rolle von Mediatoren zwischen den Polen, bei Kriegszielen und Friedensschlüssen sogar häufig nur die Aufgabe von Willensvollstreckern der OHL zu.

IV.

Daß der Reichstag - anders als beim Sturz Bethmanns - bei der Bestallung seines Nachfolgers nicht mehr ins Vertrauen gezogen wurde, rechnete man sich in der OHL dabei als ersten Erfolg einer Neubestimmung der Verhältnisse an. Für Bauer gab das gewählte Verfahren den Parlamentariern ein deutliches Signal, „daß der Kaiser regiere u. nicht sie ${ }^{214}$. Daß die "zunächst vielleicht wichtigste Aufgabe des neuen Kanzlers in den Augen der OHL innenpolitisch in der Zurückdrängung des Reichstages und hier insbesondere in der "Ausschaltung der Sozialdemokratischen Partei als ausschlaggebenden Faktors« bestand, bestätigte Ludendorffs Mitarbeiter v. Haeften dem Prinzen Max v. Baden im übrigen schon wenige Tage später ${ }^{215}$. Wie die $O H L$ generell die weitere Zusammenarbeit mit der zivilen Reichsleitung gehandhabt wissen wollte, ließ sie Michaelis außerdem bereits am 10. August 1917 in einer Denkschrift wissen ${ }^{216}$. Ausgehend von einer Mängelliste zu Lasten Bethmanns nahm sie nunmehr die Mitsprache bis in die unterstellten Bereiche hinein für alle relevanten Fragen der Kriegszielbestimmung, der Kriegswirtschaft und der Aufrechterhaltung der inneren Stimmung für sich in Anspruch. Das sollte später im Untersuchungsausschuß des Reichstags selbst den der OHL gewogenen Gutachter, Oberst a. D. Schwertfeger, mit Blick auf die Reichsregierung zu der Einschätzung veranlassen: „Fast konnte sie damals als eine Beauftragte der Obersten Heeresleitung erscheinen. “217 Damit war jene indirekte, aber faktische Machtausübung gefunden, in die auch der erneute Kanzlerwechsel vom Spätherbst 1917 keine Veränderung mehr bringen sollte. Die OHL würde in allen ihr wichtig erscheinenden politischen Fragen ihren Willen durchsetzen können, ohne sich allzusehr der Gefahr einer direkten Konfrontation mit den innenpolitischen Kräften auszusetzen.

Aber auch für die Einflußnahme auf diesem Feld hatten Tirpitz und Kapp schon Anfang September 1917 mit der Deutschen Vaterlandspartei eine organisatorische Massenbasis geschaffen, die sich ganz bewußt den Zusammenhalt der inneren Front hinter der OHL zum Ziel gesetzt hatte ${ }^{218}$. Das von dieser Seite immer wieder geforderte Instrument der offenen Militärdiktatur blieb dagegen ähnlich wie Bismarcks Staatsstreichdrohungen bis in den Sommer 1918 als Warnung über den Köpfen eventuell unbotmäßiger Parlamentarier hängen. Die Drohung mit einem »wilden General« als Alternative zu einem dann doch wohl akzeptableren Bülow hatte schon Unterstaatssekretär Zimmermann in der Juli-Krise gegenüber Scheidemann aufblitzen lassen ${ }^{219}$. Eine ähnliche Taktik sollte Staatssekretär v. Kühlmann Ende Oktober 1917 vor den Führern der Mehrheitsparteien anwenden, als er ihnen im Falle einer Ablehnung Hertlings als Kanzler die Gefahr vor Augen führte, daß sonst »diejenigen Kräfte, die schon längst eine Militärdiktatur befürworten, [. . .] Oberwasser bekommen« könnten ${ }^{220}$.

In dieses Spiel paßte auch die Haltung der OHL selbst, die sie im zweiten Halbjahr 1917 gegenüber allen an sie herangetragenen Diktaturvorschlägen einnahm. Sie ließ erkennen, daß auch sie die innenpolitischen Verhältnisse ganz im Sinne ihrer jeweiligen Gesprächspartner für revisionsbedürftig hielt; zum Aktivwerden war sie dagegen nicht zu bewegen. Das bekam vor allem Class zu spüren, als er mit seinen Plänen für ein "Kabinett in Feldgrau « im Oktober 1917 endlich bis zu Ludendorff persönlich vorstie $ß^{221}$. Der Verbandsvorsitzende schlug dem General die Berufung einer Art "politischen Generalstabs« zur Disposition der OHL vor, der für den Fall eines notwendig werdenden Übergangs zur offenen Militärdiktatur den jederzeit verfügbaren Nukleus für ein Fachkabinett abgeben konnte. Seine Mitglieder - alle dem Alldeutschen Ver- 
band zugehörig - ließen sich dafür schon jetzt als Offiziere des Beurlaubtenstandes zur OHL einberufen. Ludendorff hörte sich die Ausführungen mit Interesse an, sah aber im Augenblick keinen akuten Handlungsbedarf.

Ähnlich erging es allen denjenigen, die trotz der vielen Rückschläge mit ihrem Kandidaten nicht müde wurden, Tirpitz immer wieder als die bessere Alternative zu den wechselnden Kanzlern vorzuschlagen ${ }^{222}$. Sie durften zwar die Gewißheit des sachlichen Einverständnisses mitnehmen, insbesondere seit der Admiral in der Vaterlandspartei erfolgreich eine außerparlamentarische Siegfriedensbewegung gegen die Reichstagsmehrheit mit ihrem Verlangen nach einem Verständigungsfrieden aufzubauen verstand. Mehr war dagegen nicht zu erreichen, da weder der Kaiser dafür zu haben war, noch die innenpolitische Lage mit ersten Matrosenunruhen und Streikbewegungen in der empfindlichen Kriegswirtschaft das Risiko eines derartigen Konfliktkurses eingrenzbar machte. Mit den Siegen in Rußland und Italien hatte sich auch die Stimmung im übrigen soweit stabilisiert, daß alle Augen auf die letzte große Schlacht im Westen zu richten waren, für die seit Herbst 1917 die Planungen liefen. Hugenberg konnte seine Zuhörer aus Industriekreisen zu Jahresbeginn 1918 denn auch nur damit vertrösten, daß hoffentlich »die Männer, denen allein wir es zu verdanken haben, wenn wir jetzt militärisch so günstig stehen, auch die ausschlaggebenden sind für das, was schließlich geschieht, wenn die letzten politischen Entscheidungen kommen ${ }^{223}$. Solche Hoffnungen der einen Seite fanden ihr sorgenvolles Pendant, wenn etwa Riezler seinem Tagebuch in den Erfolgswochen der Frühjahrsoffensive anvertraute: "Glückt sie völlig, so kommt die freudig vom Volke ertragene Militärdiktatur.« "224

Wie die OHL dagegen bei politischen Meinungsunterschieden ihre indirekte Machtteilhabe in direkten Druck umzusetzen verstand, wurde materiell bei den Friedensverhandlungen von Bukarest und Brest-Litowsk, personell bei den erzwungenen Rücktritten Valentinis als Chef des Zivilkabinetts und Kühlmanns als Staatssekretär des Auswärtigen Amtes sichtbar. Im Bewußtsein ihrer faktischen Unabsetzbarkeit erklärte sie sich in solchen Fällen zum Wächter darüber, daß die militärischen Erfolge nicht auf diplomatischem Wege wieder verspielt würden bzw. daß die Stimmung in der Heimat keinen Schaden nahm ${ }^{225}$ und verlieh ihrem Willen den nötigen Nachdruck durch das Instrument der gemeinsamen Rücktrittsdrohung. Selbst wenn einmal, wie in der Kanzlerkrise vom Januar 1918, vom Kaiser der Ordnungsruf ertönte, die Generale sollten die Hände aus der Politik lassen, "um sich unbeeinflußt den Aufgaben der eigentlichen Kriegführung zu widmen “226, über den Mut zum verbalen Rüffel hinaus besaßen Kaiser und Kanzler doch in keinem Fall mehr die Kraft zur Durchsetzung ihrer Auffassungen. Meldeten sich dagegen innerhalb der OHL Bedenken, welche Folgen es auf die Dauer für den monarchischen Gedanken haben mußte, wenn Hindenburg und Ludendorff ihren Willen zunehmend durch offenen Druck auf ihren Obersten Kriegsherrn zur Geltung brachten, dann hielt der Erste Generalquartiermeister dem entgegen: "Das deutsche Volk steht mir höher als die Person des Kaisers «? ${ }^{227}$ Was daher bei der Ersetzung des ehemaligen Bethmann-Vertrauten Valentini durch den selbsterklärten »Anhänger von Tirpitz, Ludendorff «, Friedrich v. Berg, aus kaiserlichem Munde halb ironisch klingen sollte, gab denn auch ganz ungeschminkt den Grad der Resignation Wilhelms II. preis: "Man hat mir befohlen, Dich zum Chef des Zivilkabinetts zu machen. ${ }^{228}$ Ludendorff machte jedenfalls im engsten Kreise immer unverhohlener deutlich, daß er sich als Interessenwahrer einer höheren als der monarchischen Loyalitätsidee verpflichtet fühlte: dem „Glauben« an ein Deutschland, für dessen Durchbruch zur Größe er sich zur Überwindung von Widerständen und Kleinmut aufgerufen sah ${ }^{229}$.

Anlaß zur Besorgnis gaben Anfang 1918 jedoch nicht nur die Differenzen über die Friedensverträge im Osten, sondern auch die kurzzeitig in den Januarstreiks verschärf- 
te Lage im Innern. Nach der weiteren Radikalisierung der russischen Verhältnisse im Gefolge der Oktoberrevolution lösten Umfang und Verbreitung der Streikbewegung sofort erhebliche Beunruhigung bei Regierung und Heeresleitung aus. Neben den Rückwirkungen auf die materiellen Vorbereitungen der geplanten Frühjahrsoffensive resultierte das Bedenkliche der Arbeitsniederlegungen für Zivil- und Militärbehörden vor allem aus den angenommenen Zusammenhängen zwischen russischen und deutschen Vorgängen und aus den über rein wirtschaftliche Verbesserungen hinausgreifenden politischen Forderungen in der Wahlrechts- und Friedensfrage ${ }^{230}$. Daß die zivilen Behörden, anders als von Ludendorff gefordert ${ }^{231}$, nicht sofort mit härtesten Mitteln einschritten, ließ daher in und außerhalb der OHL erneut den Ruf nach exekutiver Straffung an der Reichsspitze ertönen. Der Kaiser müsse endlich "zupacken« und den Belagerungszustand ausrufen, moder noch besser, die Militärdiktatur einführen ${ }^{232}$.

Für die radikalste Konsequenz stand Anfang Februar 1918 einmal mehr Oberst Bauer, wenn er beim Kronprinzen und bei Ludendorff die Forderung vorbrachte, daß der entscheidungsschwache Kaiser »die Zügel der Regierung für einige Zeit niederlegen« müsse, wenn man noch rechtzeitig Dämme gegen die heraufziehende "Revolution « errichten wolle. Der im Herbst 1918 zur OHL kommandierte Wirtschaftsfachmann Richard Merton erinnerte sich später sogar an eine Sammlung staatsrechtlicher Gutachten, die Bauer über die Frage einer Regentschaft des Kronprinzen hatte zusammentragen lassen ${ }^{233}$. Der Plan fand indessen weder beim Kronprinzen noch bei Ludendorff die erhoffte Resonanz. Dazu waren die Streiks viel zu rasch durch weniger radikale und damit risikoärmere Maßnahmen der Regierung und die gemäßigte Haltung von SPD und Gewerkschaften beigelegt worden. Die Konzentration auf die reibungslose Vorbereitung der Frühjahrsoffensive vertrug zudem keine neuen Erschütterungen der inneren Lage. Außerdem hatte sich unter dem Einfluß des neuen Chefs des Zivilkabinetts das Verhältnis von Kaiser und OHL so weitgehend entspannt ${ }^{234}$, daß auch von daher wenig Grund für Bauers Radikalkur bestand. Immerhin hatte die Kanzlerkrise vom Januar aber bei Berg den Wunsch reifen lassen, für den Fall eines nicht mehr auszuschließenden Wechsels im Kanzleramt besser gerüstet zu sein als sein Vorgänger Valentini. Noch im Frühjahr 1918 war sein Blick auf den Generalgouverneur in Belgien, Generaloberst v. Falkenhausen, gefallen, da er seinen Kurs, Kaiser und OHL unter allen Umständen zusammenzuhalten, am besten unter einem »klugen energischen Militär" gewährleistet sah. Mitte Mai 1918 hatte er bei einem kaiserlichen Besuch in Brüssel offenbar auch Wilhelm II. für seinen Kandidaten in spe gewonnen ${ }^{235}$.

Die Frage eines Kanzlerwechsels sollte schneller als erwartet an Gewicht gewinnen, als sich im späten Frühjahr Offensive auf Offensive im Westen festlief und die Stimmung an der Front immer bedenklicher nachzugeben begann ${ }^{236}$. Oberst v. Thaer schnitt deshalb bei seiner Versetzung von der Front in die OHL vor dem Hintergrund seines schonungslosen Zustandsberichtes über die Fronttruppen auch die Kanzlerfrage an, da ihm der greise Hertling kaum der geeignete Mann zu sein schien, um einem Übergreifen erster Unruhezeichen aus der Front auf die Heimat zu steuern. Ludendorff konnte zu diesem Zeitpunkt dagegen nur stereotyp auf die Unmöglichkeit verweisen, seine Wunschkandidaten Tirpitz oder Bülow beim Kaiser durchzubringen ${ }^{237}$. Doch der Ruf nach einem Diktator als Präventivmaßnahme gegen ein allgemeines Umkippen der Stimmung für den Fall einer notwendigen Verlängerung des Krieges oder gar seines negativen Ausgangs verschwand jetzt nicht mehr von der Tagesordnung. Nur sollte er sich, bedingt durch das zeitlich gestaffelte Bewußtwerden der zugespitzten militärischen Lage, im Sommer 1918 zunächst noch auf militärinterne Kreise beschränken und erst im Herbst unter panikartigen Begleitumständen auf die nationale Öffentlichkeit übergreifen. 
Die befürchtete Wende kündigte sich am 18. Juli 1918 bei Villers-Cotterets an, am 8. August wurde sie beim englischen Einbruch zwischen Ancre und Avre zur Gewißheit. Mochte Ludendorff das öffentliche Eingeständnis einer sich abzeichnenden Niederlage noch einige Wochen hinauszögern, intern gab sich der Deutsche Kronprinz schon im Juli in einer von Bauer konzipierten Denkschrift keinen Illusionen mehr hin: „Eine Waffenentscheidung zu unseren Gunsten« sei »in weitere Ferne gerückt«; bestenfalls könne noch versucht werden, für einen »Verständigungsversuch [. . . ] durchzuhalten«; für eine derartige Kraftanstrengung aber werde der Reichstag schwerlich zu gewinnen sein, deshalb mbleibt nur übrig, ohne ihn zu regieren « ${ }^{238}$. Dabei sah Bauer, wie aus seinen zeitgleichen Aufzeichnungen hervorgeht, immerhin klar genug, um neben Repressivmaßnahmen wenigstens ansatzweise mit Verbesserungen in der Lohnfrage für Arbeiter und Soldaten sowie mit Versorgungsaufstockungen für Kriegsbeschädigte auch positive soziale Signale zu setzen. Der Kronprinz und sein Stabschef Graf Schulenburg wollten dagegen nur noch durch menergische, rücksichtslos durchgreifende Führung « zum Ziel kommen: »Diktatur, Unterdrückung aller revolutionären Umtriebe. Exemplarische Bestrafung der Deserteure und Drückeberger, Militarisierung der Rüstungsbetriebe, Ausweisung zweifelhafter Ausländer und anderes mehr«, hieß ihre Losung ${ }^{239}$. Aber wer konnte ein solches Konfliktprogramm denn noch durchstehen? General Hoffmann hatte unmittelbar nach Villers-Cotterets nur den Weg gesehen, "Ludendorff würde Reichskanzler, dann wären klare Verhältnisse « ${ }^{240}$.

Die Idee einer Zusammenfassung von Kanzleramt und Heeresleitung mußte freilich jetzt wie früher schon ein substanzloses Gedankenspiel bleiben, da sie bei ernsthafter Präsentation sofort an der Verweigerung Hindenburgs und Ludendorffs gescheitert wäre. Deshalb forcierte der Chef des Zivilkabinetts lieber seinen Kanzlerplan mit Generaloberst v. Falkenhausen. Mit ihm wurde er sich Ende Juli bei einem erneuten Treffen in Brüssel einig, daß sich der Generalgouverneur als Regierungschef auf Abruf bereithalten sollte. Falkenhausen ging auch sogleich an die personellen und politischen Vorüberlegungen für ein Kabinett, in dem neben ihm als Kanzler die zentralen Ressorts des Äußeren (Admiral v. Hintze), der Wirtschaft und Rüstung (General v. Stein) und des Kriegsministeriums (General v. Wrisberg) in militärischer Hand liegen und die klassischen Fachministerien mit Experten aus Beamtentum und Wirtschaft besetzt werden sollten. Daneben wollte er die Mehrheitsfraktionen des Reichstags "zu ködern" versuchen, um ihr Abdriften zu den Radikalen zu verhindern. Zu diesem Zweck gedachte er, den Dompropst Middendorf für das Zentrum und den rechten Sozialdemokraten Lensch als zwei ihrer national zuverlässigen Repräsentanten eher optisch in seine Regierung einzubauen. Mit diesen Scheinkonzessionen an die parlamentarischen Kräfte sollten offenbar die riskanten Nebenwirkungen eines projektierten Kurses abgefedert werden, bei dem sich »voraussichtlich gleich oder bald die Notwendigkeit herausstellen [würde], Gewaltmaßnahmen anzuwenden«. An die Stelle der offenen wäre mithin eine in halbkonstitutionelle Formen gekleidete verdeckte Militärdiktatur getreten. Nirgends wurde dies greifbarer als in den zentralen Zielen eines Kabinetts Falkenhausen, das den Reichstag auflösen, Neuwahlen auf unabsehbare Zeit hinausschieben und gegen alle Formen inneren Widerstandes unter »Anwendung militärischer Gewalt« vorgehen würde ${ }^{241}$.

Wie bedrohlich die militärischen Rückschläge in ihren Gefahren für den Bestand des Kaiserreichs selbst von gemäßigter Denkenden im Offizierkorps schon Mitte August empfunden wurden, lassen die Überlegungen Groeners für eine »Regierung der nationalen Konzentration « erkennen. Unabhängig von Bergs parallelen Planspielen sah auch er jetzt die Notwendigkeit "einer ganz starken Konzentration der Regierungsgewalt«, allerdings personell noch stärker mit der OHL verklammert. Bei ihm sollte "pro forma« unter dem Dach von Hindenburgs Popularität ein parlamentarischer Vize- 
kanzler und "Sprechminister« vom Zuschnitt des Nationalliberalen v. Payer den Reichstag zum Stillhalten bewegen, während Ludendorff als Kriegsminister und Oberbefehlshaber des Heimatheeres »den Schutz der Monarchie im Innern zu organisieren hatte. Was an taktischen Rückzügen an den Fronten noch zu leisten war, sollte Kronprinz Rupprecht von Bayern als Chef der OHL mit Hilfe v. Kuhls oder v. Loßbergs abwickeln ${ }^{242}$.

Doch solche und ähnliche Gedankenspiele, wie sie etwa auch Oberst Bauer über den neuernannten Verbindungsoffizier der OHL zum Kaiser, den Obersten Niemann, bereits Anfang August an die unmittelbare Umgebung des Monarchen herangetragen hatte ${ }^{243}$, blieben schon im Ansatz stecken, da Ludendorff nicht mitzog. Wohl sah auch er die Gefahren einer weiteren rapiden Stimmungsverschlechterung heraufziehen, nur hielt er »nach dem militärischen Mißerfolg im Juli/August 1918 [ . . ] eine Diktatur der O. H. L. nicht mehr für möglich “244. In diesem Falle vielleicht klarsichtiger als seine Umgebung, war er sich seiner vom intakten militärischen Prestige abhängigen Stellung in der Öffentlichkeit bewußt. Ohne diese Erfolgshoffnungen im Rücken aber würde sich die OHL nur in den innenpolitischen Auseinandersetzungen verschleißen. Wenn er also an einen Austausch Hertlings als ungeeignet für die sich ankündigende Krise dachte, dann allein in einer Kombination mit einem stärkeren Kanzler, der ihm auch weiterhin innenpolitisch den Rücken freihielt. Sehr zur Enttäuschung seines Vertrauten Bauer, der sich deshalb in den letzten Kriegswochen sogar von ihm abzuwenden begann ${ }^{245}$, blieb der General daher seinem Kurs einer indirekten Machtteilhabe treu. Nach Beratungen mit dem ihm nahestehenden Industriellen Stinnes im Großen Hauptquartier brachte er erneut die Sprache auf den Fürsten Bülow. Bei einem nachfolgenden Gedankenaustausch zwischen dem Großreeder Ballin und Stinnes scheint der Industrielle sogar selbst als Kanzler »mit diktatorischen Befugnissen« in die nähere Wahl gezogen worden zu sein ${ }^{246}$.

Doch vorerst blieb alles beim alten, da offenbar auch der Kaiser in der an sich schon angespannten Lage den Sprung ins Dunkle scheute und bei seinem Kurs blieb, mit dem Reichstag einen Ausgleich über Hertling zu suchen. Der Anfang August bereits vorsorglich von Berg nach Spa bestellte Falkenhausen kam deshalb nicht einmal mehr zu einer Aussprache mit Wilhelm II. und reiste unverrichteter Dinge nach Brüssel zurück. Ein ähnliches Ergebnis zeitigte ein kurzfristig anberaumtes Treffen des Generalgouverneurs mit dem Chef des Zivilkabinetts auch Mitte September in Aachen ${ }^{247}$. Hinund hergerissen zwischen dem Wunsch nach präventivem Gegensteuern gegen die sich aufbauende Krise und der Angst vor den zu gewärtigenden Risiken verharrte man in Spa letztlich in einem Zustand latenter Unschlüssigkeit. Dazu mochte nicht zum wenigsten der gesundheitliche Einbruch bei Ludendorff selbst in diesen Wochen beigetragen haben. Jahrelange Überarbeitung und akute Überreizung der Nerven als Folge der militärischen Rückschläge zwangen ihn ausgerechnet im September 1918 in eine vierwöchige ärztliche Behandlung ${ }^{248}$.

Bis Ende September verschlechterte sich die militärische Lage unterdessen so rasant, daß auch für die OHL das Eingeständnis der Niederlage nicht mehr zu umgehen war. Ludendorffs Forderung nach einem sofortigen Waffenstillstand zog daraus nur noch die - in ihrer Hektik allerdings überstürzte - Konsequenz und löste damit eine neue Kanzlerkrise aus. Hertling erbat und erhielt seinen Abschied. Was wunder, daß sich sogleich die Stimmen zu Wort meldeten, die spätestens jetzt ein Signal der Härte nach innen gesetzt wissen wollten. Noch am 20. September schien der Kaiser auch wirklich die Weichen für eine Kanzlerschaft Falkenhausens stellen zu wollen ${ }^{249}$. Das Ausmaß der militärischen Rückschläge hatte indes schon wenige Tage später die OHL »sehr kleinlaut gemacht « ${ }^{250}$. Als der Staatssekretär des Auswärtigen Amtes, Admiral v. Hintze, daher in der entscheidenden Besprechung mit Hindenburg und Ludendorff am 
29. September nur noch die Alternativen "Diktatur" oder "Revolution von oben" durch Parlamentarisierung des Reiches zur Debatte stellte, winkte der Erste Generalquartiermeister beinahe erschrocken ab, da ihm der harte Weg »ohne militärische Erfolge völlig aussichtslos erschien « ${ }^{251}$. Berg holte sich daher für seinen Kandidaten Falkenhausen bei Kaiser und OHL eine volle Abfuhr: "Das sei in einem Moment, wo das Heer zurückgehen müsse, für das Volk eine zu große Zumutung. « ${ }^{252}$ Er konnte dem Generalobersten nur telegrafisch mitteilen: »Veränderte Verhältnisse machen frühere Pläne unmöglich.« ${ }^{253}$ Ludendorff selbst schlug dagegen einen anderen Weg ein, als er noch am 29. September vor seinen Mitarbeitern in der OHL seine Aufforderung an den Kaiser zur Parlamentarisierung mit dem Argument verteidigte, "jetzt auch diejenigen Kreise an die Regierung zu bringen, denen wir es in der Hauptsache zu danken haben, daß wir so weit gekommen sind « ${ }^{254}$. Damit stieß er schon jetzt die Tür für die spätere Dolchstoßlegende weit auf.

Wie kopflos man sich in diesem Augenblick im Großen Hauptquartier gebärdete, mag man aus einem Vorstoß von Oberst Bauer ersehen, der in seiner Enttäuschung über Ludendorff den reichlich überraschten Admiral Scheer "zu einer Art MilitärdiktaturBefürwortung anstacheln« wollte ${ }^{255}$. Als er in Spa nicht durchdrang, fuhr er Anfang Oktober nach Berlin ins Kriegsministerium, um in höchster Erregung die »unverzügliche « Absetzung seines Mentors Ludendorff zu verlangen, der »seine Spannkraft verloren« habe. Hier erhielt er indes Kenntnis von Rathenaus »levée en masse«-Artikel in der Vossischen Zeitung vom 7. Oktober, der ihm einen neuen Ausweg aus der Krise zu weisen schien. Ähnlich wie der AEG-Vorsitzende, der sich offenbar schon in einer "Gambetta«-Rolle wähnte, sah auch der von gesellschaftlichen Rücksichtnahmen freie Oberst nun über die Regierungsbeteiligung der Sozialdemokraten eine Chance, »die Massen zur allgemeinen Verteidigung aufzurufen. [...] Man müsse jetzt stark sein, stark um jeden Preis und koste es selbst dynastische Interessen, sonst sei alles verloren.« ${ }^{256}$ Unter den Bedingungen eines völlig erschöpften Feldheeres, erster Auflösungserscheinungen in den Heimattruppenteilen und deutlich reservierter Mehrheitsparteien erkannte auch diesmal Ludendorff klarer als seine Kritiker, daß solche Pläne nur noch ein totgeborenes Kind zeugen konnten und lehnte sie deshalb gegenüber der neuen Reichsregierung schlichtweg ab.

Über das Episodenhafte hinaus klang freilich in Bauers Argumentation ein weiteres Stück jenes neuen radikalen Nationalismus an, der sich gedanklich aus den gesellschaftlichen Banden des Kaiserreiches zu befreien begann und bereits aus dem Wilhelminismus in die Freikorpszeit hinüberwies. Jetzt, wie später in den Kapp-Tagen, überschritt er allerdings eine Grenze innerhalb der radikalen Rechten, bei der ihm die Masse der in der Vaterlandspartei, seit 1919 in der Geheimorganisation der »Nationalen Vereinigung « Organisierten nicht folgen konnte. In ihren Augen barg vielmehr gerade die »Entwicklung zur absoluten Linksentwicklung [sic!] die größte Gefahr für Kaiser und Reich in sich «. Deshalb verstärkten ihre Repräsentanten die Forderung nach »Auflösung des derzeitigen übelberatenen Reichstages und die Verkündigung der Militärdiktatur ${ }^{257}$. In ihrem Namen wandte sich am 17. Oktober schließlich Tirpitz in einem Brief an den Prinzen Max v. Baden, der in Abschriften auch an die OHL sowie an hohe Armee- und Parteiführer gelangte, um für ein letztes "Zusammenfassen aller Kräfte der Nation und Errichtung einer Diktatur « zu werben ${ }^{258}$. Daß ihm auf diesem Weg niemand gefolgt sei, würde er nach dem Kriege mehrfach denjenigen vorwerfen, die nunmehr über die Verhältnisse nach Niederlage und Versailles klagten ${ }^{259}$.

Doch auch Ludendorff begann ab Mitte Oktober plötzlich seine Haltung noch einmal zu revidieren und für ein Weiterkämpfen »bis zum Äußersten« zu plädieren. Dabei mag die Kritik aus den militärischen Reihen an seinen überstürzten Handlungen rund um das Waffenstillstandsersuchen ebenso mitgespielt haben wie der schon bei seiner 
Parlamentarisierungsforderung geäußerte Wunsch, die eigentlich Verantwortlichen für den nahen Zusammenbruch vor der Nachwelt ganz deutlich herauszustellen. Die Art, in der er schließlich seine Entlassung beim Kaiser erzwang ${ }^{260}$, wirft ein ähnliches Licht auf seine Suche nach einem persönlichen Ausweg aus der Verantwortung. Wenn demgegenüber sein enger Mitarbeiter v. Haeften, der es besser wissen mußte, ihm das nachträgliche Denkmal zu setzen suchte: »Er allein besaß Fähigkeit und Kraft, die Führung im Kampf gegen die Revolution zu übernehmen und diese in ihren ersten Anfängen mit der nötigen Rücksichtslosigkeit niederzuschlagen « ${ }^{261}$, dann war er damit lediglich zu einem der frühesten Gefangenen in einer der vielen "Legenden aus dem Hause Ludendorff “ geworden.

Bevor auf das Weiterwirken von Diktaturüberlegungen in der Weimarer Frühzeit eingegangen wird, scheint an der Nahtstelle zwischen Weltkrieg und Revolution ein Zwischenresumée zu der eingangs angeschnittenen Kontroverse um den Charakter des späten Wilhelminismus unter Einbeziehung der vorgestellten Diktaturpläne angebracht. Selbst wenn man den Vertretern der These von einer "stillen Parlamentarisierung « des Reiches einen unbestreitbaren Bedeutungszuwachs des Reichstages gerade für die zweite Kriegshälfte mit ihrem schwieriger zu bewerkstelligenden Zusammenhalten der Heimatfront konzediert, bleibt doch zumindest für die Zeit bis zu den militärischen Einbrüchen des Sommers 1918 die Frage nach den Erfolgsaussichten der sich ebenfalls organisierenden Gegenkräfte offen. Gewiß steckte in deren Militärdiktaturplänen nicht weniger Angst vor dem Reichstag wie Hoffnung auf seine Bändigung im Verbund mit der militärischen Führung, wobei man Reichstag sagte und die als unberechenbar empfundenen Massen hinter ihm meinte. Daß die Rufe nach der offenen Diktatur nicht zum Erfolg führten, kann man auch bis zu einem gewissen Grade der gelungenen interfraktionellen Mehrheitsbildung im Parlament zurechnen, die das Risiko eines offenen Konfliktkurses als zu unkalkulierbar erscheinen lassen mußte.

Daraus aber auf einen allzu gradlinigen Positionsgewinn der parlamentarischen Kräfte zu schließen, ginge für die Zeit einer III. OHL im Vollbesitz ihrer Möglichkeiten indes erheblich zu weit. Die für die Zukunft so bedeutsame Wahlrechtsfrage stagnierte seit Bethmanns Sturz; in den Diskussionen um Kriegsziele und Friedensschlüsse konnte sich nicht einmal die Regierung voll zur Geltung bringen, während die Parlamentarier praktisch ausgeschaltet blieben; und selbst der dem Reichstag als Parteienvertreter präsentierte Kanzler Hertling entpuppte sich schnell als Schutzschild der OHL gegen das Parlament denn als Einfallstor einer parlamentarischen Einflußnahme auf die Entscheidungen im Großen Hauptquartier. Aber auch die Parlamentsfraktionen und ihr Koordinationsorgan im interfraktionellen Ausschuß wiesen in sich zu deutliche gesellschafts- und verfassungspolitische Bruchlinien auf, standen mit führenden Repräsentanten wie Erzberger und Stresemann auch viel zu lange schwankend zwischen Parlament und OHL, als daß sie sich zum geschlossenen Block des Parlamentswillens gegen das extrakonstitutionelle Wirken in und um die Militärführung hätten aufschwingen können. Das Zögern der OHL, den Wünschen ihrer Anhänger und ihren eigenen innenpolitischen Präferenzen vollends nachzugeben, hing somit eher von der Verweigerung des Kaisers und der eigenen risikoärmeren Taktik der indirekten Machtteilhabe ab als von besonderer parlamentarischer Rücksichtnahme. Erst als die Siegesaussichten schwanden, spielten bei ihrem Ablehnen einer präventiven Diktaturlösung der realistischere Blick auf den Verlust der eigenen plebiszitären Basis und das jetzt rapide anwachsende Gewicht der parlamentarischen Kräfte eine ausschlaggebende Rolle.

Da sich auch die These von der "stillen Parlamentarisierung einen spekulativen Ausblick erlaubt, daß nämlich die Novemberrevolution eigentlich eine kontinuierlich fortschreitende Entwicklung zum Parlamentarismus mehr gehemmt als gefördert habe, sei eine entsprechende Gegenvermutung versucht. Bis zum Eingeständnis der militäri- 
schen Niederlage mochten die parlamentarischen Kräfte zwar bereits eine Bevölkerungsmehrheit der zunehmenden Erschöpfung hinter sich haben, die aber durch militärische Erfolge in kritischen Phasen jederzeit aufgewogen werden konnte. Zu Recht ist daher die plebiszitäre Rolle Ludendorffs bis zum Sommer 1918 inzwischen als durchaus »systemstabilisierend « charakterisiert worden, da der Weltkrieg in seiner militärischen Schwebelage zwei Systemauswege bereitgehalten habe: den der "Demokratisierung « oder den einer »Militarisierung « von Staat und Gesellschaft ${ }^{262}$. Da der General außerdem ein Gegensteuern gegen den Reichstag auch mit diktatorischen Mitteln nie grundsätzlich, sondern immer nur situationsbedingt ablehnte, entschied erst die Niederlage wirklich zugunsten der parlamentarischen Alternative. In diesem Kontext geben die Militärdiktaturpläne deshalb ein weiteres Indiz dafür ab, daß jede Diskussion um die Entwicklungsmöglichkeiten des deutschen Konstitutionalismus im Weltkrieg auch dessen potentielles Zurückdrehen nach rechts mitzubewerten hat.

V.

Daß die allmähliche Abnabelung einer dynamisch-nationalistischen Rechten von den konservativen Honoratiorenparteien, die Neubestimmung ihres Verhältnisses zur monarchischen Frage und ihre Suche nach effizienterer und durchsetzungskräftigerer Führung über den Zusammenbruch von 1918 hinaus bis in die gesamte Weimarer Frühzeit reichte, wurde in anderem Zusammenhang bereits eingehend gewürdigt ${ }^{263}$. Die Einzelheiten der Pläne und Vorgänge können daher auf die wichtigsten Stationen und Merkmale im Lager der gegenrevolutionären Rechten in der Zeit ihres Aktionismus (bis 1923) beschränkt werden. Betrachtet man den Kontinuitätsbegriff nicht statisch, sondern bezieht die zeitbedingten Anpassungen der in ihrer Substanz gleichbleibenden Grundannahmen und Handlungsmuster mit ein, dann nimmt eine derartige Betrachtung den Einschnitten in der allgemeinen Geschichte von 1914 und 1918/19 für die radikale Rechte den Charakter des Trennenden. Kriegsbeginn und Niederlage erscheinen innerhalb des Jahrzehnts von 1913 bis 1923 vielmehr als Beschleuniger eines Prozesses der Selbstfindung, bei dem sich die rechtsextreme Analyse von den Systemschwächen des späten Kaiserreiches in ihrer Kritik nur fortwährend bestätigt fühlt. Deshalb machen Niederlage und Revolution auch kein Überdenken der eigenen Maximen, sondern lediglich ein noch ungeduldigeres Drängen auf ihr Umsetzen in die Tat notwendig. An drei Komplexen wird das Kennzeichnende dieser Radikalisierung in der Kontinuität besonders greifbar: beim Streben nach einer machtbewußteren Staatsspitze, bei der Suche nach einer eigenen Massenbasis und im Verhältnis von militärischer bzw. paramilitärischer und ziviler Komponente im Lager der Freikorps, Wehrverbände und politischen Rechtsgruppierungen jenseits der Deutschnationalen.

$\mathrm{Daß}$ sich die junge Republik als Erbin der Bewegung für einen Verständigungsfrieden im Kriege kaum für eine am Machtstaatsgedanken ausgerichtete Politik der nationalistischen Sammlung im Frieden eignen würde, stand bei den ehemaligen Anhängern eines Siegfriedens von vornherein fest. Damit mußte die Suche nach einer eigenen autoritären Gegenspitze gegen das "System von Weimar" frühzeitig oberste Priorität genießen. Die Kritik an einer schwächlichen Monarchie hatte trotz aller Heftigkeit gedanklich doch nie über das monarchische System als die geeignetste Staatsform der Deutschen hinausgeführt. Alle Überlegungen für eine Milizärdiktatur hatten letztlich vor dem Bruchpunkt haltgemacht und sich bestenfalls bis zur Idee einer zeitweiligen "Beurlaubung" des Monarchen oder seiner Abdankung zugunsten des Kronprinzen vorgewagt. Der kampflose Abgang der gekrönten Häupter im November 1918 stellte deshalb die gesamte Rechte vor eine zwar gelegentlich befürchtete, aber dann doch weithin unvorbereitete Lage. Was den konservativen Legitimisten immerhin als realisti- 
sches Zurückstecken vor der Gefahr eines Bürgerkrieges mit vorhersehbarem Ausgang erscheinen konnte, kam bei ihren radikalen Flügelmännern als Flucht aus der Verantwortung an.

Freilich hatten auch sie zunächst keine andere Alternative als eine reformierte Monarchie als Heilmittel parat. Als typisch für diese Zerrissenheit zwischen maßloser Enttäuschung über sie und weiterem gefühlsmäßigem Eintreten für sie kann Ernst Röhm gelten. Obwohl ihm wie vielen anderen jüngeren Offizieren die Abdankung des Kaisers wie »die schändlichste Unterwerfung eines Systems [. . . ] unter das Gebot und Gebrüll der Straße« vorgekommen war, apostrophierte er den bayerischen Kronprinzen Rupprecht noch 1928 als "Seine Majestät der König « ${ }^{264}$ ! Daneben waren indes auch bereits radikalere Töne zu vernehmen, wenn etwa der Freikorpsführer Gerhard Roßbach im Januar 1919 nach einem nationalen Führer verlangte, "gleichgültig, unter welcher äußeren Fahne « ${ }^{265}$. Um die eigene Bündnisfähigkeit auf der Rechten nicht in Gefahr zu bringen, verständigte man sich in den Vorbereitungsmonaten des Kapp-Putsches in der "Nationalen Vereinigung " schließlich darauf, die Frage der Staatsform hinter die Schaffung einer möglichst breiten Einheitsfront gegen die Republik zurücktreten zu lassen. Ob man dann den Deutschen Kronprinzen aus dem holländischen Exil zurückrufen oder ganz zum Wahlkönigtum zurückkehren würde, blieb daher offen ${ }^{266}$.

So viel war aber schon jetzt sicher: der Thron war für die Aktionisten auf der Rechten personell disponibel geworden. Jeder künftige Prätendent, Hohenzoller oder Wittelsbacher, würde erst den Nachweis seiner Führungsqualitäten durch aktives Hervortreten in der Umsturzbewegung zu erbringen haben. Am eindrucksvollsten sollten dies die »Königsputsch«-Pläne im Herbst 1921 belegen, als die Wehr- und Verbändeführer nach dem Ableben Ludwigs III. von Bayern seinen Sohn Rupprecht mit militärischer und paramilitärischer Unterstützung auf den Thron heben wollten. $\mathrm{Daß}$ der bayerische Kronprinz den Sprung nicht wagte, kostete ihn seine aktionsbereite Anhängerschaft auf Dauer. Als er daher in der Herbstkrise von 1923 die zerstrittene bayerische Rechte hinter seinem Gefolgsmann Kahr zu vereinen suchte, versagten ihm die an Ludendorff und Hitler orientierten schlagkräftigsten Verbände die Gefolgschaft ${ }^{267}$.

Um ihrer Integrationskraft innerhalb einer vereinten Rechten willen hielten Ludendorff und seine Anhänger zwar auch danach noch am Prinzip einer monarchistischen Restauration fest. In einem Forderungenkatalog der "Deutschvölkischen Freiheitspartei« vom Januar 1923, einer Abspaltung von der DNVP aus Parteigängern des Generals, konnten Reihenfolge und Gewichtsverteilung nach einer erfolgreichen Rechtsverlagerung im Reich dagegen ziemlich unverhüllt abgelesen werden. Den Ausgangspunkt hatte eine kämpferisch nach innen und außen wirkende »völkische Diktatur« zu bilden. In deutlichen Anleihen am Vorbild Horthys in Ungarn würde der Diktator als »Reichsverweser« die Zügel in den Händen behalten und seinen Einfluß auf Zeitpunkt und Kandidatenauswahl einer späteren Restauration geltend machen ${ }^{268}$. Man hielt also noch am Königtum fest in der Hoffnung auf seine traditionellen Bindekräfte im Innern. Das eigentliche politische Energiezentrum aber würde jener Führer ohne Krone in einem Rollenspiel darstellen, das doch sehr an die Machtverteilung aus den Jahren $1917 / 18$ erinnerte. Für diejenigen auf der extremen Rechten, die nach den Novemberenttäuschungen von 1918 nach ganz neuen Wegen suchten, dachte deren aufgehender Stern Hitler schon in den frühen zwanziger Jahren über den Tag hinaus. Um die Monarchisten in den eigenen Reihen nicht zu verprellen, erklärte er die monarchische Frage für seine Anhänger zur Privatsache, wobei er für sich selbst durchblicken ließ, daß sich das Problem mit zunehmendem zeitlichen Abstand von selbst erledigen wer$\mathrm{de}^{269}$. Die interne Machtverschiebung von den monarchistisch geprägten Paramilitärs zum zivilen Arm der radikalen Rechten um die NSDAP gab ihm nach 1923 Recht. Wichtiger noch als die Frage der künftigen Staatsform war in und nach der Revolution 
freilich die Suche nach einer verbreiterten Massenbasis, die eine auf dem Putschwege installierte Regierung dauerhaft abzustützen vermochte. Der von Class schon in seinem Kaiserbuch befürchtete Ausbruch revolutionärer Unruhen, wenn »durch irgendeinen Vorgang der inneren oder äußeren Politik die Staatsgewalt gelähmt wäre « ${ }^{270}$, war im November 1918 eingetreten. Die eigenen Parteigänger hatten die öffentliche Diskussion nur so lange offen zu gestalten vermocht, wie sie sich in ihrer Klientelrolle auf die OHL abstützen konnten. Sie waren mit Ludendorffs Abgang und der militärischen Niederlage nicht nur nachhaltig diskreditiert, ihr radikaler Nationalismus ohne zugkräftige soziale Komponente hatte sie auch selbst in ihrer Blütezeit nicht über ihre kleinbürgerlich-ländliche Anhängerschaft hinaus tiefer in die Unterschichten eindringen lassen. In den nachrevolutionären Kämpfen kamen dazu jetzt noch die deprimierenden Erfahrungen der jungen Freikorpsoffiziere mit dem Defaitismus dieser Kreise. Der Freikorps- und spätere Reichsarbeitsführer Konstantin Hierl hat seine Beobachtungen bei der Niederschlagung der Münchner Räterepublik im Frühjahr 1919 plastisch zusammengefaßt. Das ernüchternde Fazit war, daß ihm beim Bürgertum "Untätigkeit, stumpfe Teilnahmslosigkeit, engherzige Selbstsucht und politische Charakterlosigkeit« als hervorstechende Merkmale aufgefallen waren, während er dem Gegner auf der Linken »starkes Kraftgefühl, großes Selbstbewußtsein und viel politischen Idealismus « einräumen mußte ${ }^{271}$.

Oberst Bauer ging deshalb in seinen "Gedanken zur heutigen Lage« nach der Erhärtung solcher Erfahrungen durch die abwartende Haltung weiter Rechtskreise beim Kapp-Putsch davon aus, daß die "soziale Frage « für die Zukunft zur "Schicksalsfrage Europas« werde. Da für ihn der Weltkrieg nur aus Erschöpfung eingeschlafen, wegen der in den Friedensverträgen ruhenden, nationalen Sprengkraft aber jederzeit wieder aufgenommen werden konnte, würde den neuen Waffengang »dasjenige Volk [...] gewinnen, das als erstes versteht, die soziale Bewegung in nationale Bahnen zu lenken « 272 .

Nun trat der internationalistisch und pazifistisch gesinnte Teil der Arbeiterbewegung seit der Revolution allerdings so selbstbewußt auf, daß er auch in Zukunft ein ständiger Unsicherheitsfaktor in allen innen- und außenpolitischen Rechnungen bleiben würde. Deshalb mußte man offensiven Zugang zu diesem Potential an seinen derzeitigen Führern vorbei suchen. Offiziere wie Ludendorff und Bauer hatten Krieg und Revolution indes viel zu konkret erlebt, als daß sie sich bei dem Problem einer in sich stimmigen Theorie im Sinne eines "nationalen o oder "deutschen Sozialismus« naumannscher oder jungkonservativer Provenienz aufgehalten hätten. Propaganda und soziale Vergünstigungen für die Gutwilligen und Terror gegen die Nichtintegrierbaren waren vielmehr die in Freikorpskreisen aus der Niederschlagung der Revolution gewonnenen Erkenntnisse ${ }^{273}$. Was man dazu nach den negativen Erfahrungen mit einer $»$ Volksaufklärung « von oben im Kriege benötigte, war ein von den Massen angenommener Übersetzer der Botschaft, die nach Ludendorff eine "soziale Volksgemeinschaft auf den sittlichen Grundlagen des alten Heeres in Aussicht stellen sollte ${ }^{274}$.

Dem Wunsch nach einem Bündnis der beiden einzigen Gruppen, die offenbar gestählt aus Front- und Revolutionskämpfen hervorgegangen waren, galten die Planspiele um eine "Noske-Diktatur« ebensosehr wie die Kontaktaufnahmen Bauers vor und während des Kapp-Putsches zu nationalbolschewistischen Kreisen in Berlin. Beide Vorstöße scheiterten allein schon an der völligen Fehleinschätzung über die Vermittelbarkeit eines »Kriegerstaatsmodells« Ludendorffscher Prägung für die Arbeiterschaft. Sie belasteten aber auch die Bündnisfähigkeit ihrer Vertreter auf der gesamten Rechten so stark, daß sie - von Ausnahmen abgesehen - schon 1920 endgültig aufgegeben wurden. Dagegen schien der Parteiführer der jungen NSDAP in München, Hitler, geradezu ideale Voraussetzungen für eine Mobilisierung nationalistisch ansprechbarer Un- 
terschichten mitzubringen. Massenanziehende Beredsamkeit, glühender Nationalismus und soziale Agitation ohne sozialpolitische Sprengkraft ließen viele seiner frühen Protektoren aus Großbürgertum, Reichswehr und Wehrverbänden an sein selbstgestecktes Ziel eines "Zerbrechers des Marxismus ${ }^{275}$ glauben, obwohl von amtlichen Beobachtern seiner Bewegung frühzeitig der vergleichsweise geringe Zulauf aus Arbeiterkreisen registriert wurde ${ }^{276}$.

Rudolf Olden hat diese Hoffnung auf Nutzbarmachung des Gefreiten als dem politischen Agitator durch den General als den anerkannten militärischen Kopf der extremen Rechten in seiner ironisierenden Art treffend skizziert: »Er glaubt, wie alle Militärs, an den Fachmann und offenbar ist Hitler der Fachmann für Propaganda. Schwert und Wort, er und Hitler, vereint, da wird kein Feind widerstehen können. «277 Würde Ludendorff das Reich erst einmal in den "Befreiungskampf « gegen Versailles geführt haben, dann sollte sein ziviler Mitstreiter endlich das leisten, was die wechselnden Kriegskanzler nicht zuwege gebracht hatten: die wirtschaftlichen Ressourcen des Landes für die Kriegführung ständig aufs Neue zu mobilisieren und die Heimatfront stabil zu halten. Das darin enthaltene Mißverständnis über das Verhältnis des »Feldherrn« zu seinem »Trommler« sollten ebenfalls erst die Veränderungen nach dem Herbst 1923 zutage fördern, als der letzte Putschplan gescheitert und die Schwerkraft innerhalb der radikalen Rechten von der paramilitärischen Verbändebewegung auf die zivilen Rechtsparteien übergegangen war.

Gerade dieses nur allmähliche Herauswachsen eines politischen Astes aus Obhut und Bevormundung seiner militärischen Protektoren im Krieg und seiner paramilitärischen Aktionisten danach macht das eigentliche Kontinuum in der Frühzeit des deutschen Rechtsextremismus aus. Die Deutsche Vaterlandspartei war als lautestes Sprachrohr der Siegfriedensparolen aus dem Großen Hauptquartier voll in die Strudel der militärischen Niederlage hineingerissen worden. Ihre direktionslosen Reste konnten sich erst im Zuge der militärischen Freikorpserfolge wieder auf der politischen Bühne zurückmelden. Am einprägsamsten läßt sich dieser Prozeß im späteren bayerischen Reduit der gesamten Rechten für die Wochen unmittelbar nach dem Ende der Münchner Räterepublik nachzeichnen ${ }^{278}$. Ein zunächst in sektiererische Kleingruppen zerfallener Restbestand der alldeutschen Hochburg München im Kriege konnte sich erst jetzt im Schlepptau der siegreichen Truppen und Wehren wieder auf allen politischen Ebenen vom Presse- und Verlagswesen bis in die Verbände und Exekutivkräfte hinein festsetzen. Dieser Erholungsprozeß unter dem schützenden militärischen Dach stellte die politischen gegenüber den paramilitärischen Trägern dieser neuen Rechten aber auch erneut in ein der Kriegszeit vergleichbares Abhängigkeitsverhältnis.

Verstärkt und theoretisch untermauert wurde der fortbestehende Führungsanspruch dadurch, daß die führenden militärischen Köpfe der extremen Rechten als Erste Bilanz aus Weltkrieg und Zusammenbruch zogen und aus ihrer Kritik Zukunftsentwürfe militaristischer Provenienz vorstellten. In Bernhardis Betrachtungen zum zukünftigen Krieg wie in Ludendorffs theoretischem Erstling "Kriegführung und Politik" war der zurückliegende Weltkrieg in den von Clausewitz nur gedachten, »absoluten « Krieg umgeschlagen. Das angebrochene Zeitalter totaler Auseinandersetzungen aber würde nur die Völker überdauern lassen, die sich rechtzeitig und konsequent den neuen Herausforderungen stellten. Die Nation hatte sich dazu im modernen Kriegerstaat unter militärischer Führung zu organisieren, oder in Umkehrung der Clausewitz-Formel: die Politik hatte nunmehr der Kriegführung zu dienen ${ }^{279}$. Dementsprechend würde Ludendorff als das anerkannte militärische Genie in Vergangenheit und Zukunft - erste fundierte Kritik des "Zivilisten (Delbrück fruchtete daneben wenig ${ }^{280}$ - in den kommenden Jahren immer wieder nach dem politischen zweiten Mann für sein erneutes Hervortreten Ausschau halten. Dabei war es reichlich nebensächlich, wer diese $\mathrm{Zu}$ - 
arbeiterrolle übernahm, ob im März 1920 der treue Parteigänger Kapp aus Kriegszeiten, ob 1920/21 in der bayerischen Fluchtburg der dortige Ministerpräsident Kahr oder 1923 nacheinander der hoffnungsvoll begrüßte Reichskanzler Cuno und schließlich im Herbst Hitler. Stand man erst einmal vor der unvermeidlichen Neuauflage des Krieges, dann würden sich die Gewichte ganz von selbst zum ausschlaggebenden militärischen Pol hin verlagern.

In das künftige Schema passen schon die frühesten Diktaturpläne um die Person Noskes im Frühjahr und Sommer 1919281. Eine im Bürgerkrieg und den Grenzkämpfen wieder selbstbewußter gewordene militärische Führung suchte ihren Minister für eine Kanzlerschaft mit diktatorischen Vollmachten zu gewinnen. Besonders für die jüngeren Freikorpsführer war entscheidend, daß er über Popularität und Energie zu verfügen schien, um die innere Ordnung dauerhaft wiederherzustellen und aus dieser gefestigten Position die als untragbar abgelehnten Friedensbedingungen der Entente zurückzuweisen. Als er jedoch den an ihn gerichteten Appell zur nationalen Sammlung und zum äußersten Widerstand nach außen unerfüllt ließ, wandten sich sofort jene Freikorps von ihm und der Republik ab, die zu Trägern des kommenden Kapp-Putsches werden sollten.

Als neuen Koordinator erkoren sie Kapp an der Spitze eines jetzt offen gegenrevolutionären Aktionszentrums in der "Nationalen Vereinigung ", der personellen und materiellen Nachlaßverwalterin der Vaterlandspartei. Schon in den Vorbereitungsmonaten des mit seinem Namen verbundenen Märzputsches von $1920^{282}$ sah er sich dabei eingerahmt von einer ganzen Riege ludendorffscher Vertrauensoffiziere. Auslösen und Verlauf des Umsturzversuches erhärten den Befund von einem Militärputsch mit ziviler Ummantelung zusätzlich. Der zum Kanzler Vorgesehene wurde mit seinen unfertigen Planungen vom Handeln der Militärs um Lüttwitz mehr vorangestoßen als konsultiert. Und hinter ihnen hielt sich Ludendorff, der sich in den zurückliegenden Monaten durch sein Eintreten für die materiellen Interessen der ehemaligen Soldaten in Freikorpskreisen zusätzliches Prestige als sozial eingestellter, moderner General erworben hatte, zum eigenen Auftritt bereit, sobald sich die Position der Kapp-Regierung hinreichend gefestigt haben würde. Daß er dann nicht gesonnen war, »an eine zweite Stelle zu treten «, gab er Kapp sogleich unmißverständlich zu verstehen ${ }^{283}$. Die nachträgliche Bagatellisierung der eigenen Rolle sollte später nur der Abschiebung der Verantwortung auf die Zivilisten des März-Unternehmens dienen, um den fatalen Eindruck zu verwischen, den der zutage getretene Dilettantismus auf der gesamten Rechten hinterlassen hatte.

Ähnlich erging es 1920/21 dem bayerischen Ministerpräsidenten Kahr, den Reichswehr und Einwohnerwehr in einer Parallelaktion zu den Berliner Märzereignissen in den Sattel gehoben hatten ${ }^{284}$. Auch er blieb während seiner gesamten Regierungszeit der Gefangene dieser Ausgangskonstellation, wobei sich seine Probleme durch die Aufnahme der meisten strafrechtlich verfolgten Kappisten in Bayern noch erheblich verschärften. Was ihm eine paramilitärisch unangreifbare Stellung im eigenen Lande und die Machtmittel für eine eigenständige Rolle im Reich garantieren sollte, trug ihm nur die weitere Radikalisierung seiner bayerischen Basis durch den norddeutschen Zuzug und die Verwicklung in dessen gefährliche "mitteleuropäische Verschwörung" gegen das Versailler System ein ${ }^{285}$. Der Gegenschlag folgte mit der ultimativen Aufforderung der Entente zur Entwaffnung aller Wehren. Kahr wollte zwar zunächst den von paramilitärischer Seite rabiat angemahnten Widerstandskurs durchaus aufnehmen, nur ließ ihm der kombinierte Druck von Reichsregierung und Entente dann keine andere Wahl als nachzugeben. Damit bekam aber auch er Kapps Erfahrungen von Schuldzuweisung und Abwanderung der rechten Aktionisten zu spüren. 
noch nicht die von den inneren und äußeren Kritikern der Wehren erhoffte Zerschlagung ihrer paramilitärischen Basis. Die Verbände etikettierten ihre fortbestehenden organisatorischen Kader vielmehr in äußerlich dezentralisierte und unverdächtiger auftretende Bünde unter ziviler Leitung um. Ihre Verbändezentrale blieb dagegen im Geheimen bestehen. Trotzdem setzte jetzt im Zeichen einer ersten allgemeinen Beruhigung der inneren und internationalen Lage in Bayern und im Reich ein von schweren personellen Zerwürfnissen begleiteter Differenzierungsprozeß im paramilitärischen Lager ein, der es schon Ende 1922 in seine rechtskonservativen und rechtsradikalen Bestandteile zerriß ${ }^{286}$. Insbesondere Ludendorffs völlig unpolitische Inflexibilität und seine militärischen Kommandoallüren führten zu einer Polarisierung unter den Wehren, die auch im Zeichen von Ruhrkampf und Herbstkrise 1923 nicht mehr zu überbrücken war.

Mit stark geschmälertem paramilitärischem Anhang mußte er daher sein letztes Aktionsbündnis mit Hitler eingehen. Da der NS-Führer vorerst weitgehend auf seine bayerische Hochburg beschränkt war, konnte der General mit seinen auf Nord- und Süddeutschland verteilten Anhängern noch einmal hoffen, als der eigentliche "Reichsdiktator « aus dem von Hitler und ihm durch ihren Überraschungscoup im Münchner Bürgerbräukeller angestoßenen "Marsch auf Berlin" hervorzugehen. Die Selbstverständlichkeit, mit der er in den Nachtstunden vom 8. auf den 9. November 1923 im Unterschied zu einem zunehmend demoralisierten Hitler die Zügel in die Hand nahm ${ }^{287}$, schien dies zu bestätigen. Doch dieses offene Hervortreten markierte Höheund Wendepunkt seiner nachrevolutionären Militärdiktaturpläne zugleich. In den Schüssen an der Feldherrnhalle ging zwar optisch der General noch aufrecht durch das Feuer, faktisch trug aber sein Gefreiter den internen Sieg in der nachfolgenden Neugruppierung der radikalen Rechten davon. Der letzte Aktionsversuch einer in sich bereits gespaltenen paramilitärischen Verbändebewegung hatte die Untauglichkeit ihres gewaltsamen Konzeptes einer Machtgewinnung bewiesen. Hitler, der unter der Hand schon vor dem 8 . November hatte wissen lassen, daß der General im Falle des gemeinsamen Erfolges "nur eine militärische Rolle« zu spielen haben würde ${ }^{288}$, löste sich jetzt mit seiner neuen Taktik einer "legalen " Machtergreifung ganz offen aus der Umarmung seines bisherigen Mentors. Die eigenständige politische Rolle der Wehren war ausgespielt, selbst wenn kleinere Grüppchen noch über 1923 hinaus zusammenhielten. Die Mehrheit ihrer Mitglieder schied entweder ganz aus dem Verbändeleben aus oder ging in den Soldatenbünden und Parteiarmeen auf. Der Prozeß der Emanzipation einer neuen politischen Rechten aus militärischer, dann paramilitärischer Bevormundung war zum Abschluß gekommen.

Dieser Prozeß hatte den Weg der radikalen Rechten praktisch seit ihrer eigentlichen Grundlegung in den nationalistischen Agitationsverbänden der Vorkriegszeit begleitet. Dabei war der zentrale Konflikt zwischen Fremdsteuerung durch die Exekutive und eigenständigem Druckinstrument auf sie schon in der Ausgangskonstellation ihres ersten erfolgreichen Massenverbandes, des Deutschen Flottenvereins von 1898, angelegt. Ins Leben gerufen von Interessengruppen und Teilen der Exekutive zur Vermittlung einer forcierten Welt- und Wehrpolitik an die Öffentlichkeit und über sie an den Reichstag, blieb der vom Flottenverein organisatorisch zusammengefaßte extreme $\mathrm{Na-}$ tionalismus für seine Initiatoren nur solange steuerbar, wie Regierungspolitik und nationalistische Massenströmungen in die gleiche Richtung zielten. Dagegen erwies er sich im komplizierten innen- und außenpolitischen Spiel von Eskalation und De-Eskalation im letzten Vorkriegsjahrzehnt schon für Bülows "Weltpolitik« und verschärft für die zwischen Risiko und Machtkalkül schwankende Linie seines Nachfolgers Bethmann Hollweg ebenso schnell als folgenschwere Belastung. Mißfallensäußerungen des Kaisers und Eingriffe der Administration in die Zusammensetzung des Vorstandes hat- 
ten bereits beim Vorgehen gegen den Geschäftsführenden Vorsitzenden Keim kaum noch den gewünschten Disziplinierungseffekt erzeugt ${ }^{289}$.

Die einschneidende Krisenstimmung der Jahre 1911/12 beschleunigte vielmehr den Abnabelungsprozeß der um die Alldeutschen gruppierten Verbände von der Regierung und machte sie zum radikalen Kern einer bis weit in die gemäßigten bürgerlichen Parteien hineinreichenden dauerhaften Kanzleropposition. Gerade der Zwang zum Zusammenhalt dieser fragilen Einheitsfront und die Einbettung der führenden Verbandsmitglieder ins bürgerliche Honoratiorentum hielten sie jedoch von den Konsequenzen einer prinzipiellen Systemopposition zurück. Nicht Sprengung, sondern diktatorische Straffung des Systems schrieben sie daher seit 1913 auf ihre Fahnen. Dazu wanderten sie aus der gouvernementalen Bevormundung ab und stellten sich in die Dienste des aus ihrer Sicht allein intakt gebliebenen, militärischen Armes der Exekutive. Militärführung und paramilitärische Aktionisten in Krieg und Nachkriegszeit standen nunmehr vor demselben Dilemma wie vorher die Zivilregierung. Indem sie sich den agitatorischen Massendruck der Verbände zunutze machten, bekamen sie gleichzeitig deren radikale Erfolgserwartungen zu spüren. Auch sie konnten die neue nationalistische Rechte mithin nur solange an sich binden, wie sie die aktivste Hoffnung auf eine Reichsreform nach rechts im Kaiserreich bzw. auf den gegenrevolutionären Systemumsturz in der Republik zu verkörpern vermochten. Wer immer die Stoßkraft dieses jetzt eigenständigen Rechtsextremismus nach 1923 für die eigenen Ziele einspannen oder gar zähmen wollte, würde sich - so nacheinander Ludendorff, Hugenberg und Papen - nur zu bald als ihr Gefangener wiederfinden.

1 Zu dieser These vgl. insbes. E. R. Huber: Deutsche Verfassungsgeschichte seit 1789. Bd 4: Struktur und Krisen des Kaiserreichs. Stuttgart 1969, Bd 5: Weltkrieg, Revolution und Reichserneuerung 1914-1919. Stuttgart 1978, sowie M. Rauh: Die Parlamentarisierung des Deutschen Reiches. Düsseldorf 1977 (= Beiträge zur Geschichte des Parlamentarismus und der politischen Parteien. Bd 60.)

2 Am klarsten artikuliert von H.-U. Wehler: Das Deutsche Kaiserreich 1871-1918. Göttingen 1973 ( = Deutsche Geschichte. Bd 9.); speziell für den Bereich der Parteien und Verbände D. Stegmann: Die Erben Bismarcks. Parteien und Verbände in der Spätphase des Wilhelminischen Deutschlands. Sammlungspolitik 1897-1918. Köln 1970.

3 Vgl. W. Pöls: Sozialistenfrage und Revolutionsfurcht in ihrem Zusammenhang mit den angeblichen Staatsstreichplänen Bismarcks. Hamburg, Lübeck 1960 (= Historische Studien. Bd 377.); J. C. G. Röhl: Staatsstreichpläne oder Staatsstreichbereitschaft? In: Historische Zeitschrift (HZ) 203 (1966) 610-624; L. Gall: Bismarck und der Bonapartismus. In: HZ 223 (1976) 618-637.

4 Vgl. F. Hartung: Das persönliche Regiment Kaiser Wilhelms II. Berlin 1952; J. C. G. Röhl: Deutschland ohne Bismarck. Tübingen 1969.

5 Vgl. G. Ritter: Staatskunst und Kriegshandwerk. Das Problem des "Militarismus in Deutschland. Bd 3: Die Tragödie der Staatskunst. Bethmann Hollweg als Kriegskanzler (1914-1917). München 1964; Bd 4: Die Herrschaft des deutschen Militarismus und die Katastrophe von 1918. München 1968; M. Kitchen: The Silent Dictatorship. The politics of the German High Command under Hindenburg and Ludendorff, 1916-1918. London 1976.

6 F. Meinecke: Staat und Persönlichkeit. Studien. Berlin 1933, S. 214.

7 So im Untertitel von Ritter: Staatskunst, Bd 4 (wie Anm. 5).

8 Vgl. Kitchens Titel (wie Anm. 5).

9 Wehler: Kaiserreich (wie Anm. 2), S. 213.

10 E. Ludendorff: Meine Kriegserinnerungen 1914-1918. Berlin 1919, S. 424 f.

11 A. v. Tirpitz: Erinnerungen. Leipzig 1919, hier insbes. die im Anhang abgedruckten Kriegsbriefe aus den Jahren 1914 und 1915.

12 Ludendorff: Kriegserinnerungen (wie Anm. 10), S. 610.

13 E. Röhm: Die Geschichte eines Hochverräters. München 1928, S. 202.

14 Erstmals eingehender untersucht von J. Erger: Der Kapp-Lüttwitz-Putsch. Ein Beitrag zur deutschen Innenpolitik 1919/20. Düsseldorf 1967 (= Beiträge zur Geschichte des Parlamentarismus und der politischen Parteien. Bd 35.), S. 17-28; jetzt eingehende quellengestützte Darstellung bei W. Wette: Gustav Noske. Eine politische Biographie. Düsseldorf 1987.

15 Am deutlichsten in seinen Briefen vom März/April 1915, Tirpitz: Erinnerungen (wie Anm. 11), S. 457-475. 
16 Alle Zitate bei Ludendorff: Kriegserinnerungen (wie Anm. 10), S. $424 \mathrm{f}$.

17 H. Delbrück: Die Tirpitz-Erinnerungen. In: Preußische Jahrbücher 178 (1919) 309-325 und J. Ziekursch: Ludendorffs Kriegserinnerungen. In: HZ 121 (1920) 441-465.

18 Prinz Heinrich an Tirpitz, 29.10. 1919, Bundesarchiv-Militärarchiv, Freiburg (zit. BA-MA), Nachlaß Tirpitz, N 253/183.

19 Brief an Generaloberst von Moltke, 15. 8. 1915: "Ich sage gleich Euer Exzellenz Vaterland, der Feldmarschall sagt noch Kaiser«, abgedr. bei E. Zechlin: Ludendorff im Jahre 1915. In: HZ 211 (1970) 346.

20 Vgl. B. Thoß: Der Ludendorff-Kreis 1919-1923. München als Zentrum der mitteleuropäischen Gegenrevolution zwischen Revolution und Hitler-Putsch. München 1978 (= Miscellanea Bavarica Monacensia. H. 78.), S. $66 \mathrm{f}$.

21 Das Bauer-Interview ist u. a. erschienen in der Bayerischen Staatszeitung, Nr. 107 vom 8. 5. 1920, die Erklärung Hindenburgs ebd., Nr. 112 vom 15. 5. 1920.

22 Th. v. Bethmann Hollweg: Betrachtungen zum Weltkriege. Bd. 2: Während des Krieges. Berlin 1921 , S. 48.

23 Oberst Bauer: Der große Krieg in Feld und Heimat. Tübingen 1921, S. 15.

24 E. Ludendorff: Kriegführung und Politik. Berlin 1922, S. 328 f.

25 Erinnerungen des Kronprinzen Wilhelm. Aus den Aufzeichnungen, Dokumenten, Tagebüchern und Gesprächen. Hrsg. von K. Rosner. Stuttgart u. Berlin 1922, S. 230.

26 Vgl. I. Geiss: Die manipulierte Kriegsschuldfrage. In: MGM 34 (1983) 31-60; U. Heinemann: Die verdrängte Niederlage. Politische Öffentlichkeit und Kriegsschuldfrage in der Weimarer Republik. Göttingen 1983 (= Kritische Studien zur Geschichtswissenschaft. Bd 59.); W. Jäger: Historische Forschung und politische Kultur in Deutschland. Die Debatte 1914-1980 über den Ausbruch des Ersten Weltkrieges. Göttingen 1984 (= Kritische Studien zur Geschichtswissenschaft. Bd 61.)

27 Vgl. F. Frhr. Hiller v. Gaertringen: „Dolchstoß«-Diskussion und „Dolchstoßlegende«. In: Geschichte und Gegenwartsbewußtsein. Festschrift für H. Rothfels. Göttingen 1963, S. 122-160; J. Petzold: Die Dolchstoßlegende. Eine Geschichtsfälschung im Dienst des deutschen Imperialismus und Militarismus. Berlin (Ost) ${ }^{2} 1963$.

28 Meinecke: Staat (wie Anm. 6); zu A. Rosenberg sein Kapitel „Die Diktatur des Generals Ludendorff «. In: Ders.: Die Entstehung der Deutschen Republik 1871-1918. Berlin 1928.

29 Prinz Max von Baden: Erinnerungen und Dokumente. Berlin u. Leipzig 1927; Kronprinz Rupprecht von Bayern: Mein Kriegstagebuch. Hrsg. v. E. v. Frauenholz. 3 Bde. München 1929.

30 Das Werk des Untersuchungsausschusses der Deutschen Verfassunggebenden Nationalversammlung und des Deutschen Reichstages 1919-1926 (künftig zit. WUA). 4. Reihe: Die Ursachen des Deutschen Zusammenbruchs im Jahre 1918. Berlin 1925. Bde 1 und 2, hier Bd 4/1, S. 20, 28.

31 Ebd., 4/2, S. 23.

32 Abgedr. im Anhang von L. G. v. d. Knesebeck: Die Wahrheit über den Propagandafeldzug und Deutschlands Zusammenbruch. Der Kampf der Publizistik im Weltkriege. München 1927.

33 Die Aufzeichnungen des Generalmajors Max Hoffmann. Hrsg. v. K. F. Nowak. 2 Bde. Berlin 1929 (künftig zit.: Hoffmann).

34 F. v. Bernhardi: Denkwürdigkeiten aus meinem Leben nach gleichzeitigen Aufzeichnungen und im Lichte der Erinnerung. Berlin 1927.

35 H. Class: Wider den Strom. Vom Werden und Wachsen der nationalen Opposition im alten Reich. Leipzig 1932.

36 M.v. Gallwitz: Erleben im Westen 1916-1918. Berlin 1932.

37 K. Graf v. Westarp: Konservative Politik im letzten Jahrzehnt des Kaiserreichs. 2 Bde. Berlin 1935; E. v. Oldenburg-Januschau: Erinnerungen. Leipzig 1936; Mackensen: Briefe und Aufzeichnungen des Generalfeldmarschalls aus Krieg und Frieden. Bearb. von W. Foerster. Leipzig 1938; Ein Armeeführer erlebt den Weltkrieg. Persönliche Aufzeichnungen des Generalobersten v. Einem. Hrsg. von J. Alter. Leipzig 1938 (künftig zit.: Einem); H. v. Seeckt: Aus meinem Leben 1866-1917. Hrsg. von F. v. Rabenau. Leipzig 1938; General d. Inf. a. D. v. Tschischwitz: General von der Marwitz. Weltkriegsbriefe. Berlin 1940 (künftig zit. : Marwitz).

38 F. Meinecke: Die deutsche Katastrophe. Betrachtungen und Erinnerungen. Wiesbaden 1946, S. 64-78.

39 G. Ritter: Das Problem des Militarismus in Deutschland. In: HZ 177 (1954) 21-48, insbes. S. 40-44.

40 Kitchen (wie Anm. 5).

41. A. Kruck: Geschichte des Alldeutschen Verbandes 1890-1939. Wiesbaden 1954 (= Veröffentlichungen des Instituts für Europäische Geschichte Mainz. Bd 3.)

42 Neben Stegmann (wie Anm. 2) vgl. auch H. Pogge v. Strandmann: Staatsstreichpläne, Alldeutsche und Bethmann Hollweg. In: Ders./I. Geiss: Die Erforderlichkeit des Unmöglichen. Deutschland am Vorabend des Ersten Weltkrieges. Frankfurt/M. 1965, S. 7-45 (= Hamburger Studien zur neueren Geschichte. Bd 2.) und R. Chickering: We Men Who Feel Most German. Boston, London 1984.

43 Zu nennen sind u. a. W. Groener: Lebenserinnerungen. Jugend, Generalstab, Weltkrieg. Hrsg. von 
F. Frhr. Hiller v. Gaertringen. Göttingen 1957 (= Deutsche Geschichtsquellen des 19. und 20. Jahrhunderts. Bd 41.); A. v. Thaer: Generalstabsdienst an der Front und in der O. H. L. Hrsg. v. S. A. Kaehler. Göttingen 1958 (= Abhandlungen der Akademie der Wissenschaften in Göttingen. Phil-hist. Klasse. Dritte Folge. Nr. 40.); Regierte der Kaiser? Kriegstagebücher, Aufzeichnungen und Briefe des Chefs des Marine-Kabinetts Admiral Georg Alexander von Müller 1914-1918. Hrsg. von W. Görlitz. Göttingen 1959 (künftig zit. Müller); Friedrich von Berg als Chef des Geheimen Zivilkabinetts 1918. Erinnerungen aus einem Nachlaß. Bearb. von H. Potthoff. Düsseldorf 1971 (= Quellen zur Geschichte des Parlamentarismus und der politischen Parteien. Bd 7.), (künftig zit. Berg); Die graue Exzellenz. Zwischen Staatsräson und Vasallentreue. Aus den Papieren des kaiserlichen Gesandten Karl Georg von Treutler. Hrsg. v. K.-H. Janßen. Frankfurt/M., Berlin 1971 (künftig zit.: Treutler); Adjutant im preußischen Kriegsministerium Juni 1918 bis Oktober 1919. Aufzeichnungen des Hauptmanns Gustav Böhm. Hrsg. von H. Hürten und G. Meyer. Stuttgart 1977 (= Beiträge zur Militär- und Kriegsgeschichte. Bd 19.), (künftig zit.: Böhm); Adolf Wild v. Hohenborn. Briefe und Tagebuchaufzeichnungen des preußischen Generals als Kriegsminister und Truppenführer im Ersten Weltkrieg. Hrsg. von H. Reichold. Boppard 1986 (= Schriften des Bundesarchivs. Bd 34.)

44 H. Schulze: Freikorps und Republik 1918-1920. Boppard 1969 (= Wehrwissenschaftliche Forschungen. Bd 8.); H. Fenske: Konservatismus und Rechtsradikalismus in Bayern nach 1918. Bad Homburg v. d. H. 1969; H. G.W. Nußer: Konservative Wehrverbände in Bayern, Preußen und Österreich 1918-1933 mit einer Biographie von Georg Escherich 1870-1941. München 1973 (= Moderne Geschichte. Bd 1.) ; J. M. Diehl: Paramilitary Politics in Weimar Germany. Bloomington, London 1977.

45 Chickering (wie Anm. 42), S. 300.

46 Siehe Anm. 3.

47 Beispiele bei Röhl: Deutschland ohne Bismarck (wie Anm. 4) und bei Stegmann (wie Anm. 2).

48 Pogge v. Strandmann (wie Anm. 42), S. 11; Chickering (wie Anm. 42), S. 302; W. J. Mommsen: Die latente Krise des Wilhelminischen Reiches. In: MGM 15 (1974) 23.

49 Kruck (wie Anm. 41), S. 45.

so Zitate bei D. Frymann (d. i. H. Class): Wenn ich der Kaiser wär'. Leipzig 1912, S. 219 f., 263 ff.

51 Stegmann (wie Anm. 2), S. 430; Chickering (wie Anm. 42), S. 288.

52 Westarp (wie Anm. 37), Bd 2, S. 29 f.

53 Das »Kaiserbuch» erschien bis 1914 in 5 Auflagen und einer Auflagenhöhe von über 20000 Exemplaren, Pogge v. Strandmann (wie Anm. 42), S. 11.

54 Stegmann (wie Anm. 2), S. 352-448.

55 Pogge v. Strandmann (wie Anm. 42), S. 14-18; Chickering (wie Anm. 42), S. 287 f.

56 Pogge v. Strandmann (wie Anm. 42), S. 14.

57 Wilhelm II. an den Kronprinzen, 20. 11.1913, abgedr. ebd., S. 37 ff.

58 Zit. nach Stegmann (wie Anm. 2), S. 426

$59 \mathrm{Zu}$ den »Ideen von 1914 « insgesamt K. Schwabe: Wissenschaft und Kriegsmoral. Die deutschen Hochschullehrer und die politischen Grundfragen des Ersten Weltkrieges. Göttingen, Frankfurt M., Zürich 1969, S. 21-45.

60 Chickering (wie Anm. 42), S. 290 f.

61 Ritter: Staatskunst (wie Anm. 5), Bd 3, S. 27.

62 Dazu und zum Konflikt zwischen Kanzler und Marineführung über den Flotteneinsatz 1914/15 vgl. E. Zechlin: Deutschland zwischen Kabinettskrieg und Wirtschaftskrieg. In: HZ 199 (1964) $381 \mathrm{ff}$; A. v. Tirpitz: Deutsche Ohnmachtspolitik in Weltkriege. Hamburg, Berlin 1926, insbes. S. 58 ff.; H. v. Pohl: Aus Aufzeichnungen und Briefen während der Kriegszeit. Berlin 1920, S. 21 f.

63 V. R. Berghahn/W. Deist: Kaiserliche Marine und Kriegsausbruch 1914. In: MGM 7 (1970) 43; ebenso P. M. Kennedy: The Rise of the Anglo-German Antagonism 1860-1914. London 1980, S. 422.

64 Aufzeichnungen Admiral v. Pohls (wie Anm. 62), vom 20., 30. u. 31. 8. 1914; S. 21 f., 38, 41.

$65 \mathrm{Zu}$ Bethmanns Umorientierung: Zechlin: Kabinettskrieg (wie Anm. 62), S. $384 \mathrm{f}$.

66 Vgl. u. a. die Besuche des bayerischen Ministerpräsidenten Hertling, des konservativen Parteiführers Westarp und des nationalliberalen Abgeordneten Beumer im Dezember 1914: Briefwechsel Hertling-Lerchenfeld 1912-1917. Dienstliche Privatkorrespondenz zwischen dem bayerischen Ministerpräsidenten Georg Graf von Hertling und dem bayerischen Gesandten in Berlin Hugo Graf von und zu Lerchenfeld. Hrsg. v. E. Deuerlein. Boppard 1973, T. 1 (= Deutsche Geschichtsquellen des 19. und 20. Jahrhunderts. Bd 50.), S. 361; Westarp (wie Anm. 37), Bd 2, S. 30 f.; H. Thieme: Nationaler Liberalismus in der Krise. Die nationalliberale Fraktion des Preußischen Abgeordnetenhauses 1914-18. Boppard 1963 (= Schriften des Bundesarchivs. Bd 11.), S. 57.

67 So vertraute K. Riezler seinem Tagebuch schon am 22. 8. 1914 an: "Der Jesuit Tirpitz. Renaissancehafte Persönlichkeit. « Ders.: Tagebücher, Aufsätze, Dokumente. Hrsg. v. K. D. Erdmann. Göttingen 1972 (= Deutsche Geschichtsquellen des 19. und 20. Jahrhunderts. Bd 48.), S. 200.

68 H. Prinz v. Schönburg-Waldenburg: Erinnerungen aus kaiserlicher Zeit. Leipzig 1929, S. 240.

69 Seit Herbst 1914 bestand die engere Umgebung des Kaisers für Tirpitz mehrheitlich aus »schwachen, halben Leuten«, ders.: Erinnerungen (wie Anm. 11), S. 431. Zur Problematik der Kabinetts- 
chefs insgesamt: F. Hartung: Die Regierung der Kabinette im 1. Weltkrieg. In: Moderne deutsche Verfassungsgeschichte (1815-1918). Hrsg. v. E.-W. Böckenförde. Köln 1972 (= Neue Wissenschaftliche Bibliothek. Geschichte. Bd 51.), S. 311-322.

70 Sitzung des Alldeutschen Verbandes (= AVD), 28. 8. 1914, zit. nach Stegmann (wie Anm. 2), S. 458.

71 Tgb.-Eintrag vom 18. 11. 1914, Das Kriegstagebuch des Reichstagsabgeordneten Eduard David 1914 bis 1918. Hrsg. v. E. Matthias u. S. Miller. Düsseldorf 1966 (= Quellen zur Geschichte des Parlamentarismus und der politischen Parteien. Bd 4.), S. 69.

72 Tgb.-Eintrag vom 23. 12. 1914, Riezler (wie Anm. 67), S. 236.

73 Vgl. etwa die Aufzeichnung d. Flottenchefs v. Pohl, 16. 1. 1915 (wie Anm. 62), S. 102.

74 Zusammengefaßt etwa in Bethmanns Denkschrift über die innenpolitische Entwicklung während des Krieges, 9. 12. 1915, abgedr. in Militär und Innenpolitik im Weltkrieg 1914-1918. Bearb. von W. Deist. Düsseldorf 1970. T. 1 (= Quellen zur Geschichte des Parlamentarismus und der politischen Parteien. 2. Reihe. Bd 1.), S. 271-277.

75 Sitzung d. Unterausschusses d. Kriegsausschusses d. Dt. Industrie, 7. 11. 1914, zit. nach Thieme (wie Anm. 66), S. 55.

76 Dokumentiert in Militär und Innenpolitik, Bd 1 (wie Anm. 74), S. 214 ff., 223-226 u. 228 ff. Die Denkschrift selbst, die Anfang 1915 von den Zensurbehörden beschlagnahmt wurde, ist 1917 in überarbeiteter Fassung als Flugschrift veröffentlicht worden: Zum deutschen Kriegsziel. Eine Flugschrift von H. Class. München 1917.

77 Bericht über die Unterredung ebd., S. 216 f. sowie bei Pohl (wie Anm. 62), S. 102; ähnlicher Verlauf eines Gesprächs zur gleichen Zeit zwischen Class und Stinnes, Class (wie Anm. 35), S. 328.

78 Belege dazu in: Deutschland im Ersten Weltkrieg. 3 Bde. Berlin (Ost) 1968/69, Bd 2, S. 172 bzw. 176. Vgl. auch die Gespräche von Class mit Bassermann und Stresemann Anfang 1915, Class (wie Anm. 35), S. 356 u. 358.

79 Unterredung Bethmanns mit dem Nationalliberalen W. Hirsch, 31. 3. 1915, Thieme (wie Anm. 66), S. 58.

80 Ebd., S. 58 f.

81 Deutschland im Ersten Weltkrieg (wie Anm. 78), Bd 2, S. 173.

82 Vgl. insbes. Groener (wie Anm. 43), S. 200 f.

83 Jetzt umfassend dokumentiert bei E. P. Guth: Der Gegensatz zwischen dem Oberbefehlshaber Ost und dem Chef des Generalstabes des Feldheeres 1914/15. In: MGM 35 (1984) 75-111.

84 Am besten erschließbar aus Ludendorffs Briefwechsel mit dem Königsberger Redakteur Wyneken, abgedr. im Anhang von Knesebek (wie Anm. 32).

85 Brief Einems, 17. 3. 1915, ders. (wie Anm. 37), S. 108; ähnliche Sorgen äußerte wenige Monate später Bassermann vor dem nationalliberalen Zentralvorstand, 15. 8. 1915, abgedr. in: Von Bassermann zu Stresemann. Die Sitzungen des nationalliberalen Zentralvorstandes 1912-1917. Bearb. v. K.-P. Riess. Düsseldorf 1967 (= Quellen zur Geschichte des Parlamentarismus und der politischen Parteien. Bd 5.), S. 195.

86 Ritter: Staatskunst (wie Anm. 63), Bd 3, S. 153.

87 Tgb., 22. 3. 1915, Tirpitz: Erinnerungen (wie Anm. 11), S. 457.

${ }_{88} \quad$ Tgb., 27. 3. 1915, ebd., S. 460.

89 Ebd., S. 460 f.; K. W. Jonas: Der Kronprinz Wilhelm. Frankfurt/M. 1962, S. 131.

so Vgl. den sorgenvollen Bericht Wahnschaffes an Bethmann, 23. 10. 1914, Westarp (wie Anm. 37), Bd 2, S. 307 und Jonas (wie Anm. 89), S. 133. Erst im Sommer 1916 gelang die Entfernung Maltzans aus der Umgebung des Kronprinzen, vgl. Maltzans Meldung an Tirpitz, 17. 7. 1916, BA-MA, $\mathrm{N} 253 / 257, \mathrm{Bl} .20 \mathrm{f}$.

91 Tgb., 29. 3. 1915, Tirpitz: Erinnerungen (wie Anm. 11), S. 462

92 Ebd., S. $462 \mathrm{f}$.

93 Tgb.v. Müller, 18. 4.19̀15, ders. (wie Anm. 43), S. 97.

94 Brief Prof. v. Niedners an Admiral v. Müller, 1. 3. 1927, ebd., S. 98 f.

95 Ebd., S. 97 f.

9 Tirpitz: Erinnerungen (wie Anm. 11), S. 465 f.

97 Müller (wie Anm. 43), S. 98.

98 Tirpitz sprach seit 1915 nur noch von der "regierenden Hydra oder der "Kabinettswirsschaft«, vgl. etwa seine Briefe vom 18. und 20. 3. 1915, ders.: Erinnerungen (wie Anm. 11), S. 454 f.

99 Brief vom 21. 4. 1915, ebd., S. $474 \mathrm{f}$.

100 J. Kocka: Klassengesellschaft im Krieg. Deutsche Sozialgeschichte 1914-1918. Göttingen 1973, S. 113.

101 Vgl. Neben einer Fülle ähnlich lautender Stimmen die Ausbrüche bei Thaer (wie Anm. 43), S. 32 und Marwitz (wie Anm. 37), S. 95.

102 Seeckt an Landesdirektor v. Winterfeldt-Menkin, 29. 10. 1915, Seeckt (wie Anm. 37), S. 258 f.

103 Tgb., 25. 6. 1915, Groener (wie Anm. 43), S. 538.

104 Brief an Trotha, 2. 8. 1915, BA-MA, N 253/169, Bl. 29.

105 Generalfeldmarschall v. Hindenburg: Aus meinem Leben. Leipzig 1927, S. 199; vgl. auch W. Hubatsch: Hindenburg und der Staat. Aus den Papieren des Generalfeldmarschalls und Reichspräsidenten von 1878-1934. Göttingen u. a. 1966, S. 25. 
106 Beide Zitate aus Brief, 21. 4. 1915, Tirpitz: Erinnerungen (wie Anm. 11), S. 474 f.

107 Brief Groeners an seine Frau, 13. 10. 1915, ders. (wie Anm. 43), S. 543.

108 Kruck (wie Anm. 41), S. 102.

109 Berichte zum Tirpitzbesuch in Lötzen am 13./14. 8. 1915: Tirpitz: Erinnerungen (wie Anm. 11), S. $494 \mathrm{ff}$. und Hoffmann (wie Anm. 33), Bd 1, S. 80 f.

110 Tgb., 6. 3.1915, Hoffmann (wie Anm. 33), Bd 1, S. 65.

111 Ludendorff an Wyneken, 21. 12. 1915 und 6. 1. 1916, Knesebeck (wie Anm. 32), S. 151 ff., sowie Tgb.-Eintrag Westarps, 11. 2. 1916, ders. (wie Anm. 37), Bd 2, S. 125.

112 Bericht Lerchenfelds, 3. 4. 1915, Briefwechsel Hertling-Lerchenfeld (wie Anm. 66), S. 422.

113 K. Birnbaum: Peace Moves and U-Boat Warfare. A Study of Imperial Germany's Policy towards the United States. April 18, 1916 -Januar 9, 1917. Uppsala 1958, S. 46 ff.

114 Zur Thronrede und ihrem öffentlichen Echo vgl. R. Patemann: Der Kampf um die preußische Wahlreform im Ersten Weltkrieg. Düsseldorf 1964 (= Beiträge zur Geschichte des Parlamentarismus und der politischen Parteien. Bd 26.), S. $39 \mathrm{ff}$.

115 Zit. nach Deutschland im Ersten Weltkrieg (wie Anm. 78), Bd 2, S. 359. Otto Fürst zu Salm-Horstmar war von 1902 bis 1908 Präsident des Deutschen Flottenvereins.

116 Kruck (wie Anm. 41), S. 93, Militär und Innenpolitik (wie Anm. 74), Bd 1, S. 357 f.

117 Zum Verlauf d. Besuchs Anf. März 1916: Oldenburg-Januschau (wie Anm. 37), S. 175 ff.

118 Tgb.v. Müller, 5. 3. 1916, ders. (wie Anm. 43), S. 163.

119 Ebd., S. 163-167; A. Schulze-Hinrichs: Großadmiral Alfred von Tirpitz. Ziel erkannt - Kraft gespannt! Göttingen u. a. 1958 (= Persönlichkeit und Geschichte. Bd 12.), S. 96 ff. B. Kaulisch: Alfred von Tirpitz und die imperialistische deutsche Flottenrüstung. Eine politische Biographie. Berlin (Ost) 1982, S. 199 ff.

120 Tgb. v. Müller, 13. 3. 1916, ders. (wie Anm. 43), S. 166; vgl. auch das Gespräch des Kronprinzen mit Oldenburg-Januschau, ders. (wie Anm. 37), S. 177.

121 Stegmann (wie Anm. 2), S. 486.

122 Diesen Vorwurf hatte Class unmittelbar nach dem Tirpitz-Rücktritt auf der Sitzung des geschäftsführenden Vorstandes des ADV am 25. 3.1916 erhoben, ebd.

123 Kaulisch (wie Anm. 119), S. 203.

124 Hertling an Lerchenfeld, 13.7. 1916, Briefwechsel Hertling-Lerchenfeld (wie Anm. 66), S. 632; Kapp an Wangenheim, 2. 8. 1916, Stegmann (wie Anm. 2), S. 467; Maltzan an Tirpitz, BA-MA, N 253/257, Bl. $20 \mathrm{f}$.

125 Treutler (wie Anm. 43), S. 168

126 Groener (wie Anm. 43), S. 188; Einem (wie Anm. 37), S. 114; Seeckt (wie Anm. 37), S. 249.

127 Thieme (wie Anm. 66), S. $181 \mathrm{f}$.

128 Seeckt an Winterfeldt-Menkin, 29. 10. 1915, Seeckt (wie Anm. 37), S. 260 f.

129 Die Briefe Groeners und Ludendorffs aus dem Jahr 1915 wimmeln geradezu von derartigen, strategische Positionen anstrebenden Forderungen bei Friedensschluß an die Adresse der Politiker, Groener (wie Anm. 43), S. 530-546 und Zechlin: Ludendorff 1915 (wie Anm. 19), insgesamt.

130 Vgl. H.-U. Wehler: Der Verfall der deutschen Kriegstheorie: Vom "Absoluten« zum "Totalen« Krieg oder von Clausewitz zu Ludendorff. In: Ders.: Krisenherde des Kaiserreichs 1871-1918. "Studien zur deutschen Sozial- und Verfassungsgeschichte. Göttingen 1970, S. 85-112; ebenso Thoß (wie Anm. 20), S. 45-53.

131 Vgl. K.-H. Janßen: Der Kanzler und der General. Die Führungskrise um Bethmann Hollweg und Falkenhayn (1914-1916). Göttingen 1967, S. 165.

132 Ebd., S. 167; vgl. auch Röchling an Schifferer, 19. 2. 1916, Thieme (wie Anm. 66), S. 226 und Bericht Schoens an Hertling, 27. 6. 1915, Briefwechsel Hertling-Lerchenfeld (wie Anm. 66), S. 468.

133 Tgb. v. Müller, 19. 2. 1915, ders. (wie Anm. 43), S. 92.

134 Janßen (wie Anm. 131), S. 166; Treutler (wie Anm. 43), S. 228.

135 Janßen (wie Anm. 131), S. 167; Tgb. v. Müller, 1. 5. 1916, ders. (wie Anm. 43), S. 174; vgl. auch entsprechende Hinweise aus dem AA, Ritter: Staatskunst (wie Anm. 5), Bd 3, S. 599, Anm. 38.

136 Schwabe (wie Anm. 59), S. 95-124.

137 O. Hammann: Bilder aus der letzten Kaiserzeit, Berlin o. J., S. $128 \mathrm{f}$.

138 Vgl. KTB Kronprinz Rupprecht, 8. 4. 1916, ders. (wie Anm. 29), Bd 1, S. 446: „Vielleicht erklären derartige Bestrebungen die Sprache Bethmanns, der sich auf einmal auf [sic!] den starken Mann aufspielt«.

139 Seeckt an Winterfeldt-Menkin, 4. 4. 1916, ders. (wie Anm. 37), S. 362.

$140 \mathrm{Vgl}$. K.-H. Janßen: Der Wechsel in der Obersten Heeresleitung 1916. In: Vierteljahrshefte für Zeitgeschichte (VfZG) 7 (1959) 337-371.

141 Treutler (wie Anm. 43), S. 215; vgl. auch Lerchenfeld an Hertling, 20. 9. 1916, also nur drei Wochen nach dem Wechsel zur III. OHL: "Jetzt empfände es der Hohe Herr gegenüber Hindenburg schmerzlich, sich sagen zu müssen, daß er nur die Rolle Kaiser Wilhelms I. gegenüber Moltke spiele [...] Der Kaiser soll stark resigniert sein«, Briefwechsel Hertling-Lerchenfeld (wie Anm. 66), S. 712.

142 Vgl. W. J. Mommsen: Die deutsche öffentliche Meinung und der Zusammenbruch des Regierungssystems Bethmann Hollweg im Juli 1917. In: Geschichte in Wissenschaft und Unterricht (GWU) 19 (1968) 659 f. Dem Gedanken, mit Hindenburg einen Frieden der Vernunft gegen die Annexioni- 
sten erzwingen zu können, hing im Sommer 1916 auch Max Weber an, wie seine Briefe vom 20. 8. und 8. 9. 1916 belegen, W. J. Mommsen: Max Weber und die deursche Politik 1890-1920. Tübingen 1959, S. 249. Ähnliche Hoffnungen setzte schließlich Walther Rathenau in eine Militärdiktatur Ludendorffs, vgl. G. Hecker: Walther Rathenau und sein Verhältnis zu Militär und Krieg. Boppard 1983 ( = Wehrwissenschaftliche Forschungen. Bd 30.), S. 272.

143 Aufzeichnungen Mertz v. Quirnheims, 30. 8. 1916, BA-MA, Nachlaß Mertz v. Quirnheim, N 242/2, Bl. 10.

144 Den Bericht Mertz v. Quirnheims über die betonte politische Abstinenz Ludendorffs quittierte Wetzell lachend: "Ich glaube es ihm nicht, denn ich kenne meinen guten Ludendorff «, ebd., Bl. 14.

145 Brief an Kapp, 21. 9. 1916, zit. nach H. Weber: Ludendorff und die Monopole. Deutsche Kriegspolitik 1916-1918. Berlin (Ost) 1966, S. 101.

146 Müller an Holtzendorff, 10. 10. 1916, ders. (wie Anm. 43), S. 228.

147 S. v. Velsen: Deutsche Generalstabsoffiziere im 1. Weltkrieg 1914-1918. In: Die Welt als Geschichte 16(1956) 276.

$148 \mathrm{Vgl}$. dazu seine Definition von „Kriegspolitik« als Zusammenfassung von Innen- und Außenpolitik mit der Strategie unter der einheitlichen Führung eines Feldherrn-Staatsmannes, Bauer (wie Anm. 23), S. 147.

149 Vgl. A. Vogt: Oberst Max Bauer. Generalstabsoffizier im Zwielicht 1869-1929. Osnabrück 1974 (= Studien zur Militärgeschichte, Militärwissenschaft und Konfliktforschung. Bd 6.), S. 45 ff.

150 Abgedr. in Militär und Innenpolitik (wie Anm. 74), Bd 1, S. 421-424.

151 Weber (wie Anm. 145), S. 16.

152 Erger (wie Anm. 14), S. 225 ff.; Thoß (wie Anm. 20), S. 40 ff.

153 Tirpitz an Trotha, 16. 10. 1916, BA-MA, N 253/169, Bl. $95 \mathrm{f}$

154 Militär und Innenpolitik (wie Anm. 74), Bd 1, S. 423; Bauer (wie Anm. 23), S. 147 f.

155 Vgl. Vogt (wie Anm. 149), S. 80 ff.

156 Kaiser und Kabinettschef. Nach eigenen Aufzeichnungen und dem Briefwechsel des Wirklichen Geheimen Rats Rudolf von Valentini dargestellt von B. Schwertfeger. Oldenburg 1931, S. 143 (künftig zit.: Valentini).

157 Tirpitz an Trotha, 16. 10. 1916, BA-MA, N 273/169, Bl. 95 f.

158 Dr. H. v. Stein: Erlebnisse und Betrachtungen aus der Zeit des Weltkrieges. Leipzig 1919, S. 133. Auch Valentini (wie Anm. 156), S. 143 spricht bereits für den Herbst 1916 davon, daß bei Hindenburg und Ludendorff »ein völliger Umschwung in der Beurteilung Bethmanns eintrat«.

159 So der Generalgouverneur in Warschau, v. Beseler, an seine Frau, 15. 4. 1917, BA-MA, Nachlaß Beseler, N 30/55; ähnlich Oberst v. Wrisberg an Seeckt, 26. 12. 1916, Militär u. Innenpolitik (wie Anm. 74), Bd 1, S. 652 Anm 5.

160 Aufzeichnung Mertz v. Quirnheim, BA-MA, N 242/3, Bl. 70.

161 So noch Stegmann (wie Anm. 2), S. 467.

162 Besprechung Hoffmanns mit Ludendorff in Pleß am 11. 11. 1916, Hoffmann (wie Anm. 33), Bd 1, S. 150.

163 Militär und Innenpolitik (wie Anm. 74), Bd 1, S. 651 f.; Vogt (wie Anm. 149), S. 142.

164 Beispielhaft für viele ähnliche Szenen die Schilderung des kaiserlichen Frontbesuchs beim IV. Res. Korps an der Westfront im Sommer 1916, der dessen Kommandeur, General v. Boehn, »leichenblaßu zurückließ, Thaer (wie Anm. 43), S. 69; ähnlich Einem (wie Anm. 37), S. 249; vgl. auch Militär und Innenpolitik (wie Anm. 74), Bd 2, S. 1135, Anm. 5.

165 G. Breit: Das Staats- und Gesellschaftsbild deutscher Generale beider Weltkriege im Spiegel ihrer Memoiren. Boppard 1973 (= Wehrwissenschaftliche Forschungen. Bd 17.), S. 96 f.

166 Aufzeichnungen Mertz v. Quirnheim, BA-MA, N 242/3, Bl. 40.

167 Der Briefwechsel Bernhardi-Hindenburg von Ende Dez. 1916 ist abgedr. in Bernhardi: Denkwürdigkeiten (wie Anm. 34), S. 460 u. 463.

168 Besprechung zwischen OHL und Holtzendorff am 8. 1. 1917, Weber (wie Anm. 145), S. 64

169 Beim Generalsvortrag am 10. 1. 1917, Valentini (wie Anm. 156), S. 146; ähnlich Ludendorff gegenüber v. Einem bei seinem Frontbesuch am 19. 1. 1917. Einem (wie Anm. 37), S. 278.

170 Der Bremer Kaufmann Andreas Gildemeister suchte über einen ihm bekannten Major Kontakt ins Große Hauptquartier, vgl. seinen Bericht an Tirpitz, 31.1. 1917, BA-MA, N 253/249, Bl. 123-127, während Kapp in gleichem Sinne bei General Hoffmann vorstellig wurde, vgl. dessen Tgb., 16. 1. 1917, Hoffmann (wie Anm. 33), 1, S. 155.

171 Valentini (wie Anm. 156), S. 149 ff.; vgl. auch Tgb. v. Müller, 31. 1. u. 2. 2. 1917, ders. (wie Anm. 43), S. $256 \mathrm{f}$.

172 Aufzeichnungen Mertz v. Quirnheim, BA-MA, N 242/3, Bl. 70.

173 Kitchen (wie Anm. 5), S. 128.

174 Zit. nach Weber (wie Anm. 145), S. 103; hier auch die ausführlichste Schilderung der folgenden Adlon-Konferenz aus dem Nachlaß Valentini, Deutsches Zentralarchiv, Abt. Merseburg; ebenso Deutschland im Ersten Weltkrieg (wie Anm. 78), Bd 2, S. 724 ff.; zur Kontroverse Kanzler/OHL über die Rede vgl. Militär u. Innenpolitik (wie Anm. 74), Bd 2, S. 663, Anm. 7.

175 Gildemeister sprach in seinem Brief an einen ungenannten Major bei der OHL vom 25. 1. 1917 ganz offen davon, daß Hindenburg "politisch Dilettant, ja beinahe das nicht einmal, sondern vollbewußt nur Soldat ist «, und auch General Hoffmann gestand sich im Gespräch mit Kapp am 16. 1. 
1917 ein: „Ludendorff [ . . ] übersieht vorläufig auch noch nicht ganz die Zusammenhänge der Politik." Zu beiden Zitaten vgl. Anm. 170.

176 Schon im Oktober 1914 stellte er fest, „daß nicht Rußland, sondern England der Feind ist, um den es sich bei diesem Krieg handelt«, Tirpitz: Erinnerungen (wie Anm. 11), S. 423.

177 Vgl. dazu u. a. die Haltung von OberOst in der Polenfrage 1914-1916: W. Conze: Polnische Nation und deutsche Politik im Ersten Weltkrieg. Köln, Graz 1958 (= Ostmitteleuropa in Vergangenheit und Gegenwart. Bd 4.), sowie I. Geiss: Der polnische Grenzstreifen 1914-1918. Ein Beitrag zur deutschen Kriegszielpolitik im Ersten Weltkrieg. Lübeck, Hamburg 1960.

178 Gildemeister an ungenannten Major, 25. 1. 1917, BA-MA, N 253/249, Bl. 123-127.

179 Hoffmann (wie Anm. 33), Bd 1, S. 155; eine ähnliche Überlegung gibt das KTB des Kronprinzen Rupprecht wieder, 30. 5. 1917, ders. (wie Anm. 29), Bd 2, S. 178.

180 Zit. nach Weber (wie Anm. 145), S. 104.

181 Die Denkschrift ist abgedr. in Militär und Innenpolitik (wie Anm. 74), Bd 1, S. 570-576.

182 Brief an Rittmeister Dr. Bueb, 18. 4. 1917, ebd. S. 575 f., Anm. 35.

183 Weber (wie Anm. 145), S. 104.

184 Vgl. Mommsen: Die öffentliche Meinung (wie Anm. 142), S. 661, und Bethmann Hollweg (wie Anm. 22), Bd 2, S. $170 \mathrm{f}$.

185 Valentini (wie Anm. 156), S. 150.

186 Bericht Grünaus an AA über Besprechung Kaiser/Hindenburg, 14. 3. 1917, Militär und Innenpolitik (wie Anm. 74), Bd 2, S. 670 ff.; ebenso Tgb. v. Müller, 14. 3. 1917, ders. (wie Anm. 43), S. 265.

187 Dieses und die folgenden Zitate aus dem Brief Ludendorffs an Wyneken, 21.4. 1917, Knesebeck (wie Anm. 32), S. $159 \mathrm{f}$.

188 Zit. nach Kitchen (wie Anm. 5), S. 130.

189 Besonders prägnant bei Mackensen (wie Anm. 37), S. 339 f., und Gallwitz (wie Anm. 36), S. 203.

190 Ludendorff an Wyneken, 21. 4. 1917, Knesebeck (wie Anm. 32), S. 160.

191 Bericht Heines in der Fraktionssitzung der SPD vom 1. 5. 1917, abgedr. in: Die Reichstagsfraktion der deutschen Sozialdemokratie 1898 bis 1918. Bearb. von E. Matthias u. E. Pikart. 2 Teile. Düsseldorf 1966 (= Quellen zur Geschichte des Parlamentarismus und der politischen Parteien. Bd 3.), Teil 1, S. 256.

192 Erzbergers Beziehungen waren besonders intensiv im 1. Halbjahr 1917, ders.: Erlebnisse im Weltkrieg. Stuttgart, Berlin 1920, S. 228-269. Stresemann sah sich selbst nicht ungern apostrophiert als der »junge Mann Ludendorffs«, vgl. zu seiner Haltung im Krieg jetzt die Kurzcharakteristik in $\mathrm{H}$. H. Herwig/N. M. Heyman: Biographical Dictionary of World War I. Westport, London 1982, S. $327 \mathrm{ff}$.

193 Meinecke: Staat und Persönlichkeit (wie Anm. 6), S. 214.

194 Vgl. Militär und Innenpolitik (wie Anm. 74), Bd 2, S. 795, Anm. 32.

195 Ebd.

196 Bernhardi: Denkwürdigkeiten (wie Anm. 34), S. 477.

$197 \mathrm{Zu}$ den Angeboten aus der konservativen Fraktion des Preuß. Herrenhauses vgl. Gallwitz (wie Anm. 36), S. 262 und Einem (wie Anm. 37), S. 310; zu seinen Befürwortern bei der OHL und in Armeeführerkreisen: Mackensen (wie Anm. 37), S. 339; Marwitz (wie Anm. 37), S. 235; P. Herre: Kronprinz Wilhelm. Seine Rolle in der deutschen Politik. München 1954, S. 97.

198 Gallwitz (wie Anm. 36), S. 202 f.

199 Gespräch mit Mertz v. Quirnheim, Anf. Juli 1917, Militär und Innenpolitik (wie Anm. 74), Bd 2, S. 783.

200 Ebd., S. 795.

201 Rupprecht (wie Anm. 29), Bd 3, S. 14; Ludendorff: Kriegserinnerungen (wie Anm. 10), S. 424 f.

$202 \mathrm{Vgl}$. Ludendorff: Kriegführung (wie Anm. 24), S. 1-23.

203 Ludendorff: Kriegserinnerungen (wie Anm. 10), S. 425 ließ dies selbst anklingen, wenn er vom Diktator forderte, daß er ndie Verhältnisse in der Heimat vollständig übersah und kannte».

204 Ebd.

205 Vgl. Kitchen (wie Anm. 5), S. 128 f.; Deutschland im Ersten Weltkrieg (wie Anm. 78), Bd 2, S. 757.

206 Rathenau an Ballin, 12. 5. 1917, ders.: Politische Briefe. Dresden 1929, S. 136.

207 Zur Vorsprache des Kronprinzen beim Kaiser am 11. 7. 1917: Briefwechsel Hertling-Lerchenfeld (wie Anm. 66), S. 876; zum Gespräch Kronprinz-Hohenlohe am 12. 7. 1917: Ritter: Staatskunst (wie Anm. 5) Bd 3, S. 579.

208 Zu den neuen Kandidaten: Marwitz (wie Anm. 37), S. 235; Rathenau: Politische Briefe (wie Anm. 206), S. 136; V. Naumann: Dokumente und Argumente. Berlin 1928, S. 253 f.; Einem (wie Anm. 37), S. 311; Bernhardi, Denkwürdigkeiten (wie Anm. 34), S. 427 u. 476-480; Gallwitz (wie Anm. 36), S. 202 f. u. 262 f.; Kruck (wie Anm. 41), S. 101 f.; Militär und Innenpolitik (wie Anm. 74), Bd 2, S. $751 \mathrm{f}$.

209 Bernhardi: Denkwürdigkeiten (wie Anm. 34), S. 480.

210 Naumann (wie Anm. 208), S. 253 f.

211 Zur Kandidatur Bülows: Bauer (wie Anm. 23), S. 144; Rupprecht (wie Anm. 29), Bd 2, S. 221; Hubatsch (wie Anm. 105), S. 168; Einem (wie Anm. 37), S. 324 f.; W. Rathenau: Tagebuch 1907 bis 1922. Hrsg. v. H. Pogge v. Strandmann. Düsseldorf 1967, S. 216 ff.; zur Vermittlerrolle Zimmermanns, der mit der Drohung, daß sonst ein "wilder General « Kanzler werde, auch die Sozialdemo- 
kratie für ein Akzeptieren Bülows zu gewinnen suchte: Ph. Scheidemann: Der Zusammenbruch. Berlin 1921, S. 159.

212 Militär und Innenpolitik (wie Anm. 74), Bd 2, S. 794 f.; Valentini (wie Anm. 156), S. 167; Müller (wie Anm. 43), S. 303 ff.

213 Ausführlichste Schilderung der hektischen Kanzlersuche nach Bethmanns Sturz bei Valentini (wie Anm. 156), S. 167-170; vgl. auch Müller (wie Anm. 43), S. 304 ff.; Militär und Innenpolitik (wie Anm. 74), Bd 2, S. 797 f.; G. Michaelis: Für Staat und Volk. Eine Lebensgeschichte. Berlin 1922, S. $320 \mathrm{ff}$.

${ }^{214}$ Gespräch Bauers mit Mertz v. Quirnheim auf der Rückfahrt von Berlin, also wohl am 15. 7. 1917, Militär und Innenpolitik (wie Anm. 74), Bd 2, S. 798, Anm. 44.

215 Haeften an Max v. Baden, 31. 7. 1917, Prinz Max von Baden (wie Anm. 29), S. 124.

216 Abgedr. in WUA 4/2 (wie Anm. 30), S. 39 ff.

217 Ebd., S. 43.

218 Vgl. Die bürgerlichen Parteien in Deutschland. 2 Bde. Berlin (Ost) 1968, Bd 1, S. 620-628 sowie Stegmann (wie Anm. 2), S. 516 ff.

219 Scheidemann (wie Anm. 211), S. 159

220 Prinz Max von Baden (wie Anm. 29), S. 150.

$221 \mathrm{Zu}$ den Gesprächen Ludendorff-Class am 5. und 14. 10. 1917 vgl. Kruck (wie Anm. 41), S. 103 f.; Stegmann (wie Anm. 2), S. 517 f.; Vogt (wie Anm. 149), S. 114 f.

222 Vizeadmiral Kraft an Bauer, 27. 9. und Unterhaltung Ludendorffs mit Lersner, 29. 9. 1917, Militär und Innenpolitik (wie Anm. 74), Bd 2, S. 1063, Anm. 11; ähnlich Lerchenfeld an Hertling in der Michaelis-Krise, 10.10. 1917, Briefwechsel Hertling-Lerchenfeld (wie Anm. 66), S. 933 sowie die Vorstöße der Nationalliberalen um die Jahreswende 1917/18, Thieme (wie Anm. 66), S. 185 f.

223 Rede vor der Essener Handelskammer, 12. 1. 1918, A. Hugenberg: Streiflichter aus Vergangenheit und Gegenwart. Berlin ${ }^{2} 1927$, S. 194.

224 Tgb. Riezler, 15. 4. 1918, ders. (wie Anm. 67), S. 460.

$225 \mathrm{Vgl}$. Hindenburgs Schreiben an den Kaiser, 8. 1. 1918, WUA 4/2 (wie Anm. 30), S. 123 ff. (Anl. 1).

226 Wilhelm II. an Hindenburg, 24. 1. 1918, ebd., S. 70.

227 Gespräch Ludendorffs mit Haeften am 14. 1. 1918, BA-MA, Nachlaß Haeften, N 35/4, Bl. 5.

228 Berg (wie Anm. 43), S. 92 f.

229 Gespräch Ludendorffs mit Haeften, 23. 1. 1918, BA-MA, N 35/4, Bl. 7

$230 \mathrm{Vgl}$. den zusammenfassenden Bericht d. preuß. Kriegsministers v. Stein über Ursachen u. Verlauf d. Streiks, 5. 2. 1918, Militär und Innenpolitik (wie Anm. 74), Bd 2, S. 1157-1163.

231 Telegramm Lersners an AA, 30. 1. 1918, ebd., S. 1143.

232 Bauer (wie Anm. 23), S. 187; Thaer (wie Anm. 43), S. 160. Der Belagerungszustand war seit Kriegsbeginn in Kraft; gemeint konnte daher nur seine Verschärfung sein; vgl. Militär und Innenpolitik (wie Anm. 74), Bd 1, S. XXXI-XXXIX.

233 R. Merton: Erinnerungswertes aus meinem Leben, das über das Persönliche hinausgeht. Frankfurt/ M. 1955, S. 46 ff.; zu den Bauer-Plänen vom Februar 1918 Vogt (wie Anm. 149), S. 118 f.

$234 \mathrm{Vgl}$. Berg (wie Anm. 43), S. 98 f. Dies wird durch einen Tagebucheintrag v. Müllers vom 27. 2.1918 erhärtet, der in den Randbemerkungen Wilhelms II. die alten martialischen Töne wiedererkennt, ders. (wie Anm. 43), S. 359.

235 Erstmals tauchte Falkenhausen als Kandidat in der Juli-Krise 1917 auf, BA-MA, Nachlaß Falkenhausen N 21/2, S. 146; zu seiner Kandidatenrolle im Frühjahr 1918: Berg (wie Anm. 43), S. 121 f. u. 137.

236 Vgl. jetzt W. Deist: Der militärische Zusammenbruch des Kaiserreichs. In: Das Unrechtsregime. Internationale Forschung über den Nationalsozialismus. Hrsg. v. U. Büttner. 2 Bde. Hamburg 1986. Bd 1, S. 101-129 (= Hamburger Beiträge zur Sozial- und Zeitgeschichte. Bd 21.)

237 Tgb. v. Thaer 14. 5. u. 30. 6.1918, ders. (wie Anm. 43), S: 203, 211.

238 Inhaltsgleiche Aufzeichnungen Bauers von Ende Juli 1918 in Militär und Innenpolitik (wie Anm. 74), Bd 2, S. 1239-1247; die Kronprinzen-Denkschrift ist abgedr. bei Bauer (wie Anm. 23), S. 215-224.

239 Erinnerungen des Kronprinzen (wie Anm. 25), S. 230.

240 Tgb. Hoffmann, 20. 7. 1918, ders., S. 210.

$241 \mathrm{Vgl}$. die maschinenschriftl. Erinnerungen des Generalobersten in seinem Nachlaß, BA-MA, N 21/2, S. 360-363.

242 Groener (wie Anm. 43), S. 412.

243 Vogt (wie Anm. 149), S. 143.

244 Ludendorff: Kriegserinnerungen (wie Anm. 10), S. 329

$245 \mathrm{Vgl}$. unten, S. 60, dort auch Belege (Anm. 255 und 256).

246 Zu den Gesprächen von Stinnes mit Ludendorff und Ballin: Weber (wie Anm. 145), S. 141.

247 Erinnerungen Falkenhausens, BA-MA, N 21/2, S. 364 f. u. Berg (wie Anm. 43), S. 173.

248 Die Diskussion um Ludendorffs Nervenkrise ist ausführlich belegt bei W. Foerster: Der Feldherr Ludendorff im Unglück. Wiesbaden 1952, S. 71-81; kritisch dazu S. A. Kaehler: Zur Beurteilung Ludendorffs im Sommer 1918. In: Nachrichten der Akademie der Wissenschaften in Göttingen, Phil.-hist. Kl. 1953, S. 1-28.

249 Vgl. Gespräch des Kaisers mit Berg am 20. 9. 1918, Müller (wie Anm. 43), S. 416. 
250 Stimmungsbericht d. bayer. Militärbevollmächtigten aus dem Großen Hauptquartier, 29. 9. 1918, Militär und Innenpolitik (wie Anm. 74), Bd 2, S. 1287 ff.

251 Zur Besprechung der OHL mit Hintze am 29. 9. 1918: Deutschland im Ersten Weltkrieg (wie Anm. 78), Bd 3, S. 429.

252 Besprechung beim Kaiser über die Hertling-Nachfolge am 29.9. 1918, Berg (wie Anm. 228), S. $179 \mathrm{f}$.

253 Telegramm Bergs an Falkenhausen, 30. 9. 1918, BA-MA, N 21/2, S. 372.

254 Thaer (wie Anm. 43), S. 235; zur Datierung vgl. Militär und Innenpolitik (wie Anm. 74), Bd 2, S. 1292, Anm. 16.

255 Tgb. v. Weizsäcker, 28. 9. 1918, Die Weizsäcker-Papiere. Bd 1: 1900-1932. Hrsg. v. L. E. Hill. Berlin u. a. 1974, S. 287.

$256 \mathrm{Zu}$ Bauers Auftritt im Kriegsministerium: Böhm (wie Anm. 43), S. 37; zu Rathenaus Plänen einer "levée en masse«: Hecker (wie Anm. 142), S. 428-444.

257 Weber (wie Anm. 145),S. 143.

258 Gallwitz (wie Anm. 36), S. 443.

259 Tirpitz an Traub, 17. 5. 1919 und an Stinnes, 10. 6. 1920, BA-MA, N 253/265, Bl. 83 u. N 253/264, Bl. $108 \mathrm{f}$.

260 S. A. Kaehler: Vier quellenkritische Untersuchungen zum Kriegsende 1918. Göttingen 1961 (= Nachrichten der Akademie der Wissenschaften in Göttingen. Phil.-hist. KJ. Nr. 8, 1960.), S. 434-481.

261 BA-MA, N 35/6, Bl. $39 \mathrm{f}$.

262 G. Schramm: Militarisierung und Demokratisierung: Typen der Massenintegration im ersten Weltkrieg. In: Francia 3 (1976) 476-497.

263 Zum Folgenden insgesamt: Thoß (wie Anm. 20).

264 Röhm (wie Anm. 13), S. 73, 202.

265 Zit. nach M. Weißßbecker: Zur Herausbildung des Führerkults in der NSDAP. In: Monopole und Staat in Deutschland 1917-1945. Berlin (Ost) 1966, S. 118.

266 Thoß (wie Anm. 20), S. 34 f.

267 Ebd., S. 191-196 bzw. 319 ff.

268 Zit. nach Die bürgerlichen Parteien (wie Anm. 218), Bd 1, S. 767.

269 Vgl. die Hitler-Reden vom April und Juli 1922 sowie vom August 1923, Adolf Hitler. Sein Leben und seine Reden. Hrsg. v. A.-V. v. Koerber. München 1923, S. 27, 53, 74.

270 Frymann (wie Anm. 59), S. 25.

271 Erfahrungsbericht an das bayer. Militärministerium, 23.6. 1919, K. Hierl: Ausgewählte Schriften und Reden. München ${ }^{2} 1942$, S. 199-202.

272 Bundesarchiv Koblenz (BA), Nachl. Bauer, Nr. 74, Bl. 22-29.

273 Detaillierter bei Thoß (wie Anm. 20), S. 39-45.

274 E. Ludendorff: Auf dem Weg zur Feldherrnhalle. Lebenserinnerungen an die Zeit des 9. 11. 1923 mit Dokumenten in 5 Anlagen. München 1973, S. 18.

275 Aussage im Hitler-Prozeß, Institut für Zeitgeschichte, München, MA 212/3, S. 2838.

276 Vgl. M. Kater: Zur Soziographie der frühen NSDAP. In: VfZG 19 (1972) $149 \mathrm{ff}$.

277 R. Olden: Hitler. Amsterdam ${ }^{2}$ 1936, S. 104.

278 Vgl. H. Nußer: Militärischer Druck auf die Landesregierung Johannes Hoffmann vom Mai 1919 bis zum Kapp-Putsch. In: Zeitschrift für Bayerische Landesgeschichte(= ZBLG) 33(1970) 818-850; Thoß (wie Anm. 20), S. 86-102.

279 F. v. Bernhardi: Vom Kriege der Zukunft. Nach den Erfahrungen des Weltkrieges. Berlin 1920, S. 168 ff.; Ludendorff: Kriegführung (wie Anm. 24), S. 1-23.

280 Vgl. H. Delbrück: Ludendorffs Selbstporträt. Berlin 1922, sowie die hefrige militärische Kritik daran im Militär-Wochenblatt im ganzen März 1922.

$281 \mathrm{Vgl}$. Erger sowie Wette (beides wie Anm. 14).

282 Die immer noch zuverlässigste Studie dazu hat Erger (wie Anm. 14), vorgelegt, der zudem schon im Titel seines "Kapp-Lüttwitz-Putsch « den Charakter eines militärischen Unternehmens gebührend herausstellte. Zum Gewicht der "Ludendorffianer" vgl. Thoß (wie Anm. 20), S. 64-75.

283 E. Ludendorff: Vom Feldherrn zum Weltrevolutionär und Wegbereiter deutscher Volksschöpfung. Meine Lebenserinnerungen 1919-1925. München 1940, S. 99.

284 Zum sogen. »Kahr-Putsch«: P. Kritzer: Die bayerische Sozialdemokratie und die bayerische Politik in den Jahren 1918 bis 1923. München 1969 (= Miscellanea Bavarica Monacensia. Heft 20.), S. $156-163$.

$285 \mathrm{Vgl}$. L. Kerekes: Die "weiße« Allianz. In: Österr. Osthefte 7(1965) 353-366; Thoß (wie Anm. 20), S. $381-430$.

286 Zum Zerfall der Verbändefront 1922/23: Thoß (wie Anm. 20), S. 201-275.

$287 \mathrm{Vgl}$. ebd., S. $344 \mathrm{ff}$.

288 Ebd., S. 336.

$289 \mathrm{Vgl}$. W. Deist: Flottenpolitik und Flottenpropaganda. Das Nachrichtenbureau des Reichsmarineamtes 1897-1914. Stuttgart 1976 (= Beiträge zur Militär- und Kriegsgeschichte. Bd 17.), S. 217-237; und G. Eley: The German Navy League in German Politics, 1898-1914. D. Phil. Thesis. Sussex University 1974 , S. 274-318. 